\title{
MODELOS DE DECISÃO NA ANÁLISE ECONÔMICA DE EXPERIMENTOS AGRÍCOLAS
}

JOSÉ ARLINDO DE CAMARGO PACHECO

Orientador : CICELY M. AMARAL

Dissertação apresentada à Escola Superior de Agricultura "Luiz de Queiroz", da Universidade de São Paulo, para obtenção do título de Mestre em Economia Agrária.

PIRACICABA

Estado de São Paulo - Brasil Julho - 1985 


\section{AGRADECIMENTOS}

Ao Prof. Dr. Cicely Moitinho Amaral, pela orien tação segura.

Ao Prof. Dr. Evaristo Marzabal Neves, pelia orientação inicial.

Aos Professores Dr. Geraldo S.C. Barros e José Ferreira Noronha, pela cuidadosa leitura dos originais.

Ao Dr. Elmar Rodrigues da Cruz, pela colaboração na fase-inicial deste trabalho.

Ao Dr. Celso Roberto Crócomo, pela collaboração no processamento dos dados em computador.

Ao Dr. Osmar Muzilli do IAPAR, pela cessão dos resultados experimentais.

A Engạ Agrạ Maria Eugênia B.C. Pacheco, pela co laboração nas anälises estatísticas.

Aos colegas do Centro Nacional de Pesquisa de Gado de Corte, EMBRAPA, pelo estimulo. 
Aos colegas do Curso de Economia Agrāria pela va liosa convivência.

Aos amigos de Piracicaba.

A EMBRAPA, pela oportunidade de realização do curso.

A CAPES, pela bolsa de estudos concedida.

A Srạ Márcia M.B. Correia, pela datilografia. 
LISTA DE TABELAS $\ldots \ldots \ldots \ldots \ldots \ldots \ldots \ldots \ldots \ldots \ldots \ldots \ldots$

LISTA DE FIGURAS $\ldots \ldots \ldots \ldots \ldots \ldots \ldots \ldots \ldots \ldots \ldots \ldots \ldots \ldots \ldots \ldots \ldots$

RESUMO $\ldots \ldots \ldots \ldots \ldots \ldots \ldots \ldots \ldots \ldots \ldots \ldots \ldots \ldots \ldots \ldots \ldots \ldots$

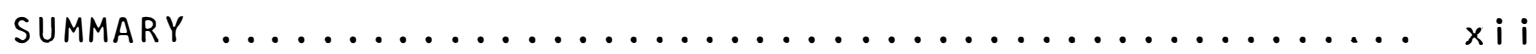

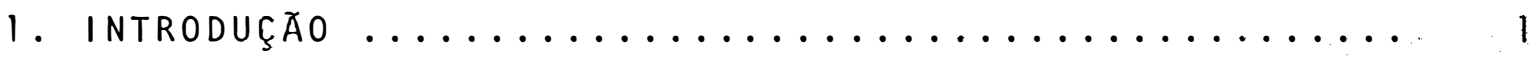

1.1. Importância do Problema ................. I

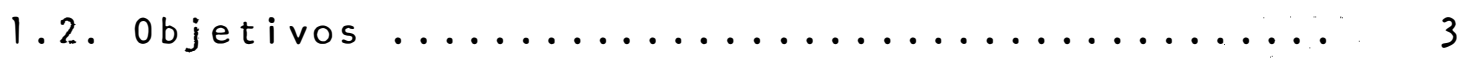

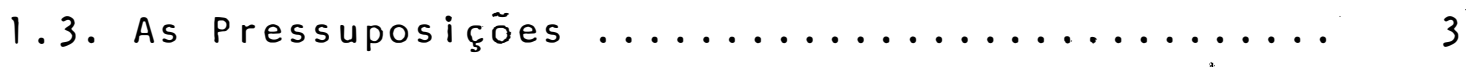

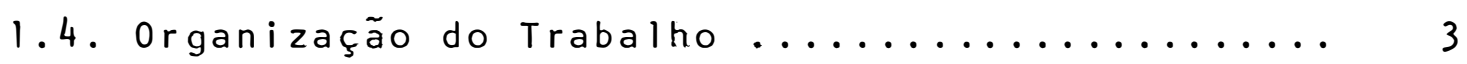

2. INCERTEZA, UTILIDADE E DECISĂO ............. 5

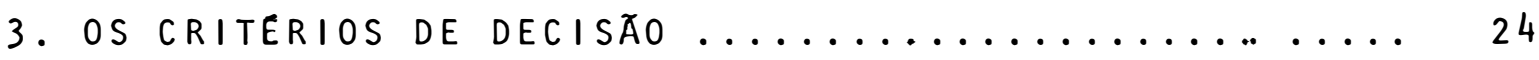

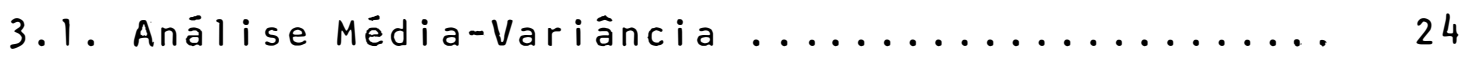

3.2. Dominância Estocástica ................. 36

3.3. Dominância Estocástica com Respeito a uma Fun-

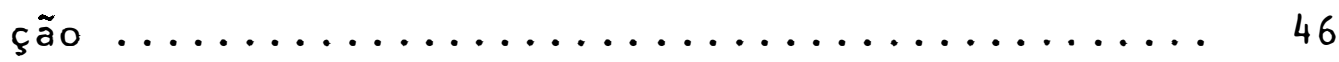

4. ANALISE DE RISCO EM EXPERIMENTAÇÃO AGROPECUARIA ... 52

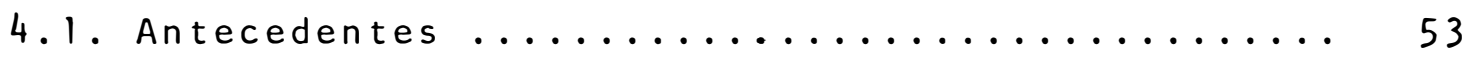

4.1 .1 . A Análise tradicional ............. 53

4.1.2. 0 comportamento do produtor rural ..... 55

4.1.3. A análise envolvendo risco ......... 58

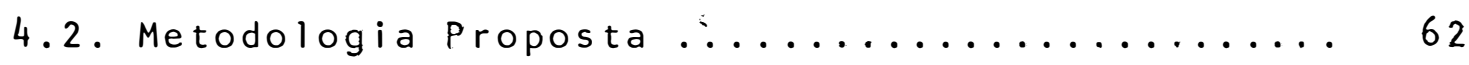

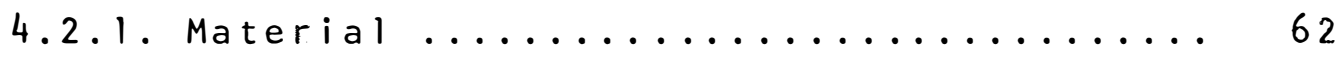

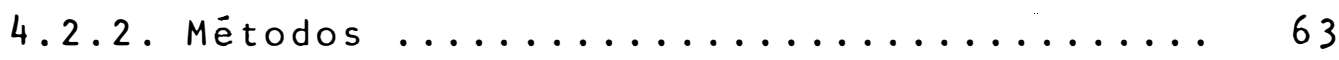


4.2.2.1. A interpretaçăo dos resultados experimentais $\ldots \ldots \ldots \ldots \ldots$

4.2.2.2. A geração das distribuições de probabilidade ...............6 68

4.2.2.3. Seleção pela Anālise E-V ..... 72

4.2.2.4. Seleção pela Dominância Estocás tica $\ldots \ldots \ldots \ldots \ldots \ldots$

4.2.2.5. Seleção pela Dominância com Res peito a uma Função ........... 74

5. RESULTADOS, DISCUSSÃO E CONCLUSÕES ............. 77

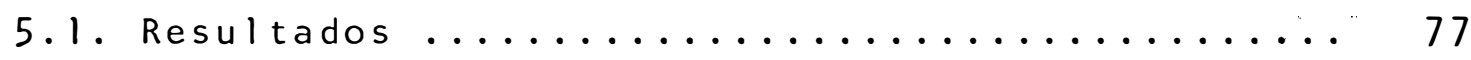

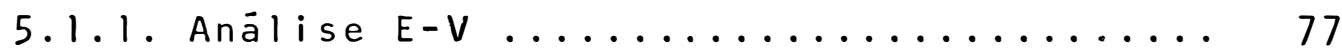

5.1.2. Dominância Estocāstica ............. 78

5.1.3. Dominância Estocástica com Respeito a uma Função .................... 82

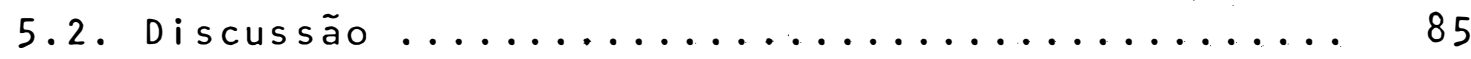

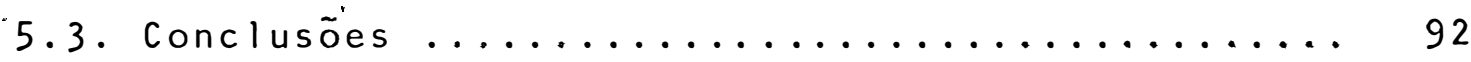

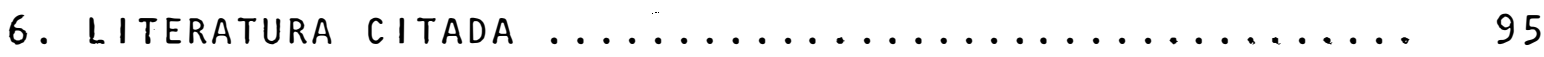

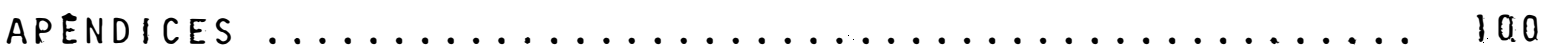

1. Estimativa de Custo e Exigência Física de Fatores. Produção da Cultura do Milho com Produtividade Acima de $3501 \mathrm{~kg} / \mathrm{ha}$. Estado do Paranā, Safra 83/

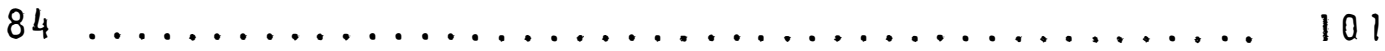

2. Mēdia, Desvio-Padrão e Aśsimetria das Distribuições de Probabilidade do Lucro, Associados aos Di ferentes Niveis de Utilização de Nitrogênio ..... 
3. Critērios de Seleção pelo Primeiro e Segundo Graus de Dominância Estocästica (ANDERSON, 1974)....... 103

4. A Função Utilidade Exponencial Negativa......... 106

5. A Função Quadrática de Utilidade e a Anälise E - V 109 
1 Anälise de Variância para a Cultura do Milho para as Três Safras Consideradas ........... 64

2 Análise de Variância para a Cultura do Milho,

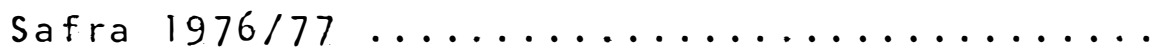

3 Análise de Variância para a Cultura do Milho,

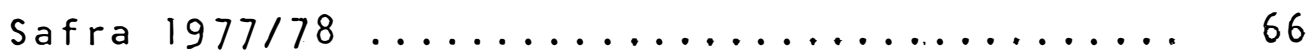

4 Análise de Variância para a Cultura do Milho,

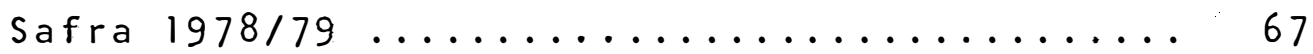

5 Seleção pela Anālise E-V ................ 80

6 Seleção pela Dominância Estocástica $\ldots . . . . .81$

7 Seleção pela Dominância Estocástica com Respei to a uma Função, para Propensos ao Risco .....

8 Seleção pela Dominância Estocástica com Respei to a uma Função, para Avessos ao Risco ...... 84 


\section{LISTA DE FIGURAS}

Figura n?

Página

1 Representação do Problema de Decisão em um Es -

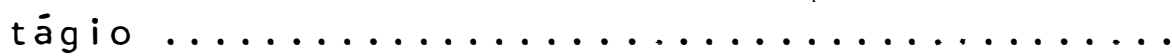

2 Representação da Função Utilidade obtida pelo

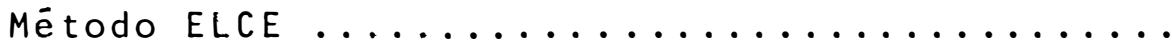

3 Função de Utilidade de Individuos Avessos (1), Neutros (2) e Propensos ao Risco (3) ........

4 Prêmios de Risco para os Diferentes Tipos de Comportamento $\ldots \ldots \ldots \ldots \ldots \ldots \ldots \ldots \ldots \ldots \ldots \ldots \ldots \ldots \ldots \ldots \ldots$

5 Mapa de Indiferença de Individuos Avessos ao

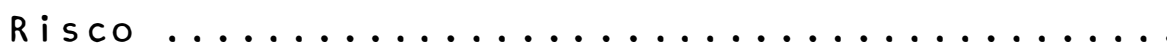

6 Relação entre o Mapa de Indiferença e Possí-

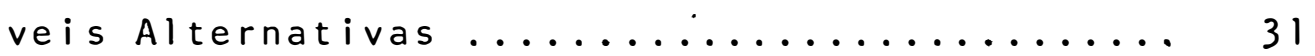

7 Distribuições Cumulativas de Probabilidade ... 40

8 Dominância pelo Primeiro Grau de Dominância Es

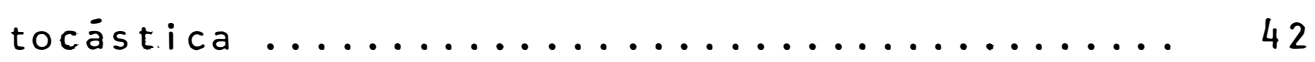

9 Dominância pelo Segundo Grau de Dominância Es -

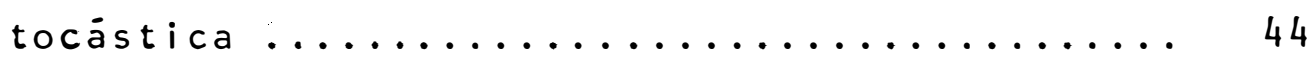

10 Resposta do Milho ao Nitrogênio ........... 65

11 Relação Média x Desvio-Padrão para os Diferentes Niveis de Nitrogênio.(kg/hà) ........... 79

12 Função de Utilidade Exponencial Negativa .... . 109

13 Propriedades das Funções Utilidades Exponen-

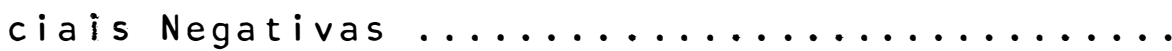


RESUMO

A produção agropecuāria apresenta-se em todas suas etapas, do plantio à comercialização da colheita, como atividade especialmente sujeita a riscos, sejam eles derivados de fatores de ambiente ou de mercado. Esta característica faz com que não se possa considerar o produtor rural como um indivíduo voltado exclusivamente para a maximização de lucros dado o nivel de risco com que ele se defronta.

Ocorre porèm, que grande parte das informações técnicas geradas por órgãos de pesquisa agropecuāria, deixa de considerar a influência dos riscos da produção quando da avaliação de novas tecnologias. Resulta daí um hiato entre as in formações geradas e aquelas que são demandadas pelos agriculto res, estes sim efetivamente influenciados em seu processo de decisão, pelo risco associado às suas ações.

Neste trabalho propõem-se três mētodos alternativos de avaliação de experimentos agropecuärios, que ao incor 
porarem o risco envolvido na produção como parâmetro importan te para a decisão do produtor rural, podem enriquecer o conteú do informativo das recomendações técnicas, aproximando-as daquelas realmente buscadas.

Os métodos propostos, que são critērios que podem pautar o processo de decisão sob risco, correspondem à Anālise Média-Variância, Dominância Estocāstica e Dominância Estocástica com Respeito a uma Função, e se desenvolvem através da comparação das distribuições de probabilidade associadas às diferentes tēcnicas avaliadas.

A geração das distribuições de probabilidade é feita atravēs da inclusão de variāveis de clima em uma função de produção, que relaciona níveis de nitrogênio à produção de milho, seguida da simulação de 1000 anos hipotéticos de experi mentação.

Algumas das conclusões seguem:

I. Os critērios Análise Média-Variância e Dominância Estocástica, mesmo partindo de pressupostos distintos, conduzem a idênticos resultados, caracterizando-se pelo reduzi do poder de seleção de alternativas;

2. As alternativas selecionadas por estes dois critērios, como igualmente eficientes são bastante distintas entresi,.. dificultando uma recomendação definitiva a agricultores;

3. Apenas com maior rigor nas pressuposições em torno da função utilidade do indivíduo, atravēs da Dominância 
Estocāstica com Respeito a uma Função, e que se consegue maior poder de discriminação de alternativas, selecionando apenas uma para cada um dos grupos de produtores, avessos e propensos ao risco.

De uma forma geral considera-se que a anālise econômica de experimentos agropecuārios, envolvendo risco, deve ser incorporada à rotina de avaliação em órgãos de pesquisa, como forma de tornar mais reais as informaçōes geradas, contribuindo para o processo de adoção de novas präticas. 
$x i \mathrm{i}$

SUMMARY

Agricultural production, in all of its stages, from planting to marketing, is an activity tipically subjected to environmental or market-related risks. This characteristic prevents the analyst from considering the agricultural producer merely as an individual devoted to profit maximization.

It frequently happens, however, that the technical information generated within the official agriculture research apparatus misconsiders the production risks influence when analysing new technologies. As a result, a gap appears between the information generated and what is effectively demanded by the producers.

The proposition of this study encompasses three alternative methods of agricultural experimentation evaluation. These methods by embodying risk as an important parameter in the decision-making process, may contribute to the improvement of technical information quality level.

The methods here proposed, being helpfull 
criteria in the decision making process under uncertainty, are the E-V Analysis, the Stochastic Dominance and the Stochastic Dominance with Respect to a Function. They are developed by the comparison of the probability distributions associated to the different techniques.

The probability distributions generation is achieved via the inclusion of climate variables into aproduction function that relates maize production to the nitrogen levels, followed by a thousand year simulation.

Some of the key conclusions of this study are the following:

1. E-V-Analysis and Stochastic Dominance even assuming distinct assumption sets, drive to identical results, characterized by a reduced discrimination power of the alternatives;

2. The alternatives selected under these two criteria, although, equally efficient preserve their individual differences and are not applicable to a definitive reccomendation.

3. A stronger alternative discrimination power is only achieved when a more stringent assumption set is established around the decision-maker utility function, by means of the Stochastic Dominance with Respect to a Function.

It is generally considered that the $\equiv 2$ economic analysis of agricultural experimentation involving risk, must be a mandatory part of the evaluation routine in the research 
agencies, as a means to bring closer to reality the informational output, thus contributing to the process of improved practices adoption. 
1. INTRODUÇÃO

I.1. Importância do Problema

O estágio final de grande parte dos ensaios experimentais conduzidos em instituições de pesquisa agropecuäria, deve corresponder a uma cuidadosa avaliação econômica de seus resultados destinada a assegurar aos produtores rurais, destino final das informações, um importante parâmetro, fundamental ao processo de decisão quanto à adoção de novas práticas.

Para tanto é preciso que se reconheça que todas as etapas da produção agropecuária, do plantio à comercialização da colheita, são extremamente sujeitas a riscos derivados de variações de clima é de preços, incidência de pragas e doen ças, bem como de outras fontes. Deste modo no dia-a-dia da produção, nem sempre as conseqüências das decisões assumidas correspondem àquelas previamente esperadas, fazendo com que o produtor rural passe a se mostrar sensivel ao risco envolvido 
na atividade, pautando suas decisões de forma a tambèm atender a um requisito de segurança.

E necessário que as informações de pesquisa recebam um tratamento tal, que permita sua avaliação em condições de risco, sendo então verificada a estabilidade de seus resultados econômicos, à semelhança do que ocorreria quando le vadas a campo. Com išso se permite ao produtor a seleção de práticas adequadas a seus objetivos tanto de lucro como de segurança na atividade.

ocorre porém que as avaliações econômicas de dạ dos experimentais tradicionalmente realizadas, parecem não reconhecer as diferentes fontes de risco presentes no ambiente a gropecuário, uma vez que consideram que o processo de decisão do produtor rural é orientado apenas pela maximização de lucros, deixando de lado qualquer requisito de segurança.

E preciso que novas formas de avaliação econômi ca sejam utilizadas, e que se passe a incorporar a importância do nível de risco envolvido, para o processo de decisão, como forma de aumentar o conteūdo informativo das recomendações tèc nicas. Grande número de modelos teóricos de decisão sob risco estão presentes na literatura, e são potencialmente aplicáveís à avaliação econômica de experimentos agropecuários, e è isto que se busca verificar neste trabalho. 
1.2. Objetivos

Discutir alguns dos fundamentos, avaliar a viabilidade da aplicação e comparar os resultados, de três modelos teóricos de decisão sob risco empregados na avaliação econômica de experimentos agropecuários.

Os modelos em questão se referem à Anālise Média-Variância, Dominância Estocástica, e Dominância Estocástica com Respeito a uma Função, e se aplicam à determinação das doses de nitrogênio em milho (Lea mays) eficientes com respeito ao risco.

1.3. As Pressuposições.

1.3.1. Fatores de ambiente e de mercado tornam incerta a produção agropecuāria

1.3.2. O comportamento do produtor rural é influenciado pelo risco envolvido na atividade, sendo caracterizado pela maximização da utilidade esperada.

1.3.3. Diferentes individuos reagem de diferentes maneiras, quando submetidos as mesmas condições de risco.

1.4. Organização do Trabalho

o Capitulo 2 discute os fundamentos da teoria 
da decisão aplicada a situações de risco. No Capitulo 3 , são colocadas as características dos modelos de decisão que se procura comparar. 0 Capitulo 4 discute as formas usuais de análise de experimentos e descreve a proposta metodológica deste trabalho. O Capitulo final trata da discussão dos resultados, conclusões e sugestões para futuros trabalhos. 
2. INCERTEZA, UTILIDADE E DECISÃo

No processo de tomada de decisão, o comportamen to do indivíduo resulta da interação de suas preferências pessoais com o grau de informação de que dispõe a respeito das conseqüências das ações alternativas, objeto de sua escolha. São fundamentos da teoria da decisão tanto o estabelecimento de um quadro consistente de preferências, como de uma avaliação pessoal das conseqüências das diferentes ações.

$$
\text { No arcabouço da teoria econômica, a noção de }
$$

preferência, seja ela por bens e serviços seja por atributos, acha-se ligada ao conceito mais amplo de utilidade, que permite o entendimento daquilo que se pretende seja o comportamento do individuo no processo de decisão.

De outro lado, o grau de informação se relaciona à possibilidade de se antecipar total ou parcialmente as conseqüências das decisões tomadas, mantendo-se portanto na de pendência das características do ambiente que cerca o tomador 
de decisão, sendo que distintos estados podem condicionar grau de informação disponível, exercendo importante influência no processo de decisão.

Considera-se que o ambiente associado à certeza de resultados faz com que, de cada ação particular, derive invariavelmente a mesma conseqüência, tornando-a como è lógico, antecipadamente conhecida. A certeza de resultados, é pressuposto básico utilizado na teoria econômica ao estabelecer os postulados da racionalidade do individuo, que caracterizam a coerência em suas preferências.

Bem mais plausível parece ser a noção de que os processos de decisão se desenvolvem em condições de incerteza ou de risco, quando então de cada ação passa a derivar um conjunto de conseqüências possiveis. Considera-se que sob condições de risco, os eventuais resultados obedecem distribuição de probabilidade conhecida, ao passo que sob incerteza nada se conhece a respeito da forma de ocorrência dos resultados.

WINKLER (1972) destaca que sempre existe algum conhecimento prévio das conseqüências, já que se admite que in variavelmente sejam formuladas distribuições subjetivas de pro babilidade. Existe portanto, sempre, um nivel de informação prévio, mesmo quando influências exógenas ao tomador de decisão, retiram de seu direto controle os resultados das decisöes tomadas, de forma que risco e incerteza podem ser assumidas co mo expressões de idêntica significação. 
Fatores estocásticos presentes no ambiente fazem com que risco e incertezase associem a situações onde cada ação só possa ser caracterizada pelas distribuições de probabi lidade correspondentes, DILLON (1971).

Fica portanto eliminada a hipótese de se determinar com antecipação os resultados das decisões assumidas, co mo forma de bem explicar o comportamento do individuo em condi ções de incerteza, situação que se aplica com exatidão ao cená rio em que se desenvolve a produção agropecuária, no qual variações de clima e preços, bem como a incidência de pragas e doenças, conferem natureza bastante aleatória à atividade.

Simplificadamente, a incerteza faz com que se obedeça ao chamado "problema de decisão em um estágio", onde a pós o processo efetivo de decisão ocorre um fenômeno estocásti co afetando diretamente o resultado da ação. A figura 1 repré senta tal situação.

Nesta figura, $x_{j}(j=1 \ldots n)$ são as possiveis açoes, $N_{k}(k=1 \ldots m)$ os possiveis estados da natureza que ocorrem com probabilidade $p_{k}$ e ainda $x_{j k}$ são as conseqüencias das decisões tomadas, resultantes da interação destas com os estados na natureza que se verifiquem.

Foi considerando que as conseqüências das ações se ligam a resultados incertos, que Daniel Bernoulli procurou pela primeira vez na histōria econômica caracterizar aquilo que seria o comportamento do indivíduo sob incerteza (SIMONSEN, 1966). 


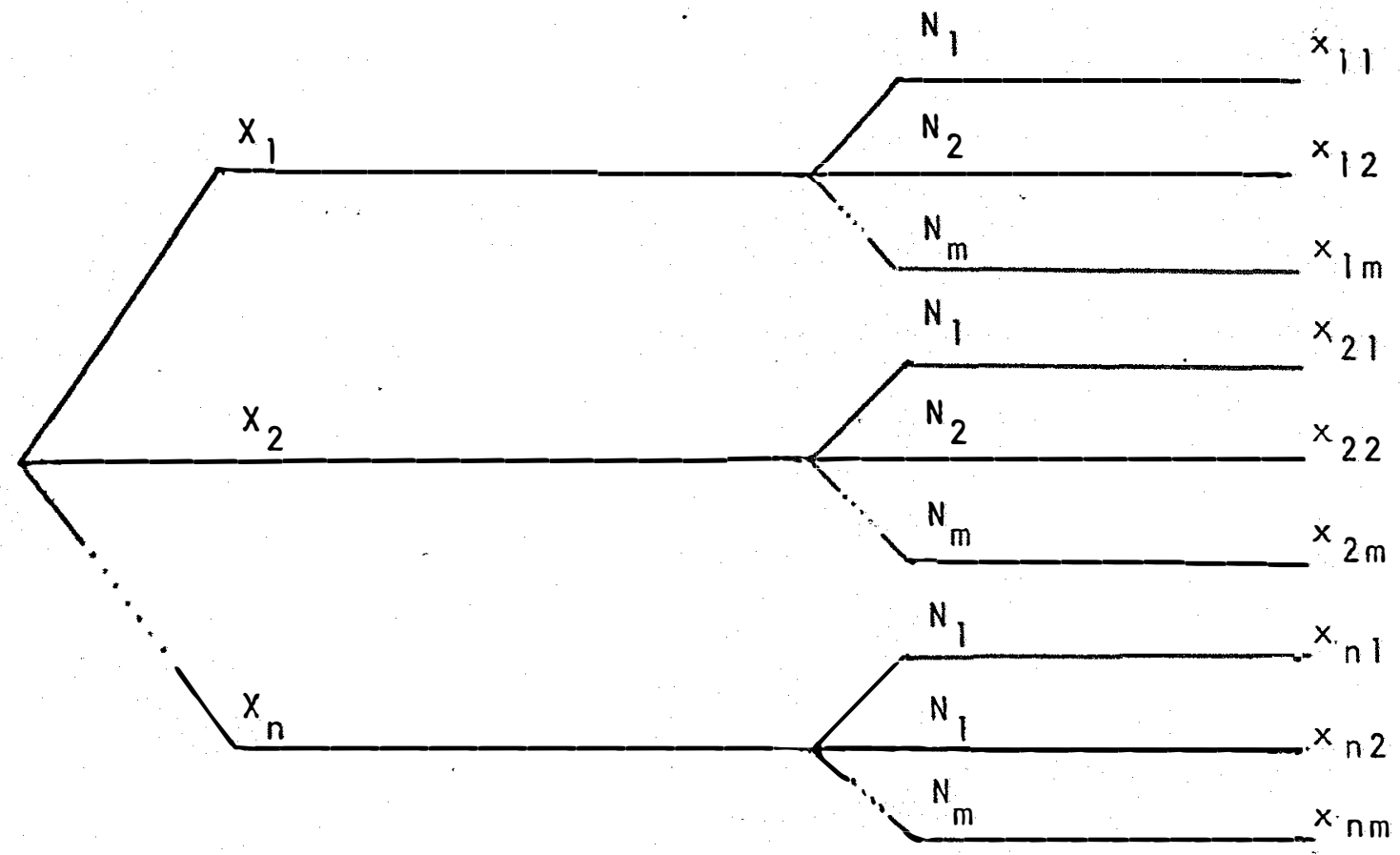

Figura 1. Representação do Problema de Decisão em um Estágio.

Sem lançar mão do conceito de utilidade, ele considerou que entre diferentes alternativas de conseqüencias imprevistas, o tomador de decisão escolheria aquela de mais elevada "esperança moral", dada através da ponderação dos possi veis resultados pelas respectivas probabilidades de ocorrência; seria a esperança moral das ações, o instrumento que pautaria as decisões sob incerteza.

Desenvolvimentos posteriores, mantiveram-se apoiados na pressuposição de que as intensidades de satisfação associadas aos diferentes estados ou situações pudessem ser di retamente quantificáveis. A idéia de esperança moral passava a ser substituida pela idéia de utilidade esperada, com o indi viduo se comportando de modo a maximizar a utilidade esperada, média das utilidades dos possiveis resultados, ponderada pe- 
las probabilidades de ocorrência destes.

Estava presente a noção de que o tomador de decisão fosse capaz não apenas de ordenar suas preferências, como também de estabelecer as diferenças entre os níveis de utilidade ou satisfação, admitindo que estes fossem de natureza cardinal.

A congruência entre função de preferência e noção de probabilidade, como condicionantes do processo de decisão sob incerteza, é constatada em economistas clássicos como Jevons citado por ELLSBERG (1954, p.539), ao afirmar que,

"na seleção de ações que dependam de situaçö futuras, $\bar{e}$ preciso multiplicar a quantidade de satisfação associada a cada uma delas pela fraçã correspondente $\bar{a}$ sua probabilidade.".

E a função utilidade esperada governando as decisões sob incerteza, jā que preferências, expressas cardinalmente, e distribuições subjetivas de probabilidade permitiam determinà-la.

$$
\text { Sejam } x_{j}(j=1, \ldots, n) \text { as ações colocadas à }
$$
escolha do individuo, onde cada uma delas apresenta $x_{j k}$ ( $k=$ $=1, \ldots, m)$ resultados possíveis associados às probabilidades Pjk. 0 processo de decisão consistiria em encontrar a ação cu ja utilidade esperada fosse māxima. Dever-se-ia encontrar a j-ésima alternativa que maximizasse 


$$
\bar{U}\left(x_{j}\right)=\sum_{k=1}^{m} U\left(x_{j k}\right) \cdot P_{j k}
$$

onde $U\left(x_{j k}\right)$ é a utilidade associada ao resultado $x_{j k}$.

ocorre porēm que a evolução da teoria econômica viria retirar ênfase da idéia de utilidade cardinal, questionando grande parte do que havia sido desenvolvido até então em termos do entendimento do processo de decisão sob incerteza. o que era proposto na teoria ordinal de utilidade fazia com que seus indices não fossem ligados ao nível absoluto de satis fação, tornando pouco razoável a idéia de utilidade esperada como parâmetro de decisão.

$$
\text { Em HICKS (1968, p.17) tais idéias estão resumi- }
$$

das assim,

$$
\text { "ele lo mapa de indiferençal permite }
$$
apenas que se estabeleça a preferência entre duas cestas de bens, ... nada revelando, ao contrārio da superfície de utilidade, em quanto uma delas é preferida em relação à outra.".

No momento em que a função utilidade do indivíduo assegura apenas a ordenação e a transitividade das preferências, sua aplicação passa a se restringir apenas ao entendi mento do processo de escolha sob absoluta certeza de resultados, o que se explica uma vez que se os resultados das ações são conhecidos com certeza e antecipação, a simples ordenação 
das preferências permite que se estabeleça a decisão que maximiza a utilidade.

A incoerência entre a teoria ordinal de utilida de e a questão da escolha envolvendo risco è reconhecida por diversos autores, FRIEDMAN e SAVAGE (1948), HENDERSON E QUANDT (1958) e é sintetizada por BAUMOL (1958, p.668),

"... porém, quando cada ação se caraç teriza pela distribuição de probabilidades de seus resultados, o estabelecimento da escolha exige algo mais que a simples orde nação das preferências.".

Se, de um lado, a idéia de medida ordinal de utilidade era algo mais prōximo do razoável, de outro, deixava com reduzida sustentação teörica a questão da decisão sob incerteza, característica fundamental da realidade que cerca o individuo, hiato. que só viria ser reduzido anos a frente com VON NEUMAN e MORGENSTERN (1953) e sua teoria cardinal moderna de utilidade, formulada de modo a permitir o entendimento do processo de decisão sob incerteza.

A despeito da nomenclatura utilizada, não ocorre a retomada da hipótese clássica de medida cardinal de utili dade, já que o indice sugerido apresenta natureza exclusivamen te operacional. De acordo com, o texto original de VON NEUMAN e MORGENSTERN (1953, p.17),

$$
\text { "... podemos prosseguir um passo além }
$$
das negaçöes, que são apenas cuidados con- 
tra prematuras assertivas da impossibilida de de mensuração da utilidade. Pode ser visto que sob as condições nas quais a ana lise baseada em curvas de indiferença se apōia, muito pouco esforço extra é requeri do para que se alcance a atribuição de indices numéricos de utilidade.".

A conceituação de utilidade, proposta por VON NEUMAN e MORGENSTERN, è o vértice de todas as teorias posterio res que buscam a compreensão do processo de decisão sob incerteza, correspondendo à forma encontrada para permitir que a no ção de utilidade, fundamento da teoria econômica, tivesse sua aplicação extendida ao entendimento do comportamento do indiví duo em condições de incerteza.

A idéia de esperança moral, de Bernoulli, passa a ser retomada a se considerar que o tomador de decisão age como se pautasse seu comportamento na maximização da utilidade esperada, utilidade entendida como proposto por VON NEUMAN e MORGENSTERN .

Ficam estabelecidas algumas condições bàsicas em torno do comportamento do individuo sob incerteza, que uma vez atendidas garantem a existência de uma função utilidade que governa as preferências em tais situações.

Seguiu-se extensa polèmica em torno da coerên- 
cia das ideias lançadas por VON NEUMAN e MORGENSTERN, com destaque para os trabalhos de ALCHIAN (1953), STROTZ (1953) e OZGA (1956). A questão levantada dizia respeito à natureza dos indices de utilidade propostos, concluindo-se que não havia liga ção direta entre estes e as sensações de satisfação associadas aos diferentes eventos uma vez que tais indices apresentam ori gem e escala de medida tomadas de maneira totalmente arbitrária ficando anulada qualquer possibilidade de comparações interpessoais de niveis de satisfação.

A base teörica da proposição de VON NEUMAN e MORGENSTERN pressupõe que em situações de incerteza de resulta dos, o individuo apresenta invariavelmente, um comportamento coerente com um conjunto de axiomas que, uma vez respeitados, asseguram a consistência do quadro de preferências pessoais. Considere-se A, B e C como sendo as ações alternativas, de resultados incertos, sujeitas ao processo de seleção do individuo, os seguintes axiomas se apresentam:

Axioma da Ordenação: Frente as alternativas o tomador de decisão estabelece a preférência ou indiferença entre elas, sendo que tais relações são transitivas.

Axioma da Continuidade: Dado que A seja preferi da a B, e esta por sua vez o seja a C existirá então a probabi lidade $p$, por definição $0 \leqslant p \leqslant 1$, tal que ocorra indiferença entre $B$ 'e uma loteria $L(A, C, p, 1-p) \stackrel{l}{\prime}$.

I/ $L(A, C, P, I-p)$, se refere a uma ação de resultados incertos $A$ ou $C$, que ocorrem com probabilidades $p$ e $1-p$, respectivamente. 
Axioma da Independência: Desde que A seja prefé rída a B, e B o seja a C, então uma loteria L, ( ferida a uma outra, $L_{2}(B, C)$, desde que as probabilidades de ocorrência de A e B sejam as mesmas em ambas as loterias. presença de C não distorce as preferências.

Axioma da Monotonicidade: Frente a duas alterna tivas de idênticos resultados a preferência se estabelece em torno daquela em que há maior concentração de probabilidades em torno de resultados mais favoráveis.

Se o comportamento do tomador de decisão não viola qualquer destes axiomas, existirá então uma função utili dade da forma proposta por VON NEUMAN e MGRGENSTERN que passa a regular o processo de decisão.

Esta função associa indices numéricos de utilidade a toda e qualquer ação de resultados incertos, colocada à escolha do individuo, e deve apresentar três propriedades fundamentais:

a) desde que $A$ seja preferida a B, o indice de utilidade atribuido a A é mais elevado que aquele associado a $B$, ou seja $U(A)>U(B)$.

b) a utilidade de cada alternativa é dada por sua utilidade esperada, soma dos indices associados a cada um de seus resultados, ponderada pelas respectivas probabilidades de ocorrência. Seja X esta alternativa, de possíveis resulta- 
dos $\{x\}$, apresentando função densidade de probabilidade $f(x)$; o valor da utilidade esperada, $E[U(X)]$ é dado por

$$
E[U(x)]=-\int^{\infty} U(x) \cdot f(x) \cdot d x
$$

c) qualquer transformação monotônica, linear e positiva de uma função utilidade, reproduz o quadro de preferências do individuo da mesma forma que a função original, ou seja $U^{*}=a U+b$, onde $a>0$, desempenha o mesmo papel de $U$.

Assumindo a existência de função utilidade desta natureza, há base para se admitir que sob incerteza o comportamento é regido pela maximização da utilidade esperada, re caindo a escolha sobre a alternativa de maior valor de utilidade.

Contra a proposição de VON NEUMAN e MORGENSTERN pesa seu excessivo grau de generalidade, já que embora reconfie ça a existência de uma função que governa as decisões sob condições de incerteza, deixa de considerar a influência do nível de risco de cada ação particular no processo de decisão.

Apenas o valor esperado ou médio de utilidade é considerado como relevante para a decisão, não sendo levada em conta, nenhuma medida de dispersão de resultados, que caracteri zaria o nivel de risco envolvido.

A forte pressuposição no modelo de. VON NEUMAN e MORGENSTERn é de que a utilidade de uma ação é função ùnica e exclusiva do resultado econômico esperado ou seja, a utilida 
de é linear com respeito ao valor monetário das ações, não sen do considerado qualquer fator que modere as preferências.

A aceitabilidade dos axiomas propostos também encontra oposição: BAUMOL (1958), SIMONSEN (1966) e DILLON (1971) levantaram uma série de questões, em especial o fato de que verificações empiricas dão conta da limitada ocorrência de transitividade de preferências. A noção de continuidade também é questionada por exigir que o individuo conheça sua taxa de substituição entre as alternativas propostas.

DILLON também se refere ao fato de VON NEUMAN e MORGENSTERN estabelecerem que apenas um atributo das diferentes ações, seu resultado econômico, seja relevante na decisão, aplicando-se a funções utilidade unidimensionais, deixando de reconhecer que diferentes objetivos podem influir na tomada de decisão. Funções multidimensionais permitem abrigar a situação bastante plausivel de que na decisão é preciso antes de mais nada o atendimento de um requisito de segurança, ligado à própria subsistência do individuo.

A despeito da pertinência de boa parte das limi tações apontadas, os fundamentos de VON NEUMAN e MORGENSTERN permanecem assegurando o entendimento das decisões sob incerte za, jā que formulações posteriores correspondem apenas a refinamentos destinados a restringir o excessivo grau de generalidade das idéias iniciais.

Entretanto, fica patente a necessidade de que se estabeleça algum nivel de conhecimento em torno da função u 
tilidade do individuo, como forma de tornar possível o entendi mento de seu comportamento. Isto é reconhecido por HADLEY (1967, p.199),

"... o tomador racional de decisão se comporta, na seleção de ações incertas, de forma a escolher aquela que maximiza a uti lidade esperada. Assim sendo, se se contie ce sua função utilidade pode-se determinar qual a ação ele irā preferir, encontrando aquela que maximiza sua utilidade esperada." .

A tentativa de se estabelecer a função utilidade do tomador de decisão se processa buscando fazer com que ma nifeste suas preferências frente a alternativas incertas hipotèticas. Originalmente, na propostá de VON NEUMAN e MORGENSTERN, este procedimento consistia em submeter o individuo a avaliações sucessivas de suas preferências entre uma alterna tiva de resultado conhecido, e outra onde eram dois os possiveis resultados. Atribuindo-se valores de utilidade hipotéticos a cada resultado, e manipulando-se as probabilidades associadas aos resultados da alternativa incerta, estabelecia-se o ponto em que se dava a indiferença entre elas.

Um refinamento desta proposição, surgido mais recentemente permite a derivação da suposta função utilidade

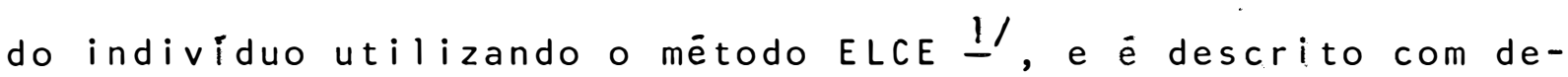
I/ ELCE. Equally Liquely risky prospect and its Certainty Equivalent. 
18.

talhe em ANDERSON e outros (1977). 0 método, fundamentado no axioma da continuidade, procura determinar o equivalente assegurado, valor que obtido com certeza torna o indivíduo indife rente entre ele e uma alternativa de resultados incertos, que ocorrem com idêntica probabilidade $(p=1 / 2)$, não mais se mani pulando niveis de probabilidade, e sim os valores dos possíveis resultados das alternativas incertas.

Considere-se que $X$ e $Y$ correspondam respectivamente ao mais desfavorável e ao mais favorävel dos eventuais resultados de uma determinada ação; o procedimento consiste em determinar a ação $W$, que obtida com certeza, torna o indivíduo indiferente entre $W$ e a ação incerta de resultados $X$ e $Y$.

$$
\begin{aligned}
& \text { Assim sendo, } \\
& U(W)=\frac{1}{2} \cdot U(X)+\frac{1}{2} \cdot U(Y),
\end{aligned}
$$

e como $X$ e $Y$ correspondem a eventos extremos pode-se atribuir indices arbitrários de utilidade a cada um, determinando com isso a utilidade do equivalente assegurado, W.

A liberdade em se arbitrar níveis de utilidade aos eventos extremos se justifica, uma vez que a função utilidade é única para uma determinada transformação monotânica, 1 i near e positiva.

$$
\text { Assumindo que } U(X)=0 \text { e } U(Y)=1.000 \text {, }
$$




$$
U(W)=\frac{1}{2} \cdot 0+\frac{1}{2} \cdot 1000=500 \text {, }
$$

e seguindo em seqüencia, pode-se determinar os indices de utilidade para todos os eventos no intervalo $X-Y$. Torna-se então possivel a derivação da forma da suposta função utilidade do tomador de decisão, como mostrada na Figura 2 .

Embora o uso de probabilidades neutras, $\mathrm{p}(\mathrm{X})=$ $=p(Y)=1 / 2$, torne 0 método ELCE mais aplicável que o propos to por VON NEUMAN e MORGENSTERN, alguns viēses permanecem: ROBINSON e KING (1981) detalham falhas na forma como se questiona o individuo, problemas na estimação estatistica das funções, e a dificuldade de alguns indivíduos na manifestação de preferências.

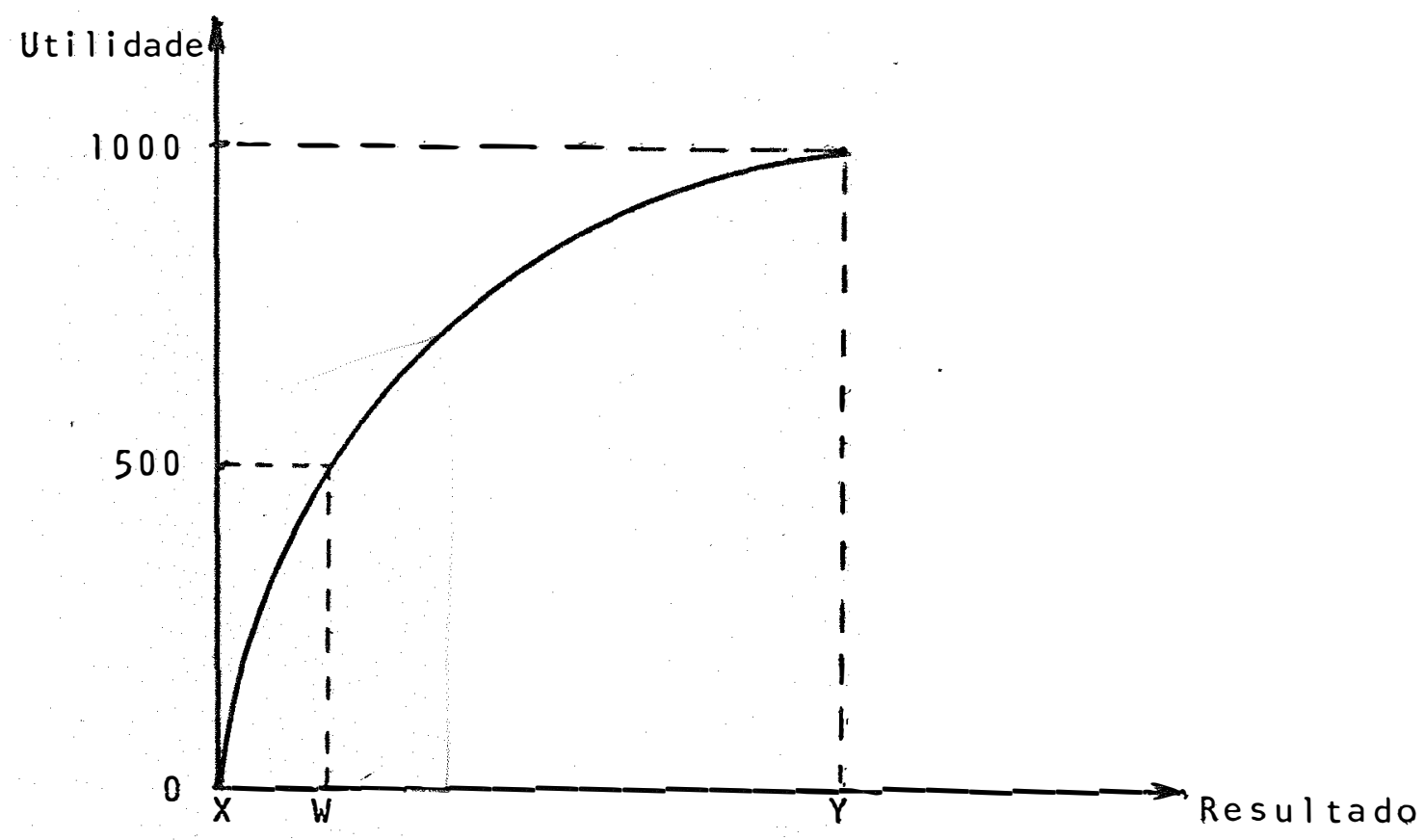

Figura 2. Representação da Função obtida pelo Método ELCE. 
A aplicação empírica da derivação de funções de utilidade encontra-se em. LIN e outros (1974), acabando por sugerir que a função de utilidade de tomadores de decisão não é função direta e exclusiva do resultado esperado. Tal idéia contraria frontalmente o estabelecido na teoria económica convencional, onde se admite a congruência entre a maximização do lucro e da utilidade.

A variāvel que passa então a tambēm ser conside rada na formulação da decisão, è o nível de incerteza envolvido, característico de cada ação, incorporando-se a noção de que diferentes individuos reagem de diferentes maneiras face à pre sença da incerteza, passando a maximização da utilidade espera da a envolver outros parâmetros e não apenas o resultado esperado das ações.

o papel da incerteza na tomada de decisão está descrito em TOBIN (1958), ao expor sua teoria da preferência pela liquidez, para explicar o comportamento apresentado por investidores quando da composição de ativos financeiros. Considerou como sendo três os diferentes tipos de comportamento frente ao risco ou incerteza: propensão, indiferença ou aversão, recorrendo às idēias formuladas por FRIEDMAN e SAVAGE (1948), segundo as quais a utilidade marginal da renda poderia ser crescente, constante ou decrescente para diferentes indivi duos.

Propensão, indiferença ou aversão ao risco, caracterizariam individuos com utilidade marginal da renda res- 
pectivamente crescente, constante ou decrescente, como representado na Figura 3. 0 entendimento destas diferentes formas de comportamento pode ser conseguido atravēs da manifestação das preferências do individuo, quando do processo de derivação de sua função de utilidade; o indivíduo ávesso ao risco, ao es tabelecer o ponto em que se torna indiferente entre a ação incerta de resultados $X$ e $Y$, e aquela de resultado conhecido, W, o faz de modo que

$$
W<\frac{1}{2} X+\frac{1}{2} Y,
$$

ou seja, o valor monetário de $W$, o equivalente assegurado (E A), seria inferior ao valor esperado da ação incerta (VME).

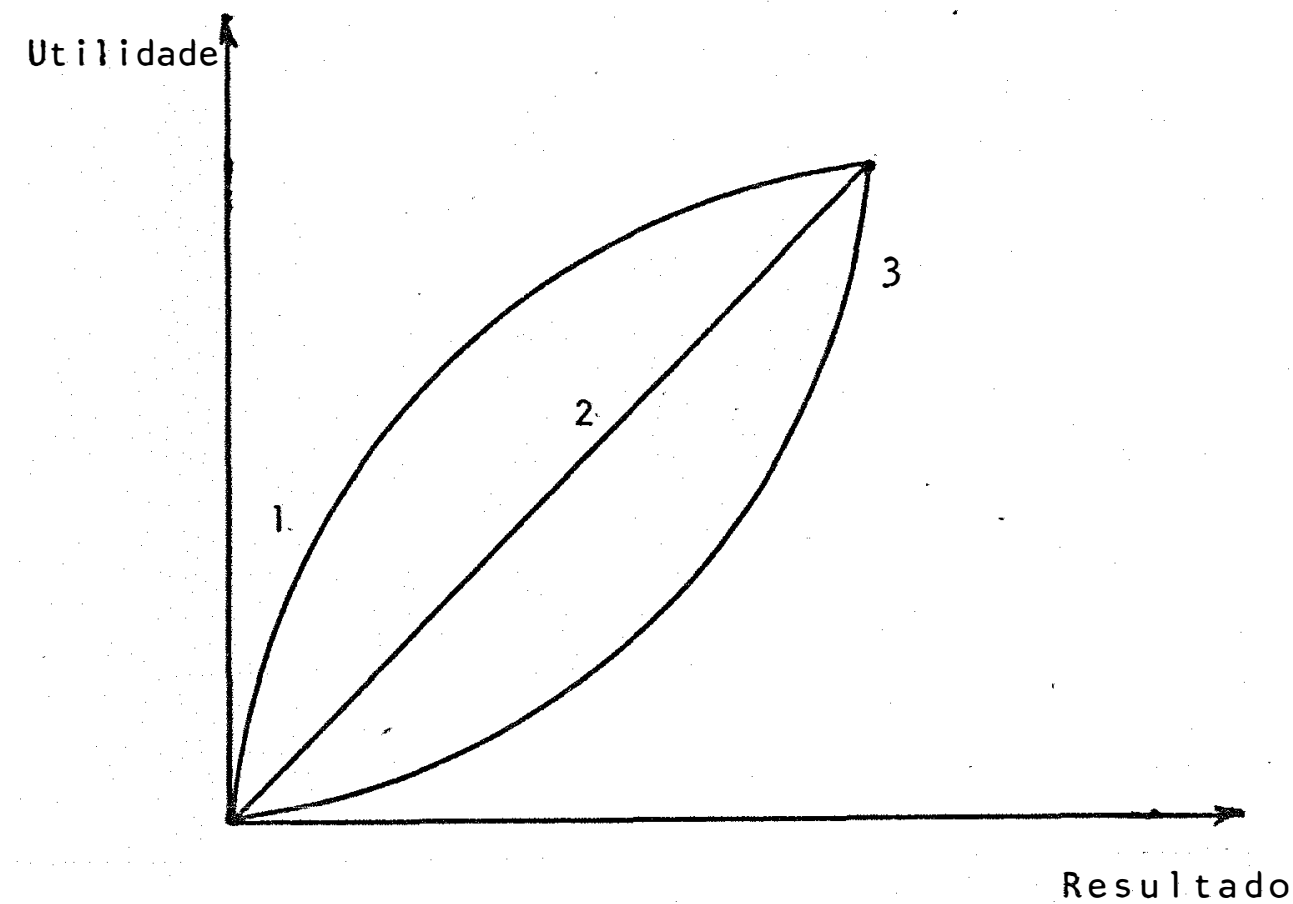

Figura 3. Função de Utilidade de Individuos Avessos (1), Neutros (2) e Propensos ao Risco (3). 
Esta diferença (VME - EA), de valor positivo para avessos ao risco è o chamado prêmio de risco, e corresponde a quantia que o indivíduo se dispõe a "pagar" ou de outra forma, deixar de receber, desde que se garanta sua segurança, enquanto que individuos propensose neutros ao risco apresentam prêmio de risco negativo e nulo, respectivamente (Figura 4). Logicamente, a indiferença ao risco, faz com que a função de ut lidade coincida com o segmento $A B$, tornando nulo o prêmio de risco.

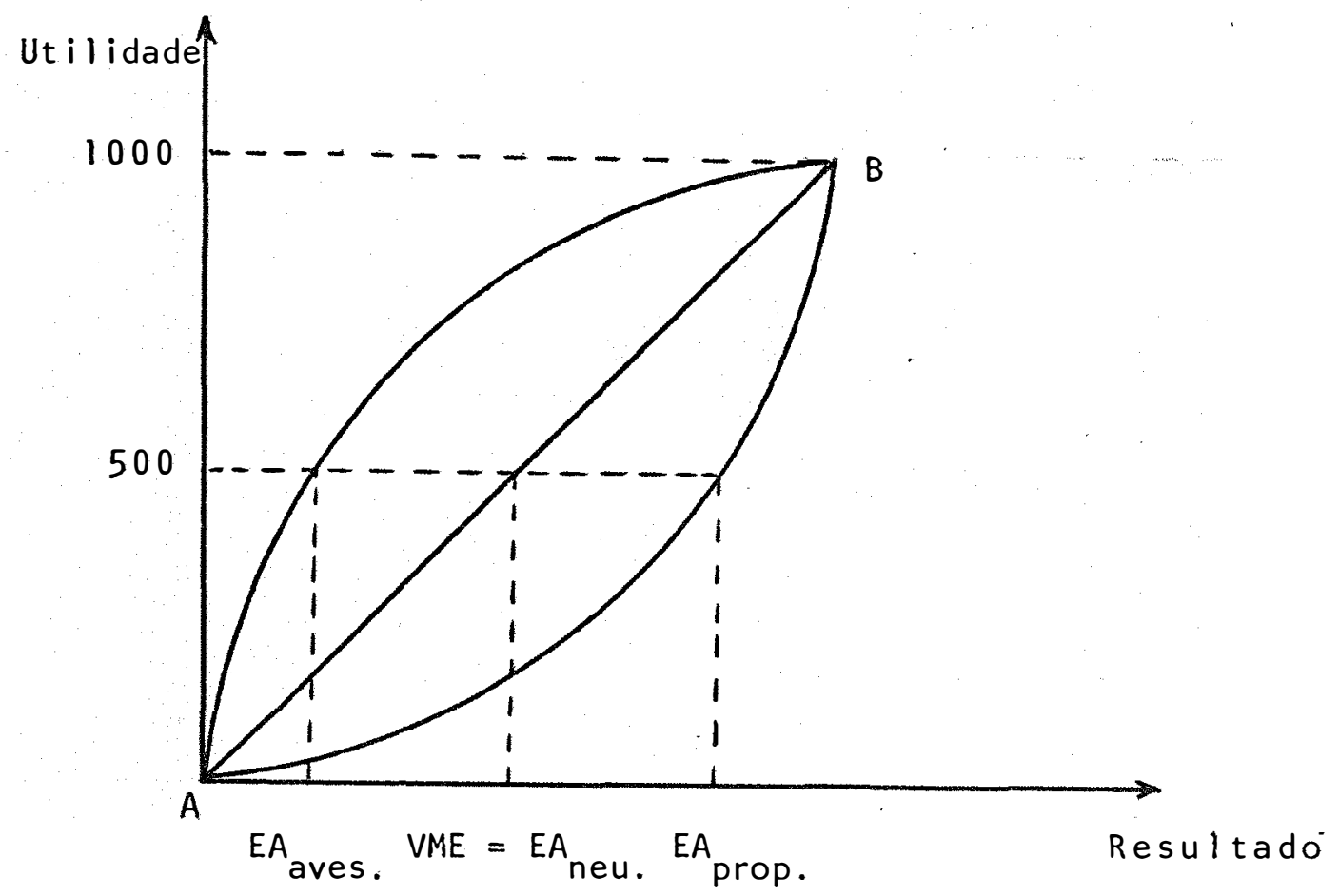

Figura 4. Prêmios de Risco para os Diferentes Tipos de Comportamento. 
Reconhecido o fato de que a função utilidade a $\underline{s}$ sim obtida é ünica apenas para uma dada transformação monotôni ca, linear e positiva, verifica-se que os parâmetros que descrevem sua forma se alteram na medida em que se determine esca la e origens diferentes. Na busca de uma medida que descreven do a função de utilidade, fosse caracteristica do comportamento do individuo, PRATí (1964) propõe a função de aversão absoluta ao risco, $r(x)$, que seria a ünica característica da função de utilidade que se mantém inalterada quaisquer que sejam as transformações sofridas. Traduz o grau de concavidade ou convexidade local da função utilidade, e é expressa pela relação entre suas duas primeiras derivadas.

$$
r(x)=-u^{\prime \prime}(x) / u^{\prime}(x)
$$

indicando aversão, indiferença ou propensão ao risco ao assumir valor positivo, nulo ou negativo, respectivamente.

E extensa a literatura associada à caracterização de funções de utilidade de tomadores de decisão, sendo que suas propriedades estão resumidas e detalhadas em ANDERSON e outros (1977) e LIN e CHANG (1978). OFFICER e HALTER (1968), LIN e outros (1974) verificaram, empiricamente, que funçōes de utilidade do tipo VON NEUMAN e MORGENSTERN, e que incorporam a influência do risco no processo de decisão, se aproximam muito mais do comportamento observado em agricultores, do que a hipó tese de exclusiva maximização de lucros. 
Com base nos fundamentos teöricos descritos no Capitulo anterior, uma série de regras vieram sendo propostas como boas representantes do processo de decisão do indivíduo, sob incerteza de resultados, e correspondem aos chamados crité rios de decisão.

Neste Capitulo pretende-se descrever as proprie dades e apontar algumas das limitações, de três destes critérios: Análise Média-Variância (TOB।N, 1958), Dominância Estocástica (QUIRK e SAPOSNIK, 1962) e Dominância Estocástica com Respeito a uma Função (MEYER, 1977). São critērios de decisão que se mantém coerentes com a préssuposição de que sob incerte za, o tomador de decisão atua como um maximizador da utilidade esperada e não apenas de lucros.

\subsection{Anālise Média-Variância.}

Seudesenvolvimento se deu com vistas à com- 
preensão do comportamento do investidor na composição de seus ativos em mercados financeiros, e sua formulação original è de TOBIN (1958). Corresponde à proposição formal de que não è apenas o resultado esperado de uma ação que condiciona a tomada de decisão. Pela primeira vez se reconhecendo que, neste processo, o nivel de risco envolvido participa de forma decisiva. Nas palavras de TOBIN (1958, p.72),

"o risco associado a um portfolio $\bar{e}$ medido pelo desvio padrão de seus resultados... Assim sendo, $\bar{e}$ intuitivo que se ve rifique que um portfolio que apresenta ele vado desvio padrão oferece ao investidor a oportunidade de ganhos elevados de capital, isto ao custo de chances equivalentes de elevadas perdas.".

O pressuposto fundamental da Análise Média-Variância (EV Analysis) $\stackrel{1}{ } /$ é de que a decisão do individuo depende das propriedades das funções densidade de probabilidade cor respondentes às diferentes ações.

Seriam dois os paràmetros destas funções, relevantes para a decisão: o primeiro momento em relação à origem ou valor esperado, e o segundo momento em relação à média, ou variância.

I/ EV è a abreviação de Expected Value-Variance. 
A noção de risco é incorporada através da cons deração da variância, medida da dispersão dos eventuais resultados em torno do valor esperado. E de fato um avanço em rela ção ao pressuposto por VON NEUMAN e MORGENSTERN, que limitava o processo de decisão á consideração única e exclusiva do valor esperado dos resultados. Vale lembrar que, como reconheci do por TOBı́N, a variância não é a ūnica medida de risco, jā que qualquer medida de dispersão serviria a este propósito.

Ao se considerar que estes dois parâmetros, valor esperado e variância, sejam os únicos fatores que pesam na decisão, é possível o entendimento das supostas formas de comportamento sob incerteza. Indivíduos avessos ao risco só acei tam alternativas de variância mais elevada, se estas, em contrapartida, oferecerem retorno esperado que mais que compense o maior risco assumido, ao passo que aqueles propensos ao risco buscam espontaneamente ações de variância elevada como $\because$ forma de se habilitarem a retornos bastante elevados, a despeito de. eventuais reveses, enquanto que os indiferentes ao risco ignoram a dispersão de resultados das ações buscando aquelas de mais elevado valor esperado.

Na medida em que se limita o critērio de decisão à consideração dos dois primeiros momentos das distribuições de probabilidades duas restrições devem ser satisfeitas: a função de utilidade do indivíduo deve ser quadrática, ou as distribuições de probabilidade devem ser normais. 0 não atendimento de pelo menos uma delas, faz com que o modelo proposto 
não se aplique ao processo de decisão.

A distribuição do tipo Normal, também conhecida como de "dois parâmetros" se caracteriza por ser completamente descrita por seus dois primeiros momentos, valor esperado e va riância. Ao esgotarem a ${ }^{3}$ informação em torno das distribuições de probabilidade, estas duas medidas, passam a ser os ūnicos e exclusivos fatores de definição de preferências.

Por outro lado a pressuposịção de função de ut lidade quadrática traz implicações mais delicadas, que ao serem detalhadas e discutidas, asseguram o entendimento daquilo que o modelo EV pretende que seja a racionalidade no processo de decisão sob incerteza.

ANDERSON e outros (1977) sugerem que a forma quadrätica corresponda a uma aproximação via sērie de Taylor, da verdadeira porēm desconhecida função de utilidade do tomador de decisão.

Expressa em função de $\{x\}$, conjunto dos possiveis resultados, a função quadrática de utilidade assume a for $\mathrm{ma}$

$$
u(x)=x+b x^{2}
$$

Uma vez que sob incerteza, o comportamento passa a ser de maximização da utili idade esperada, à função de ut i lidade ( 7 ) devem ser aplicadas as propriedades da esperança matemātica, de modo que 


$$
E[U(x)]=E(x)+b E\left(x^{2}\right) \text {. }
$$

Depois de algumas transformações, que estão detalhadas no Apêndice 5 , esta expressão que traduz a função utilidade esperada do individuo passa a ser expressa como

$$
E[U(x)]=E(x)+b[E(x)]^{2}+b V(x)
$$

que por sua vez relaciona a preferência do tomador de decisão aos dois primeiros momentos das distribuições de probabilidade consideradas, valor esperado, $E(x)$ e variância, $V(x)$.

o comportamento usualmente assumido como racional é aquele em que a utilidade marginal dos retornos é positi va, garantida porém a aversão ao risco. As propriedades de sua função de utilidade $(9)$, caracterizam algumas características do comportamento deste individuo.

Tomando as derivadas parciais da função, temos,

$$
\frac{\delta E[U(X)]}{\delta E(X)}=1+2 b E(X)>0
$$

$$
\begin{aligned}
& \frac{\delta E[U(x)]}{\delta V(x)}=b<a \\
& \frac{\delta^{2} E[U(x)]}{\delta E(x)^{2}}=2 b<0 .
\end{aligned}
$$


Deste modo em (10) está patente que a utilidade marginal é positiva, ao passo que a aversão ao risco ou seja a preferência pela estabilidade dos resultados é garantida por (11). E importante notar a expressão (12), que garante a idéia de que a utilidade marginal dos resultados é decrescente, suge rindo um nível máximo de utilidade, fazendo com que o risco en volvido atue como moderador das preferências.

Assim sendo, o comportamento presumido pela Aná lise EV, se expressa através da utilidade marginal dos resulta dos positiva e decrescente, aliada à utilidade marginal da variância, que è negativa.

As caracteristicas de comportamento associadas a este tipo de função de utilidade podem ser derivadas a partir das curvas de iso-utilidade do individuo, obtidas tomando (9), mantido um nivel fixo de utilidade, $U^{*}$, de forma que,

$$
U^{*}=E(X)+b[E(X)]^{2}+b V(X)
$$

dividindo-se por b todos seus termos e rearranjando,

$$
V(x)=\frac{U *}{b}-\frac{E(X)}{b}-[E(x)]^{2}
$$

As propriedades das curvas iso-utilidade no pla no $[E(X), V(X)]$, são conseguidas pela diferenciação de (14), 


$$
\begin{aligned}
& \frac{d E[U(x)]}{d V(X)}=-b /[1+2 b E(X)]>a \\
& \frac{d^{2} E[U(X)]}{d V(X)^{2}}=\frac{2 b^{2}}{[1+2 b E(X)]^{2}} \cdot \frac{d E}{d V}>0 .
\end{aligned}
$$

Face à aversão ao risco (11) e à utilidade marginal dos retornos positiva (10), as expressões (15) e (16) se tornam positivas. Com isso verifica-se que o mapa de indiferença do individuo avesso ao risco, é composto por curvas inclinadas positivamente e com a concavidade voltada para cima, que expresso em termos de retorno esperado e variância, é mostrado na Figura 5.

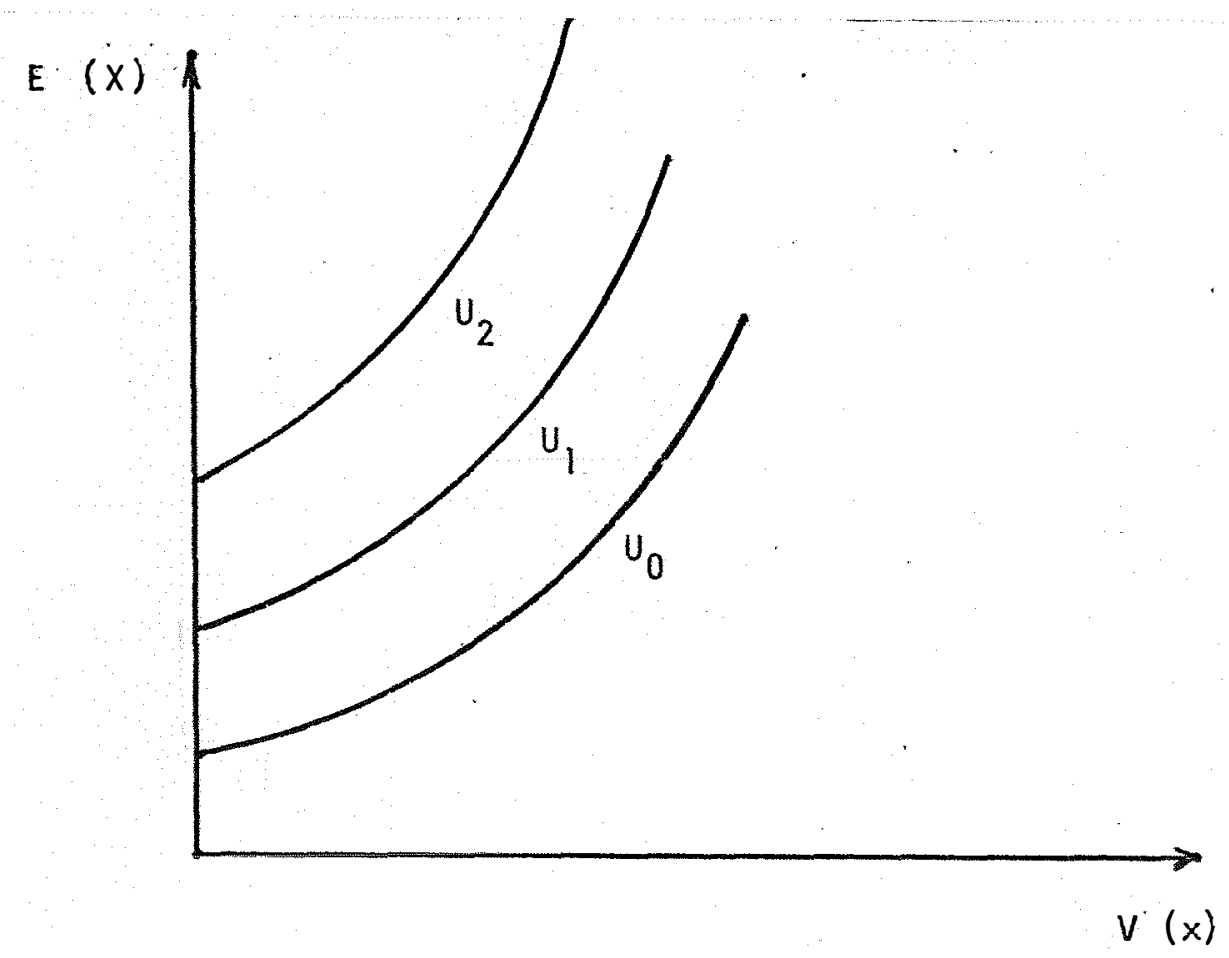

Figura 5. Mapa de Indiferença de Individuos Avessos ao Risco. 
E fäcil verificar que, em tais circunstâncias, - individuo exige um aumento no retorno esperado como forma de compensar uma elevação no risco, de modo a manter inalterado o nivel de utilidade.

Por outro lado é imediato que se verifique que o aumento compensatōrio requerido em $E(X)$ è cada vez mais ele vado à medida que se eleva o risco, medido por $V(x)$.

Aquelas ações que, para cada nível de risco, apresentam o mais elevado retorno esperado, constituem a chamada fronteira eficiente, que reúne as ações consideradas igualmente eficientes de acordo com a Anälise E-V.

Esta situação é visualizada na Figura 6, que reūne o mapa de indiferença e as possíveis ações alternativas.

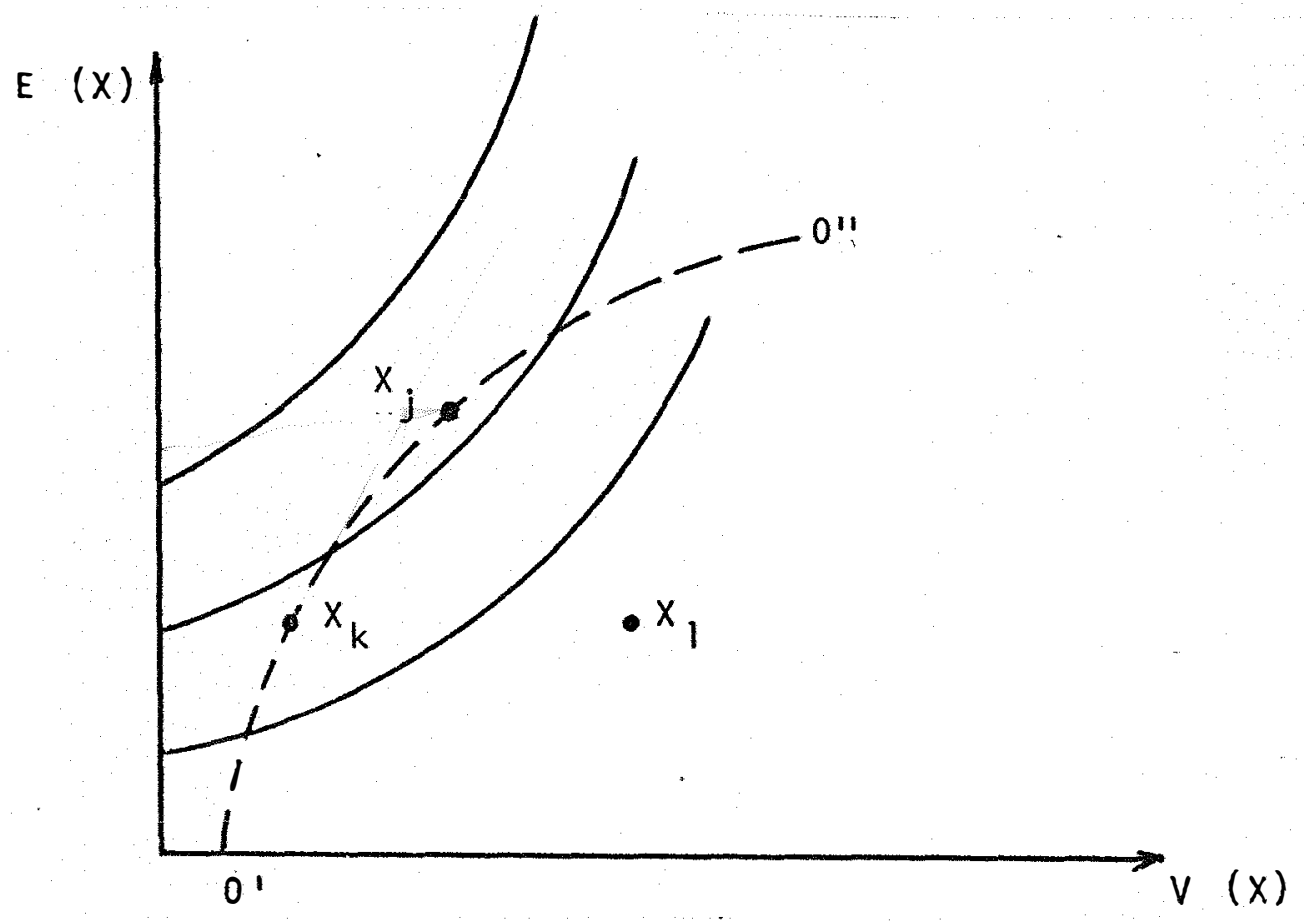

Figura 6. Relação entre o Mapa de Indiferença e Possíveis Alternativas. 
Desde que $E\left(x_{j}\right)>E\left(x_{k}\right)$ e $v\left(x_{j}\right)>v\left(x_{k}\right), x_{j}$ e $X_{k}$ se colocam sobre a fronteira eficiente $0^{\prime}-0^{\prime \prime}$, e são con sideradas igualmente eficientes.

Uma vez que $E\left(x_{k}\right)=E\left(x_{1}\right)$, mas $v\left(x_{k}\right)<v\left(x_{1}\right)$, então $x_{1}$ è considerada ineficiente em relação a $x_{k}$, ou seja è dominada por $X_{k}$, para qualquer individuo avesso ao risco.

Vale lembrar que não ocorre a definição da melhor alternativa, aquela que maximiza a utilidade esperada, já que para tanto se exigiria a perfeita especificação dos parâme tros da função utilidade, o que não ocorre na Análise EV que exige apenas as restrições impostas pelas condições (15) e (16).

E passivel a demonstração algébrica das regras básicas que permitem a seleção das alternativas, de acordo com a. Análise EV. Para isso tomemos a expressão ( 9 ), que submeti da a uma transformação monotônica, linear e positiva dá origem a uma nova função utilidade $E[\bar{U}(x)]$, que caracteriza as mesmas preferências da função original,

$$
E[\bar{U}(X)]=\frac{-1}{b} \cdot E(X)+\frac{-1}{b} \cdot b \cdot[E(X)]^{2}+\frac{-1}{b} \cdot b \cdot V(X)
$$

e como $L=-1 /\left(\begin{array}{ll}2 & b\end{array}\right)$ é o limite superior do dominio de $U(X)$, temos

$$
E[\bar{U}(x)]=2 \therefore L \cdot E(X)-[E(X)]^{2}-V(x)
$$

Deste modo, quando frente a duas alternativas $x_{j}$ e $x_{k}$ o tomador de decisão irá preferir $x_{j}$ ou se mostrará in 
diferente entre ambas, se

$$
E\left[\bar{U}\left(x_{j}\right)\right]-E\left[\bar{U}\left(x_{k}\right)\right] \geqslant 0
$$

ou seja $X_{j}$ será preferida desde que sua utilidade esperada seja maior que a correspondente a $x_{k}$.

Desenvöivendo-se (19), como detalhado no Apêndi ce 5, temos

$$
\text { 2. } \Delta E \cdot(L-\bar{E})-\Delta V \geqslant 0
$$

onde, $\Delta E=E\left(x_{j}\right)-E\left(x_{k}\right), \quad \bar{E}=\frac{E\left(x_{j}\right)+E\left(x_{k}\right)}{2} e$

$$
\Delta v=v\left(x_{j}\right)-v\left(x_{k}\right)
$$

Uma vez que L è o limite superior do dominio de $U(X)$, seu valor será sempre superior ao de $\bar{E}$, de forma que a condição (20) è satisfeita desde que $\Delta E$ seja positivo ou nulo, e $\Delta V$ negativo ou nulo. Portanto a preferência ou indiferença por $x_{j}$ em relação a $x_{k}$ exige que

$$
\begin{aligned}
& E\left(x_{j}\right) \geqslant E\left(x_{k}\right) \\
& V\left(x_{j}\right) \leqslant v\left(x_{k}\right)
\end{aligned}
$$

Na medida em que estas condições não se verifiquem simultaneamente, as alternativas sob comparação são consi 
deradas igualmente eficientes, no sentido de que não são compa ráveis entre si.

HANOCH e LEVY (1970) desenvolvem um critērio bastante similar ao que baseia a Análise EV de TOBIN, a partir da verificação do fato de que as expressões (21) e (22) são consideradas suficientes porēm não estritamente necessārias ao estabelecimento das preferências. Estes autores propõem um critério de seleção que conduz à determinação do conjunto de alternativas eficientes, considerando minimo; por força do maior poder de discriminação face às restrições menos severas.

$$
\text { Estas novas condições são conseguidas pela }
$$

substituição: em (20) do valor de L limite superior do domínio de $U(X)$, pelo mais elevado valor esperado que se apresente no conjunto de alternativas sob comparação. Sejam elas $x_{j}$ e $x_{k}$ de forma que $E\left(X_{j}\right)>E\left(X_{k}\right)$, (20) se torna

$$
2 \cdot \Delta E \cdot\left(E_{j}-\bar{E}\right)-\Delta V>0
$$

ou ainda

$$
(\Delta E)^{2}-\Delta V>0
$$

Esta situação é apontada como suficiente para o estabelecimento da preferência por uma das alternativas, sendo bem menos severa que (21) e (22), e assegurando a transitivida de da escolha. Com ela consegue-se o estabelecimento de prefe rências em situações nas quais a Anälise EV como originalmente formulada não permitia comparações. 
A distinção entre a formulação original e a pro posta de HANOCH e LEVY é que nesta ültima a preferência se estabelece ainda que a alternativa escolhida apresente variância mais elevada, contrariando frontalmente (22), bastando para is so que esta possua um valor esperado dos resultados que mais que compense seu mais elevado nivel de risco.

Algumas restrições são colocadas frente à aplicabilidade dos critérios de seleção que se fundamentam na consideração dos dois primeiros momentos das distribuições de pro babilidade associadas às diferentes ações. HADAR e RUSSEL (1969) lembram que tais modelos só se justificam quando a função utilidade do tomador de decisão é quadrática, ou os resultados seguem distribuição Normal de probabilidade, o que limita estes modelos, seja face à dificuldade na determinação da forma correta das funções utilidade; seja pela verificação de que não raro a distribuição Normal não se ajusta às situações observadas. Apontam também para o fato de que a maximização da utilidade esperada, deva envolver todos os momentos das dis tribuições e não somente média e variância.

DILLON (1971) verifica que a hipótese de função quadrática de utilidade implica na existência de uma região em seu domínio, $x>-1 /(2$ b $)$, na qual o comportamento é irracional, por apresentar utilidade marginal negativa, para os resul tados esperados. Além disto tal forma de função utilidade implica em aversão crescente ao risco, independentemente da evolução do patrimônio pessoal do indivíduo. 
TSIANG (1972) demonstra, a nível teörico, a improcedência destas limitações, e a conseqüente validade da aplicação da Análise E-V, desde que o nível de risco assumido pelo individuo seja pequeno em relação a seu patrimônio.

Cabe retomar a idéia já citada de que ainda que esteja envolvido nestes critērios o princípio da máximização da utilidade esperada, o que se consegue são conjuntos de alternativas igualmente eficientes, e não a determinação da alternativa considerada ótima, o que só seria conseguido a partir da completa especificação dos parâmetros da função utilida de do tomador de decisão.

\subsection{Dominância Estocāstica}

Aoser reconhecida a rigidez presente no processo de determinação da natureza das funções de utilidade, infor mação básica para a análise E-V, foi apresentado de forma inde pendente por QUIRK e SAPOSNIK (1962) e HADAR e RUSSEL (1969) O critērio de Dominância Estocástica, como representativo do pro cesso de decisão sob incerteza. Este critērio consta de um grupo de regras destinadas a permitir a seleção de alternativas incertas, mesmo sem conhecimento detalhado a respeito da função de utilidade do tomador de decisão, ou da efetiva forma como se distribuem os eventuais resultados das ações.

$$
\text { Em sua proposição são flagrantes as críticas à }
$$

Anālise E-V, como por exemplo, 
"... a especificação das distribuifoōes em termos de seus momentos não produzirá bons resultados, essencialmente porque informações sobre estes momentos não podem ser utilizados eficientemente na seleção de ações de resultados incertos em condições nas quais a função utilidade do individuo seja desconhecida." HADAR e RUS SEL (1969, p.25).

o critērio de seleção se baseia na comparação entre as distribuições cumulativas de probabilidade associadas às diversas alternativas, de forma que o estabelecimento das preferéncias è feito fundamentado no Axioma da Monotonicidade, de VON NEUMAN e MORGENSTERN, onde se estabelece que a decisão recai sobre a alternativa em que a probabilidade de ocorrência de resultados mais favoráveis seja a mais elevada, ou como pro posto por HADAR e RUSSEL (1969, p.26),

"a concentração de probabilidades em torno dos resultados mais elevados, distin gue as ações preferidas, daquelas consideradas inferiores.".

Uma vez que as distribuições cumulativas de prô babilidade (DCP) caracterizam a forma como se concentram as probabilidades associadas aos resultados, a comparação.. entre as distribuições associadas às ações permite o processo de seleção. A determinação das ações preferidas ou estocasticamen- 
te dominantes, exige que os valores das distribuições cumulati vas de probabilidade ligadas às dominantes não excedam seus correspondentes nas distribuições consideradas dominadas.

A comparação das distribuições caracteriza o processo de decisão do indivíduo, desde que se reconheça duas propriedades de carāter geral que devem ser apresentadas pelas funções utilidade dos individuos, independentemente da especificação de sua forma algēbrica:

a) a função utilidade esperada $E[U(X)]$ deve a presentar utilidade marginal dos resultados positiva, e

b) que estes retornos marginais sejam decrescen tes.

Tais propriedades definem os chamados primeiro e Segundo Graus de Dominância Estocāstica. Verifica-se que as características de comportamento do indivíduo são idênticas às pressupostas pela função utilidade quadrätica: ele prefere sem pre maior retorno, e é avesso ao risco, porēm, isto é feito sem que se requeira a explicitação nem das funções de utilidade, nem das formas das distribuições de probabilidade dos resultados.

Quanto às distribuições cumulativas, cabe defini-las com precisão uma vez que são conceitos utilizados a seguir. Seja $f(X)$ a função densidade de probabilidade associada à variável $X$, que pode assumir qualquer valor no intervalo contínuo ( $a, b)$, de modo que suas distribuições cumulativas sucessivas são assim definidas: 


$$
\begin{aligned}
& F_{1}(R)=a^{\int^{R}} f(x) \quad d x \\
& F_{2}(R)=a^{\int^{R}} F_{1}(x) \quad d x
\end{aligned}
$$

onde $F_{1}(R)$ e $F_{2}(R)$ são definidas para qualquer $R \varepsilon$ (a, b).

$$
\text { ANDERSON (1974), lembra que para consistência, }
$$

fica estabelecido que $F_{0}(R)=f(X)$. $F_{1}$ e $F_{2}$ podem ser referidas como distribuições cumulativas de primeiro e segundo graus da distribuição original $f(X)$, e expressas graficamente tomam a forma da Figura 7 .

o critério de seleção pelo Primeiro Grau de Dominância Estocástica (PGD) pressupõe que a função utilidade do tomador de decisão seja monotonicamente crescente caracterizan do utilidade marginal positiva para $X$, sem qualquer referencia à importância do risco na determinação das preferências.

$$
\text { Sejam } f(X) \text { e } g(X) \text { as funções densidade de }
$$
probabilidade que caracterizam duas alternativas; $f(X)$ serä preferida ou estocasticamente dominante se sua utilidade esperada, $\bar{U} f$, for mais elevada que a correspondente a $g(x), \bar{U} g$, ou seja se

$\bar{U} f-\bar{U} g={ }_{a} \int^{b} U(x) \quad f(x) \quad d x-a_{a} \int^{b} U(x) \quad g(x) \quad d x \geqslant 0$

que pode ser desenvolvida, como mostrado no Apêndice 3 , alcançando $\overline{U f}-\bar{U} g=\left[U(x) \quad\left[F_{1}(x)-G_{1}(x)\right]\right]_{a}^{b}-a_{a}^{b}\left[F_{1}(x)-G_{1}(x)\right] \quad U^{\prime}(x) \quad d x \geqslant 0$ 


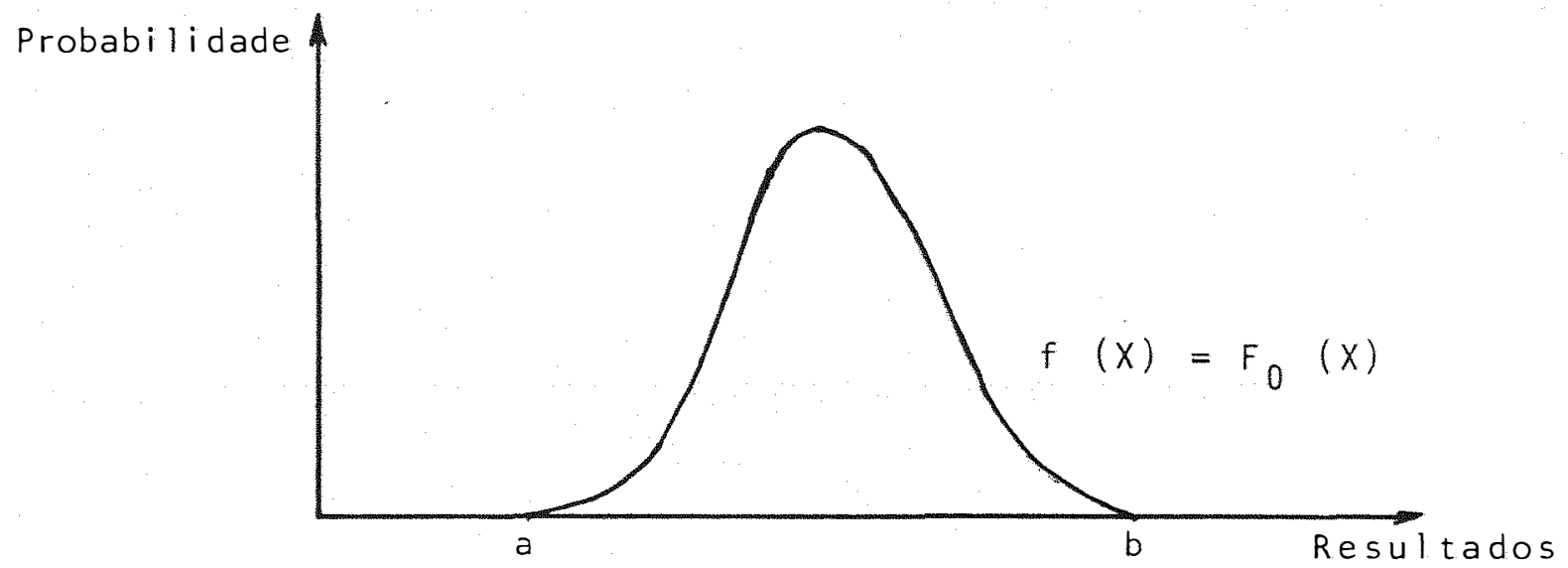

40.
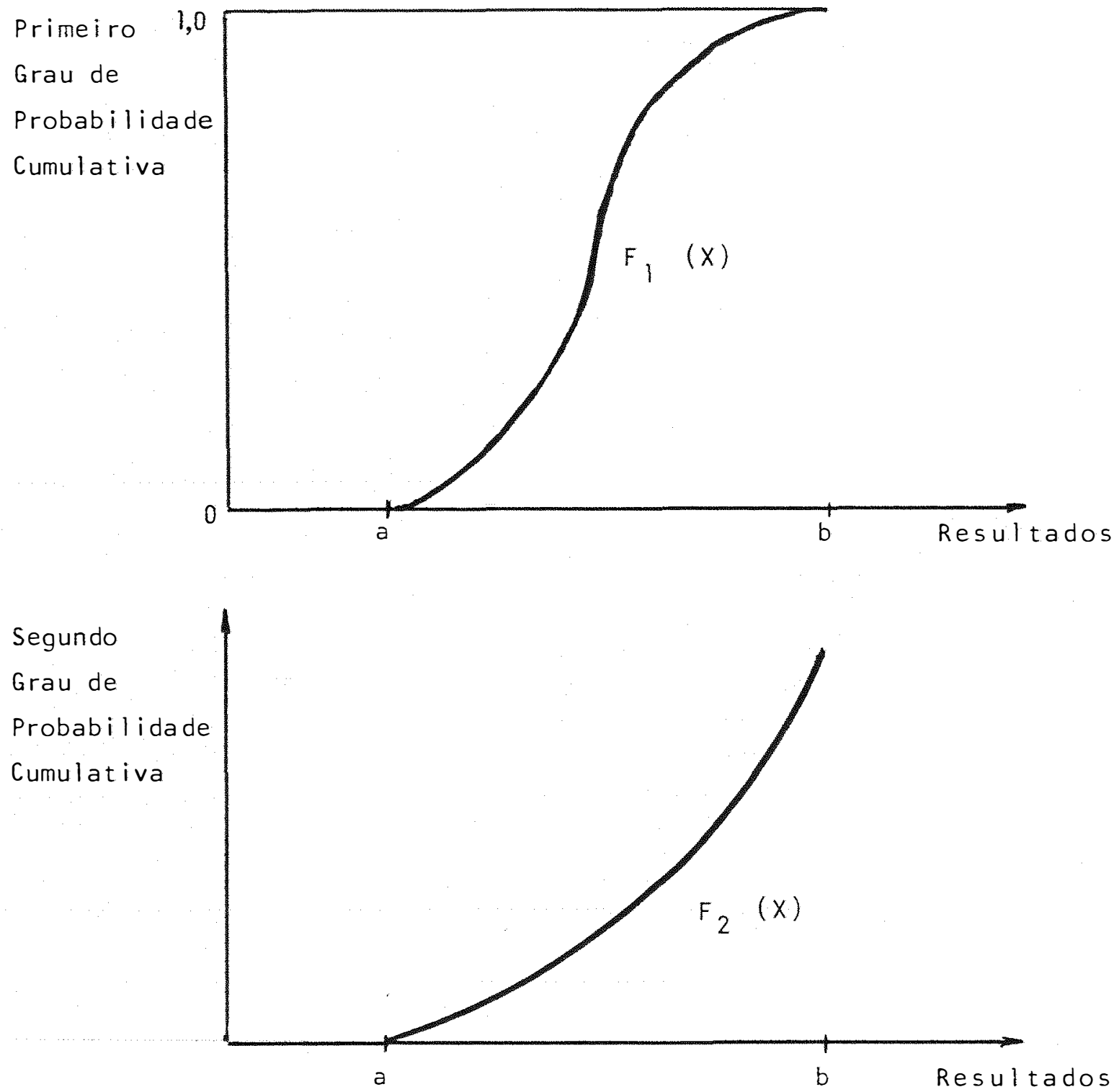

Figura 7. Distribuições Cumulativas de Probabilidade. 
Uma vez que as distribuições cumulativas têm li mites inferiores e superiores coincidentes, $F_{1}(a)=G_{1}(a)=0$ e, $F_{l}(b)=G_{1}(b)=1$, verifica-se que o primeiro termo à di reita da igualdade se anula, de modo que

$$
\bar{U} f-\bar{U} g=-\int^{b}\left[F_{1}(x)-G_{1}(x)\right] \quad U^{\prime}(x) \quad d x \geqslant 0 \text {. }
$$

A dominância de $f(X)$ ocorrerä sempre que

$$
\bar{U} f-\bar{U} g=a_{a}^{b}\left[G_{1}(x)-F_{1}(x)\right] \quad U^{\prime}(x) \quad d x \geqslant 0 .
$$

Face às pressuposições iniciais, $U^{\prime}(X)$ é positiva, de modo que (30) se verifica ou seja a distribuiçãof ( $X$ ) é preferida em relação a $g(X)$ se e somente se $F_{1}(X) \leqslant G_{1}$ (X) para todo e qualquer valor em (a, b), desde que a desigual dade se verifique para ao menos um deles.

Representando graficamente, o estabelecimento de preferência pelo PGD, exige que a curva associada à distribuição cumulativa da alternativa dominante não se situe à es querda da curva correspondente à dominada, em nenhum ponto do intervalo (a, b), como na Figura 8.

As ações selecionadas através do PGD, correspon dem àquelas que seriam preferidas por individuos maximizadores da utilidade esperada, que se caracterizam por utilidade margi 
nal da renda positiva, ou seja dão preferência a ações de maio res retornos, sem que considerem o nivel de risco envolvido.

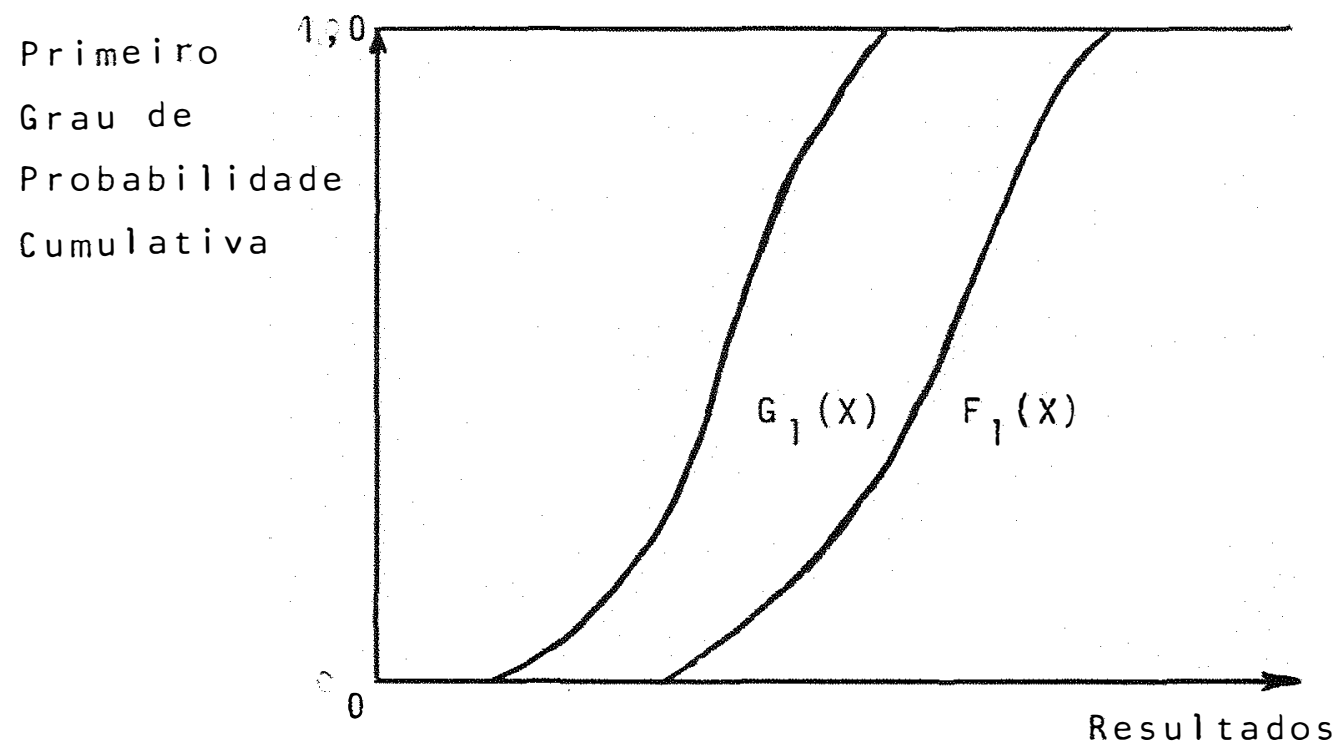

Figura 8. Dominância pelo Primeiro Grau de Dominância Estocástica.

Deste modo O PGD se relaciona ao comportamento de individuos que podem ser tanto propensos, como avessos, ou ainda indiferentes ao risco, o que faz com que o poder de discriminação de alternativas seja reduzido face à disparidade das caracteristicas dos individuos cujo comportamento pretende - se seja reproduzido. De maneira similar, ANDERSONe outros (1977). relacionam o reduzido poder de discriminação do PGD, ao fato de que DCP's de diferentes familias tendem a se interceptar ao 
menos uma vez, de forma a reduzir a freqüéncia com que se esta belece a dominância de acordo com este critério.

A seleção mais eficiente de alternativas é conseguida através de restrição adicional quando se passa a consi derar que a totalidade dos individuos considerados demonstram aversão ao risco, o que caracteriza utilidade marginal de renda positiva porém decrescente, e a concavidade da superfície de utilidade. 0 estabelecimento do Segundo Grau de Dominância Estocástica (SGD) discrimina as alternativas compativeis com tal forma de comportamento, aversão ao risco, dando origem a um conjunto de alternativas eficientes mais reduzido quando comparado àquele resultante do PGD, conseqüência direta da con sideração do risco no processo de decisão.

o critério de seleção associado ao SGD pode ser entendido tomando-se (29), que desenvolvida se torna

$$
\begin{aligned}
\bar{U} f-\bar{U} g= & -\left[U^{\prime}(x) \quad\left[F_{2}(x)-G_{2}(x)\right]\right]_{a}^{b}+ \\
& +a^{f^{b}} U^{\prime \prime}(x) \quad\left[F_{2}(x)-G_{2}(x)\right] \quad d x \geqslant 0 .
\end{aligned}
$$

Na medida em que se mantentha a pressuposição da utilidade marginal positiva e decrescente, $U^{\prime}(X)>0$ e $U^{\prime \prime}(X)<0$, e ainda que se verifique que $F_{2}(a)=G_{2}(a)=0$, tem-se que a condição (31) se estabelece, ou seja $f(X)$ è preferida em relação a $g(X)$ de acordo com o SGD desde que $F_{2}(X)$ $\leqslant G_{2}(X)$ para todo e qualquer valor em (a, b), com a desigual- 
dade se verificando para ao menos um deles.

Graficamente representado, o estabelecimento da preferência por $f(X)$ pelo $S G D$ exige que a distribuição $F_{2}(X)$ não se situe à esquerda de $G_{2}(X)$ em nenhum ponto de intervalo (a, b), como na Figura 9 .

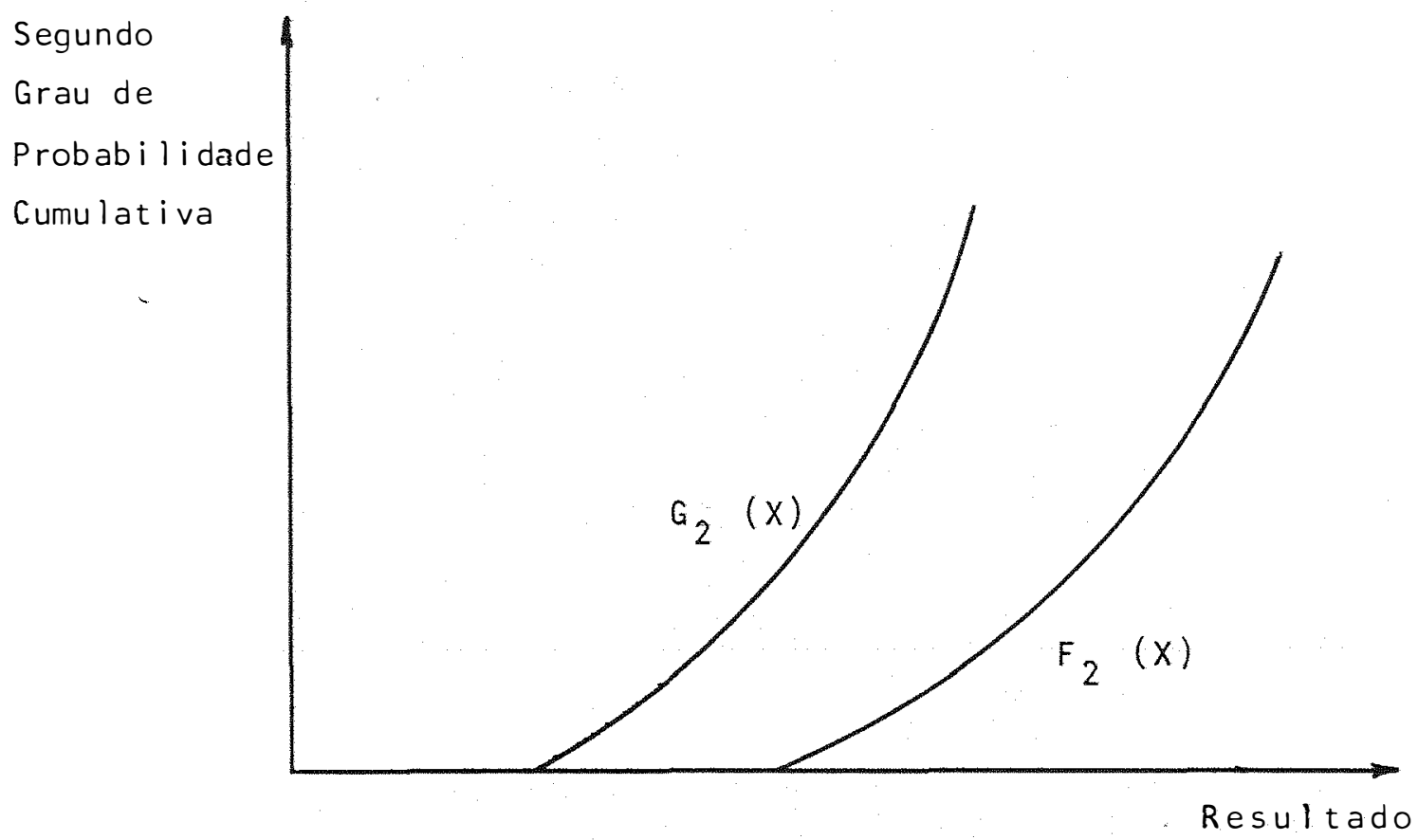

Figura 9. Dominância pelo Segundo Grau de Dominância Estocásti ca.

A consideração do comportamento frente ao risco faz com que os resultados do SGD sejam bem mais importantes que os conseguidos através do PGD quando esta caracteristica do individuo era desconsiderada. Ressalve-se que a aversão ao risco pode não corresponder à norma de comportamento invariävelmente apresentada, porém parece intuitivo que se considere tal hipótese como muito mais próxima à realidade do que a idéia 
de indiferença ao risco.

Quanto às alternativas selecionadas, ANDERSON e outros (1977) demonstram que em situações nas quais as distribuições de probabilidade são da forma Normal, o conjunto eficiente selecionado pelo SGD coincide com o resultante da Análi se EV.

São duas as condições consideradas necessärias porém não suficientes para o estabelecimento de dominância pelos dois primeiros graus: que tanto o valor esperado, como o limite inferior da distribuição dominante, sejam mais elevados que séus correspondentes na distribuição dominada, sendo esta excessiva ênfase na comparação das caudas inferiores das distribuições apontada como limitação do método, face à pequena probabilidade de ocorrência associada a tais regiões.

$$
\text { Ainda quanto as propriedades do modelo cabe, }
$$
lembrar que se de um lado as regras de dominância estocástica se desenvolvem sem que se requeira detalhamento da função utilidade do tomador de decisão, por outro lado é necessário profunda especificação das distribuições de probabilidade associą das às alternativas, e o método tem sua eficiência reduzida na medida em que as distribuições utilizadas se distanciam daquelas subjetivamente formuladas pelos individuos a que se destinam as informações. 
3.3. Dominância Estocástica com Respeito a uma Função.

Corresponde a um critërio de decisão sob incerteza proposto por MEYER (1977), e é colocado como uma alternativa aos critérios anteriores uma vez que reconhece e oferece alternativa, à limitação derivada do fato de que apenas a forma algēbrica das funções utilidade, não consegue caracterizar suficientemente o comportamento do individuo.

Colocado de outra forma, parte-se do reconhecimento de que as propriedades gerais das funções utilidade mani festadas pelos individuos não correspondem a medidas eficientes de seu comportamento, o que já era reconhecido por PRATT (1964) ao verificar que a ünica caracteristica das funções ut lidade que permanece constante qualquer que seja a transformação monotónica, linear e positiva, è a função de aversão absoluta ao risco, $r(x)$,

$$
r(x)=-u^{\prime \prime}(x) / u^{\prime}(x)
$$

que è uma medida do grau de concavidade ou convexidade local da função utilidade, estando portanto intimamente relacionada às preferências do individuo em situações de risco.

No texto original, MEYER (1977, p. 327),

"Pareceria natural descrever grupos de individuos a partir das propriedades de suas funções utilidade... porém tal crité- 
rio nã̃ se mostra conveniente fa que estas bunções nã̃ são representações ūnicas de um determinado conjunto de preferências, de forma que as restrições impostas a estas funções, são satisfeitas por qualquer transformação linear e positiva,... o que impede a definif̧ão de grupos de individuos já que isto permanece na dependência da particular representação de preferências que tenha sido adotada.".

A premissa fundamental è de que apenas a função de aversão absoluta ao risco é capaz de caracterizar o comportamento dos tomadores de decisão, fazendo com que a partir des ta medida seja possivel caracterizar grupos especificos de individuos, uma vez que restriçōes em $r(x)$ correspondem diretamente a restriçōes nas respectivas funções utilidade, o que não era satisfatoriamente conseguido fixando-se apenas algumas de suas propriedades.

Neste sentido MEYER (1977) demonstra que o primeiro e segundo graus de domináncia estocástica, correspondem a critérios de seleção coerentes com o comportamento de indiví duos cuja função de aversão ao risco se caracteriza respectiva mente por $-\infty \leqslant r(X) \leqslant+\infty$ e por $0 \leqslant r(X) \leqslant+\infty$, marcando bem a extrema diversidade de comportamentos abrigados nestes proce dimentos, o que implica no reduzido poder de discriminação dos critérios de dominância estocástica, como descritos por HADAR 
e RUSSEL (1969).

Apoiado no concei to de função de aversão absolu ta ao risco, MEYER (1977) propõe as regras de Dominância Estocástica com Respeito a uma Função, como um critério de decisão com poder de discriminação bastante superior aos associados aos critérios até então utilizados. Corresponde a um modelo em que se busca definir o conjunto de alternativas que atenda às preferências unānimes de grupos bastante específicos de individuos.

A maleabilidade conferida ao método pela introdução da função de aversão absoluta ao risco como característí ca fundamental dos tomadores de decisão, permite que se passe a considerar tambēm o comportamento daqueles indivíduos considerados propensos ao risco, que apresentam utilidade marginal da renda crescente, e que eramignorados em critérios anteriores, que consideravam a aversão ao risco como comportamento in variavelmente observado.

A definição dos grupos de individuos é feita res tringindo-se o intervalo de variação em que ocorrem os diferen tes valores da função de aversão absoluta ao risco, $r(x)$, as sociados aos elementos componentes destes grupos, ou seja se estabelecem limites superior e inferior para o grau de aversão ao risco dos individuos considerados.

Desta forma, lembrando que $r(x)$ pode se apresentar em qualquer ponto do intervalo $[-\infty,+\infty]$, os grupos são tais que 
$U\left[r_{1}(x), r_{2}(x)\right]$ é a função utilidade que caracteriza as prẹ ferências dos individuos que apresentam $r_{1}(X) \leqslant-U^{\prime \prime}(X) / U^{\prime} \leqslant$ $\leqslant r_{2}(x)$, onde $r_{1}(x)$ e $r_{2}(x)$ são respectivamente os limites inferior e superior do grau de aversão ao risco.

Em essência o método propõe, que a differença en tre as utilidades esperadas associadas a duas alternativas sob comparação, seja minimizada para todos os individuos pertencen tes ao grupo de interesse, de forma que se o resultado da mini mização for positivo existirà preferência unânime por uma delas.

Sejam $F_{f}(X)$ e $G_{1}(X)$ as distribuições cumulativas de. probabilidade associadas às ações alternativas $f(X)$ eg $(X)$, que podem apresentar resultados dentro do intervalo (a, b), sendo que

$$
\bar{U} f-\bar{U} g={ }_{a}^{f^{b}}\left[G_{1}(x)-F_{l}(x)\right] \quad U^{\prime}(x) \quad d x
$$

corresponde à diferença entre a utilidade esperada, associada a $f(X)$ e aquela associada a $g(X)$. 0 procedimento consiste em se de terminar a função utilidade $U(X)$ que minimiza a expressão (33) sujeito a

$$
r_{1}(x) \leqslant u^{\prime \prime}(x) / u^{\prime}(x) \leqslant r_{2}(x)
$$

garantindo que $U^{\prime}(a)=1$ de forma a retirar a possivel indeterminação de $(34)$.

Determinando a diferença entre as utilidades es 
peradas associadas a $f(X) \in g(X)$, paratodos os individuos cuja função utilidade satisfaça (34), e na medida em que seu menor valor seja positivo (ou nulo), a preferência (ou indiferença) por $f(X)$ em relaçãoa $g(X)$ será unânime para os individuos considera dos.

Na hipōtese de que este valor mínimo seja negativo a relação de preferência não será unânime, devendo pois ser verificada a relação simétrica, ou seja, se ocorre a prefé rência por $\ddot{g}(X)$ em relaçãoa $f(X)$, o que é conseguido tomando-se expressão anàloga a (33)

$$
\bar{U} g-\bar{U} f=a^{f^{b}}\left[F_{1}(X)-G_{1}(X)\right] \quad U^{\prime}(x) d x
$$

e minimizando-a sujeita a (34). Se este valor for positivo en tão se dará preferência unânime por $g(X)$ em relaçãoa $f(X)$. Porém quando o valor mínimo em ambas as expressões, (33) e (35) ë ne gativo, então nenhuma das duas alternativas será unanimemente preferida pelos individuos considerados, sendo pois consideradas não comparáveis.

MEYER (1977) propõe que este processo de minimi zação se faça pela teoria do controle ótimo, onde a variável de controle-U"o $(x) / U{ }_{0}(x)$ que minimiza (33) sujeito a é dada por 


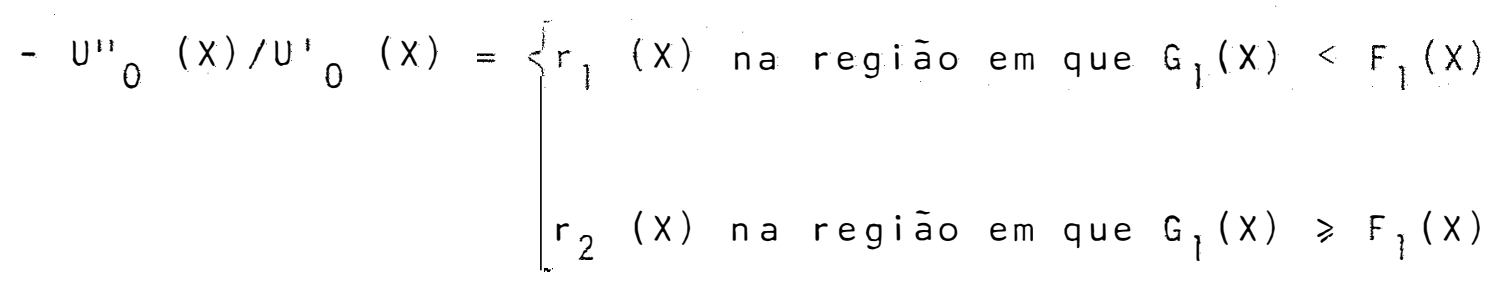

Admitindo que a função de aversão absoluta ao risco se relaciona ao património pessoal do individuo, e que este para um instante do tempo é fixo, é razoável se considerar que seu comportamento frente ao risco, dado por $r(x)$, seja constante no momento considerado. A função de utilidade da forma exponencial negativa satisfaz esta condição, ou seja a relaçào entre suas duas primeiras derivadas é constante em todo seu domínio.

Valendo-se desta função de utilidade, descrita com mais detalhe no Apêndice 4 , e do resultado do processo de minimização (36), é possível se encontrar a forma de U' ( $x$ ) que substituida em (33) permite a verificação da relação de preferência entre as alternativas sob comparação, e por conseguinte, do processo de seleção.

A Dominância Estocástica com Respeito a uma Fun ção apresenta um poder de discriminação de alternativas mais elevado que os outros critérios já que pode determinar a prefe rência, mesmo que as distribuições cumulativas de probabilidade se cruzem uma ou mais vezes. Porém fica claro que sua eficiência se mantēm dependente da qualidade das informaçōes quan to aos valores da função de aversão absoluta ao risco. 
o instrumental teörico descrito no Capitulo anterior, parece ser adequado à anàlise económica de experimentos agropecuārios, já que permite a incorporação da incerteza de resultados, caracteristica importante no processo de decisão do produtor rural, objetivo final das informações de pesquisa.

Nesta secção, procura-se de início situaros procedimentos mais comumentes usados na análise económica de experimentos. Discute-se a seguir algumas características de comportamento dos produtores rurais, de forma a sugerir a análise de risco na seleção das práticas mais adequadas. Por fim, é feita uma breve revisão dos trabalhos aplicados à avaliação de experimentos, envolvendo risco, e são propostos para comparação três diferentes modelos de decisão sob incerteza de resultados. 
4.1. Antecedentes.

4.1.1. A. Análise Tradicional

A condução de experimentos agropecuários em ins tituições de pesquisa no Brasil apresenta uma deficiência estrutural: o isolamento mantido pelo pesquisador biológico de seus pares, estatistico e economista, quando do delineamento dos ensaios. Este fato compromete, em especial, a análise eco nômica, já que são raras as oportunidades em que métodos mais precisos de avaliação podem ser aplicados, por deficièncias presentes já na implantação dos experimentos. Com isso, grande parte das avaliações económicas de resultados de pesquisa se restringe à aplicação de técnicas de orçamentaçōes parciais, simples contabilizações dos procedimentos conduzidos a campo, e välidas para um dado instante no tempo, reduzindo em muito o conteūdo informativo das experimentações realizadas.

Avaliações mais exatas exigem em geral a utilização do instrumental da análise de regressão, ajustando super ficies de resposta aos casos de um produto e um insumo, ou um produto e vários insumos. Neste caso, o que se busica è a esti mação do nível ótimo de utilização de insumos, que conduza à maximização de lucros, dadas as diferentes relações entre preço de insumos e de produtos.

Porém, este procedimento implica na. pressu posição de que ano apōs ano as condições de clima e solo, se mantenham constantes, já que as funções de produção propostas 
são em geral da forma

$$
y=f\left(x_{1}, x_{2}, \ldots, x_{n} \mid x_{n+1}, \ldots, x_{m}\right) \text {, }
$$

onde $x_{1} \ldots x_{n}$ são os insumos variāveis na condução do experimento, $e x_{n+1} \cdots x_{m}$ são os insumos considerados fixos, nos quais se incluem clima, solo, pragas e outros fatores do ambiente.

Aplicadas as noções da teoria econômica da produção se consegue a determinação da melhor alocação dos níveis dos insumos variāveis, tudo o mais constante.

Neste ponto é vālido lembrar a posição de DILLON (1975, p.5), quando relata,

"... a maioria (dos experimentos) $\vec{e}$ conduzida em base intra-anual, abstraindo-se das fontes inter-anuais de variação. ... o resultado pretendido é uma experimen tação controlada, em que todos os fatores se mantēm constantes. Em conseqüencia, as informações geradas situam-se muito aquēm das que os agricultores gostariam de possuir em função das incertezas com que se defrontam.".

Mais recentemente ao grupo dos insumos variáveis, e que portanto atuam como variāveis independentes nas funções de produção, juntou-se informações de clima e solo, co mo nos trabalhos de FONSECA (1976) e PORTO (1980).

A determinação de niveis ötimos de insumos fica 
dificultada face à alternāncia climática e de solo que ocorre ano apōs ano. De cada nível de utilização não mais deriva um só resultado físico, e sim um conjunto de possíveis resultados.

\subsection{2. o comportamento do Produtor Rural}

Se, do lado das instituições de pesquisa hà relutància em incluir as fontes de incerteza em seus procedimentos analiticos, os produtores rurais que são o destino final das informações geradas se mantēm permanentemente atentos às possíveis variações nos resultados de suas práticas. Seu comportamento é fortemente influenciado pelo fato de o cenário em que desenvolvem sua atividade, ser pródigo em incertezas.

PEARSE (1975), ao manifestar uma posição pró-bayesiana na avaliação de resultados experimentais aponta seis possiveis fontes de incerteza a atingir os produtores rurais: econômica, ambiental, da mão-de-obra, governamental, téc nica e tecnolōgica.

Sejam elas quais forem, para cada região ou pro dutor em particular, o fato é que atuam de modo a tornar incer ta a produção agropecuária. Neste momento, o comportamento de cada tomador de decisão assume caracteristicas próprias, e revela sua posição quanto à incerteza de sua atividade.

E importante destacar que a hipótese de que o agricultor age como um maximizador de lucros implica no fato de que ele se mostra indiferente ãs incertezas, se dedicando a uma atividade onde com antecipação é possivel conhecer o resul 
tado das decisões tomadas.

Fica claro o distanciamento desta hipótese daquilo que ocorre na realidade da produção rural, onde nada existe a recomendar a pressuposição de que a utilidade seja fun ção direta e exclusiva dos lucros derivados das ações.

A inconsistência entre a hipōtese de maximização de lucros e o comportamento realmente observado em produto res rurais, foi constatada empiricamente por LIN e outros $(1974)$. o princípio de maximização da utilidade esperada è considerado mais real, uma vez que é capaz de explicar os dife rentes comportamentos apresentados por individuos sujeitos às mesmas condições, e por não excluir a maximização do lucro, assumindo-a como um caso especial da utilidade esperada.

Com uma amostra de pequenos proprietärios do México, MOSCARDI e de JANVRY (1977), verificaram que o grau de aversão se constitui numa distribuição de probabilidades, claramente assimétrica, concentrada em individuos avessos ao risco. Esta caracteristica é apontada como a principal causa das substanciais diferenças entre os níveis de aplicação de fertilizantes recomendados por örgãos de extensão rural, e aqueles realmente utilizados pelos produtores.

A importância do conhecimento das diferentes for mas de comportamento é apontada por MOSCARDI e de JANVRY (1977, p.715),

"o conhecimento da atitude frente a. risco de diferentes categorias de produto- 
res torna possivel a determinação de pacotes tecnológicos e prāticas institucionais, mais adequados ao comportamento econômico destes individuos, aumentando as chances de sucesso de programas de desenvolvimento rural.".

Reconhecida a importāncia da atitude frente ao risco por parte de produtores rurais, na adoção de novas prät cas, vale lembrar que a aversão ao risco não é a forma de comportamento universalmente encontrada. DILLON e SCANDIZZO (1978) trabalhando com amostra de produtores da região Nordeste, do Brasil, determinaram que mantida a condição usual, qual seja assegurando-se a subsistência, $70 \%$ dos proprietärios se mostram avessos ao risco, enquanto que esta taxa cai para $58 \%$ quando se trata de parceiros.

Para produtores da região do Cerrado, no Brasil, CROCOMO (1979) verificou que para pequenos e médios proprietários a aversão ao risco é o comportamento predominante atingin do $90 \%$ e $68 \%$ respectivamente dos individuos, enquanto que para grandes proprietários, as proporções de avessos e propensos ao risco são bastante pröximas situando-se em torno de $40 \%$.

Claro está que as diferentes formas de comporta mento frente ao risco da produção, se relaciona com as caracte rísticas sócio-econômicas dos individuos, em geral, idade, grau de instrução, renda derivada de outras fontes, e tipo de posse da terra. Este tipo de relação está detalhado em MOSCARDI e 
de JANVRY (1977), e CROCOMO (1979).

Note-se que a maior parcela dos modelos teöricos de decisão sob incerteza, Anälise E-V e Domināncia Estocāstica por exemplo, se apoiam na premissa básica de que os produtores rurais são sempre avessos ao risco, ignorandoa clas se que se dispõe a aceitar algum risco de forma a se habilitar a melhores resultados, e cuja existência foi empiricamente constatadat.

\subsubsection{A Anälise Envolvendo Risco}

o passo inicial no sentido de incorporar as diferentes fontes de incerteza à anälise de dados experimentais, veio através da inclusão de variāveis de clima e solo às super ficies de respostas.

Assim, a produção física derivada de cada nivel aplicado de insumo è assumida como variàvel aleatöria, dada sua interação com fatores estocāsticos, caracteristicos do ambiente.

SMITH e PARKS (1967) ajustam função de produção com dados de 19 anos de ensaios relacionando a produção forrageira a niveis de nitrogènio e ao nümero de dias sem chuva no periodo de desenvolvimento da planta. Para cada nivel de fertilizante, fixando-se o preço do produto, simulou-se 100 anos hipotéticos de experimentação.

BONDAVALLI e outros (1970), em experimento de 8 
anos consecutivos, relacionam a produção de milho a niveis de nitrogènio e à precipitação em diversos períodos, e concluem que a dose econômica é fortemente influenciada pela chuva, variando em $3,6 \mathrm{~kg} / \mathrm{ha}$ para cada $\mathrm{cm}$ de chuva.

$$
\text { Para condições brasileiras, FONSECA (1976) e }
$$

PORTO (1980), estabelecem o relacionamento entre a produção de trigo e niveis de insumos e diversas variáveis de clima como precipitação, insolação e outras.

PORTO (1980), indica que o número de variāveis cli máticas usadas como regressores nãoé aleatório, e sim função do nümero de anos em que o experimento foi conduzido. Fica estabelecido que se o ensaio é conduzido no mesmo local, e coma mesma variedade por $n_{A}$ anos pode-se introduzir na função de produção um máximo de $n_{A}-1$ variáveis climáticas.

Verifica-se porém que estes trabalhos, mesmo reconhecendo a incerteza presente na produção agropecuária, nạ da acrescentam quanto às ações mais recomendadas. Fica sugeri do que de cada ação (nivel de utilização do insumo), deriva um conjunto de possiveis resultados econômicos, descritos por dis tribuições de probabilidades. Resta saber como compará-las, e informar os produtores a respeito das estratégias mais adequadas a suas condições.

Ao se procurar estabelecer a seleção entre diversas alternativas tecnológicas, avaliadas experimentalmente, é preciso que se determine algumas caracteristicas da forma de 
comportamento dos produtores, em especial sua atitude frente ao risco, uma vez que se trata da comparação de ações de resul tados imprevistos.

Neste sentido uma primeira tentativa é feita por de JANVRY (1972) na determinação das doses ótimas de nitro gênio, para milho e trigo, em condições de risco. A medida de aversão ao risco proposta é um nivel a de probabilidade, que caracteriza as chances do produtor ao menos cobrir os custos com o fertilizante usado em um ano qualquer.

o trabalho de FROHBERG e TAYLOR (1975) è bastan te semelhante. ao de JANVRY com a aversão ao risco sendo dada pelo nivel "a" de probabilidade que traduz as chances de que o retorno liquido devido ao fertilizante seja maior que zero. Pa ra cultivares de milho e diferentes relações de preços nitrogênio/milho, são determinadas as doses eficientes quanto ao risco, para os niveis de aversão ao risco de 0,95 e 0,99.

A aplicação do modelo de Dominância Estocástica para a seleção de alternativas é encontrada em ANDERSON (1974) ao comparar 36 combinações diferentes de nitrogénio e fósforo para trigo, encontrando 7 delas como as dominantes pelo Segundo Grau de Dominância Estocástica, recomendadas para produtores avessos ao risco.

0 mesmo modelo ē utilizado por GARCIA e CRUz (1979) na determinação das populações de plantas de milho e ní veis de adubação NPK mais adequados. São colocados trés possi 
veis niveis de preço do produto e para cada um são definidas as estratégias dominantes pelo 2 ? e $3:$ graus.

Nestas aplicações da Domināncia Estocástica vale dizer que a geração das distribuições de probabilidades dos resultados das ações foi feita apoiando-se na regra não paramé trica de Schlaiffer de acordo com a qual se uma amostra de $n$ observações (médias anuais das ações) é arranjada em ordem crescente, a k-ésima observação é uma razoável estimativa do $k /(n+1)$ fractil da distribuição.

Alternativamente para a geração destas distribuições pode ser usada a técnica de simulação de valores, como feito por PORTO e outros (1982) para a definição das melhores práticas culturais para o arroz irrigado. Combase na média e no desvio-padrão de preços, rendimentos e custos são geradas através de processo de Monte Carlo, as distribuições de probabi lidade das margens brutas das diversas alternativas.

o trabalho de PORTO e outros compara a eficiência na discriminação de alternativas oferecida pelos métodos Anälise E-V tradicional, e E-V de HANOCH e LEVY (1970) apontan do para o fato deste ūltimo apresentar poder de discriminação sensivelmente mais elevado.

A aplicação da Dominância Estocāstica com Respeito a uma Função, de MEYER (1977) na seleção de práticas agricolas é encontradas em CROCOMO (1979). A partir de um total de 1000 estratégias de aplicação de föforo à cultura do mi Iho na região do Cerrado, são selecionadas as alternativas e- 
ficientes, separadamente para as classes de produtores avessos, neutros e propensos ao risco. Os conjuntos de alternativas pro postos como recomendáveis para cada classe, atingia apenas $0,5 \%$ do total demonstrando o elevado poder de discriminação do método.

\subsection{Metodologia Proposta.}

\subsubsection{Material}

Os resultados experimentais que fundamentam es te trabalho, se referem a um ensaio conduzido durante 3 safras consecutivas $(1976 / 77$ a 1978/79), em área de Latossolo Roxo distrófico submetida por vários anos ao uso intensivo por agri cultura tradicional (Instituto Agronômico do Paraná, Londrina, PR.).

Por ocasião da implantação do ensaio, o solo apresentava as seguintes condiçōes:

$\begin{array}{ll}\mathrm{pH}\left(\mathrm{H}_{2} \mathrm{O}\right) & 5,3 \\ \text { Fósforo solüvel (Mehlich) } & 2,2 \mathrm{ppm} \\ \text { Matēria orgānica } & 3,30 \% \\ \text { Cátions trocāveis } & E \mathrm{mg} / 100 \mathrm{ml} \text { TFSA } \\ \mathrm{Ca} & 4,18 \\ \text { Mg } & 1,37 \\ \mathrm{~K} & 0,21 \\ \text { Al } & 0,13 \\ \text { Avaliou-se plantas de milho (Zea mays) mais es- }\end{array}$


cificamente seu híbrido duplo AG-162 de porte alto e ciclo tar dio, em blocos ao acaso, parcelas subdivididas. As parcelas corresponderam a duas densidades de semeadura $(50.000$ e 70.000 plantas/hectare) e as sub-parcelas a 6 níveis de adubação nitrogenada $(0,30,60,90,120$ e $150 \mathrm{~kg} \mathrm{~N} / \mathrm{ha})$, na forma de Sulfato de Amónio, com $1 / 3$ da dose na semeadura e os $2 / 3$ restantes em cobertura 35-45 dias após emergência.

Para todas as safras a semeadura se deu entre 20 de setembro e 10 de outubro. Vale acrescentar que apenas a primeira safra (1976/77) se caracterizou pela adequada ocorrên cia e distribuição de chuvas.

\subsubsection{Métodos}

4.2.2.1. A interpretação dos resultados experimentais

A interpretação da anālise de variància (Tabela 1) permite distinguir três efeitos importantes afetando a produção: a dose de nitrogênio, o ano considerado e a interaçãonitrogènio x ano.

o efeito ano está na verdade captando todas as variações de clima e solo ocorridas no periodo, e permite concluir que estas influenciaram significativamente a produção.

A importância de se considerar fatores de clima pode ser avaliada pela figura lo que traduz os efeitos dos diferentes niveis de nitrogènio nos três anos considerados. 
Tabela 1. Análise de Variáncia para a Cultura do Milho para as três safras consideradas.

Causas de

Vari ação
G.L.
$S \cdot Q$.
Q.M.

F

\begin{tabular}{|c|c|c|c|c|}
\hline Blocos & 2 & 3.681 .681 & 1.840 .840 & \\
\hline Densidade (D) & 1 & 224.498 & 224.498 & $2,84 \mathrm{n} . \mathrm{s}$ \\
\hline Residuo (a) & 2 & 157.852 & 78.926 & \\
\hline Nitrogènio (N) & 5 & 12.176 .817 & 2.435 .363 & $13.36 * \star$ \\
\hline$D \times N$ & 5 & 1.056 .890 & 211.378 & $1,16 \mathrm{n} . \mathrm{s}$ \\
\hline Residuo (b) & 20 & 3.645 .742 & 182.287 & \\
\hline Anos (A) & 2 & 377.577 .683 & 188.788 .842 & $1.071,70 * \star$ \\
\hline$D \times A$ & 2 & 1.280 .433 & 640.217 & $3,63 *$ \\
\hline$N \times A$ & 10 & 25.285 .481 & 2.528 .548 & $14.35 \star \star$ \\
\hline$D \times N \times A$ & 10 & 5.140 .266 & 514.027 & $2,92 \star \star$ \\
\hline Residuo (c) & 48 & 8.455 .744 & 176.161 & \\
\hline
\end{tabular}

Através da distribuição dos pontos é imediato que se verifique que o efeito da elevação da dose de nitrogénio sō è significativo na safra $76 / 77$, onde ocorreu adequada distribuição de chuvas. Este fato é confirmado pelas anälises de variância de cada ano (Tabelas 2, 3, 4) onde se verifica que apenas para a safra $76 / 77$ os efeitos das doses diferem entresi significativamente. 


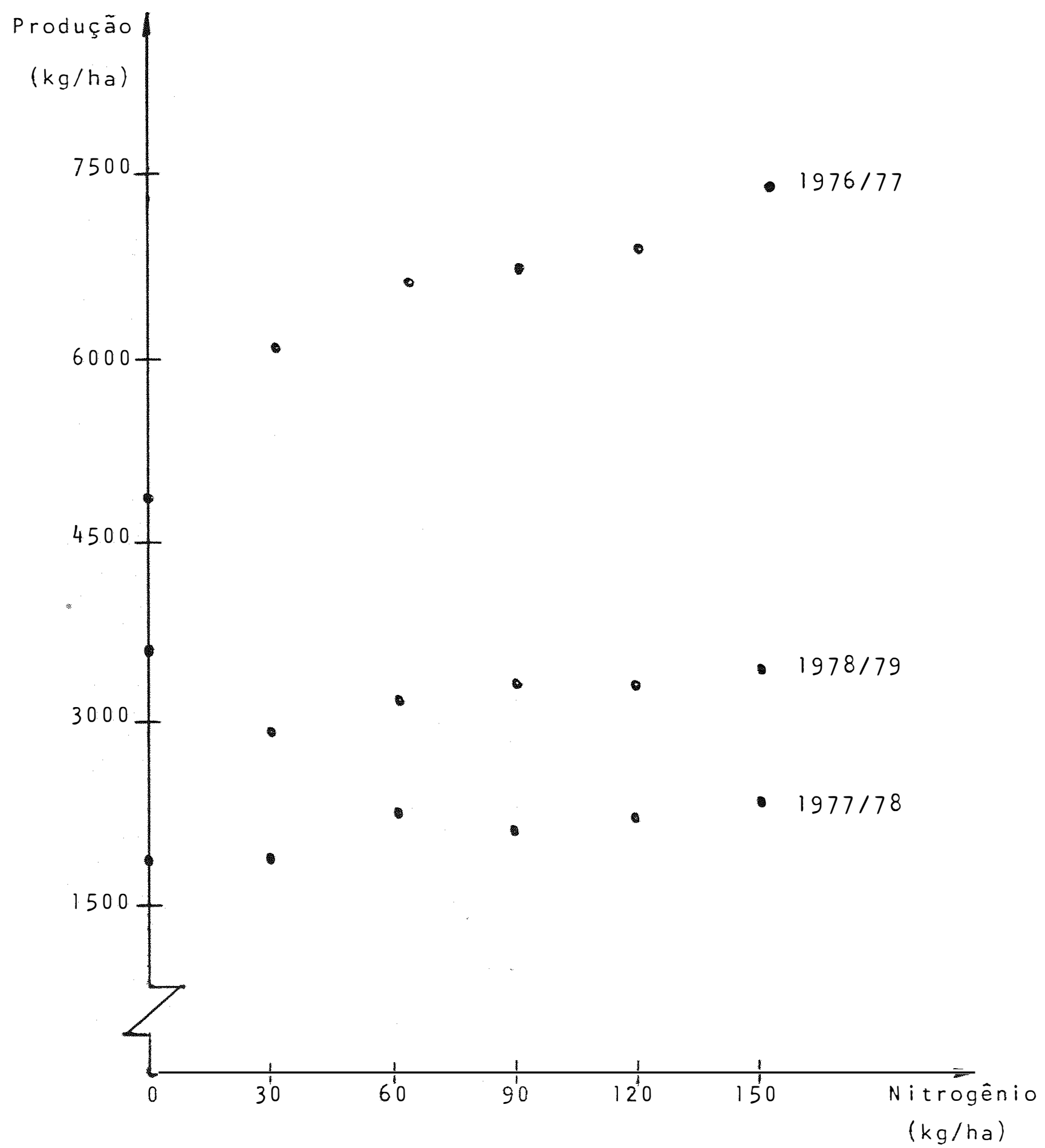

Figura 10. Resposta do Milho ao Nitrogênio. 
Tabela 2. Análise de Variância para a cultura do milho, safra $1976 / 77$

Causas de

vari ação

$G \cdot L$.

$S \cdot Q$.

Q.M.

F

\begin{tabular}{lrrrr}
\hline Blocos & 2 & 1.728 .500 & 864.250 & \\
Densidade (D) & 1 & 238.306 & 238.306 & $0,69 \mathrm{~ns}$ \\
Residuo (a) & 2 & 691.110 & 345.555 & \\
\hline Nitrogênio (N) & 5 & 36.293 .405 & 7.258 .681 & $89,03 * *$ \\
DxN & 5 & 3.274 .497 & 654.899 & $8,03 * *$ \\
Residuo (b) & 20 & 1.630 .669 & 81.533 & \\
\hline
\end{tabular}

Tabela 3. Análise de Variáncia para a cultura do milho, safra $1977 / 78$

\begin{tabular}{lcccc} 
Causas de & G.L. & S.Q. & Q.M. \\
variação & 2 & 2.813 .314 & 1.406 .656 & \\
\hline Blocos & 1 & 374.544 & 374.544 & 1,03 n.s. \\
Densidade (D) & 2 & 728.651 & 364.325 & \\
Residuo (a) & 5 & 452.986 & 90.597 & $0,64 \mathrm{n} . \mathrm{s}$. \\
\hline Nitrogênio (N) & 5 & 690.421 & 138.084 & $0,97 \mathrm{n} . \mathrm{s}$. \\
D x N & 20 & 2.837 .794 & 141.890 & \\
Residuo (b) & & & &
\end{tabular}


Tabela 4. Anälise de Variância para a cultura do milho, safra $1978 / 79$.

Causas de variação G.L. S.Q.

Q.M.

$\mathrm{F}$

\section{variação}

$+2$

Blocos

2

673.743

336.871

Densidade (D)

1

892.080

892.080

1,35 n.s.

Residuo (a)

$2 \quad 1.317 .902$

658.951

Nitrogênio (N)

5

715.906

143.181

$0,87 \mathrm{n.s}$.

$D \times N$

5

2.232 .237

446.447

2,71 n.s.

Residuo

(b)

20

4.109 .137

164.365 
Ao se tentar ajustar uma função de resposta que relacione apenas o efeito do fator variável que é o nitrogênio, com as produções alcançadas no conjunto dos três anos, o melhor resultado conseguido é,

$$
Y=3371+11,31 N-0,03 N^{2} \quad\left(R^{2}=0,026\right)
$$

4.2.2.2. A geração das distribuições de probabi lidade

Face ao caráter incerto da produção de miliho, os métodos usualmente empregados na análise econômica, por se apoiarem na hipótese de maximização de lucro parecem nãoser os mais adequados.

os instrumentos considerados apropriados dizem respeito à anălise econômica envolvendo risco, e estabelecem as alternativas adequadas, a partir da consideração de suas distribuições de probabilidade e respectivos parāmetros de for ma, como foi visto em capitulo anterior.

$$
\text { Assim sendo é importante que se consiga gerar }
$$
as distribuições de probabilidade para cada nivel de utilização de nitrogênio, de forma a permitir o estabelecimento das preferencias de acordo com os diferentes modelos de decisão.

A forma escolhida para a geração destas distri- 
buições, foi o ajustamento de uma função de produção envolvendo também parâmetros climáticos, seguida da simulação destes valores.

os parâmetros de clima escolhidos apös consulta a especialistas, correspondem à precipitação atmosfërica ( $\left.W_{1}\right)$ na ocasião do florescimento, e ao deficit hidrico $\left(W_{2}\right)$ na ocasião do enchimento dos grãos, medidos respectivamente em mm e porcentagem.

Uma série de modelos foi ajustada, e a relação que se segue foi"a que mostrou maior coerência e representatividade, ao reproduzir as produções ocorridas nos três anos em função do nível de nitrogênio e das duas variáveis climáticas:

$$
\begin{aligned}
& Y=3338+199,81 \cdot N-0,91 \cdot N^{2}-11,90 \cdot N \cdot \sqrt{W_{1}}+ \\
& (* *) \quad(* *) \quad(* *) \\
& +\begin{array}{c}
0,05 \cdot N^{2} \cdot \sqrt{W_{1}}+0,01 \cdot N^{2} \cdot W_{2}-1,58 \cdot N \cdot W_{2} \\
(* *)
\end{array}
\end{aligned}
$$

Encontrada a relação considerada como boa repre sentação da relação $Y=f\left(N, W_{1}, W_{2}\right)$, simulando valores para $W_{1}$ e $W_{2}$, mantendo fixos os niveis de $N$, consegue-se as distribuições de probabilidade buscadas.

E preciso porēm que se determine a forma como se distribuem as variáveis aleatōrias $W_{1}$ e $W_{2}$. 
A precipitação na ëpoca do florescimento $\left(W_{1}\right)$, que corresponde ao período que vai de 6 a 25 de dezembro foi contabilizada para um total de 24 anos de observação em Londri na, PR.

A disposição destes 24 pontos em papel de distribuição normal, sugere um bom alinhamento. A partir daí con siderou-se que $W_{1}$ segue distribuição normal com média de 200 $\mathrm{mm}$ e desvio padrão de $81 \mathrm{~mm}$.

Quanto ao deficit hídrico por exigir medições diārias do balanço da àgua do solo, foi calculado para os meses de janeiro e fevereiro, pelo período de 7 anos, de 1976 a 1982.

Colocando suas observações em ordem crescente, e seguindo o proposto por ANDERSON e outros (1977) para situações de dados esparsos, fez-se a proximação gräfica daquilo que seria a distribuição cumulativa de probabilidade de $W_{2}$. A seguir procurou-se a equação que melhor relacionasse os níveis de probabilidade aos valores de $W_{2}$, e a encontrada foi,

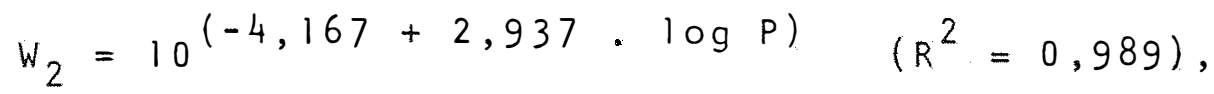

onde $w_{2}$ é o deficit hidrico medido em porcentagem, e p sua pro babilidade cumulativa tal que $0 \leqslant P \leqslant 1$.

Da expressão (39) é simples a derivação da função lucro, esta sim de relevância na tomada de decisão. Para 
tanto è preciso estabelecer o preço que estarä vigorando na época da comercialização e os custos envolvidos, de forma que

$$
\pi=P_{\text {milho }} \cdot f\left(N, W_{1}, W_{2}\right)-P_{n i t} \times N-C
$$

onde

$$
\begin{aligned}
& P_{\text {milho }}=\text { preço do milho }(C r \$ / k g) \text { na comerciali- } \\
& \text { zação } \\
& P_{\text {nit. }}=\text { preço do nitrogênio (Cr\$/kg) no plan- } \\
& \text { tio } \\
& N=\text { dose de nitrogènio (kg/ha) } \\
& C=\text { outros custos envolvidos. }
\end{aligned}
$$

Para efeito dos cálculos admite-se a hipótese de que a tomada de decisão em torno de que dose de nitrogénio aplicar se dê em agosto de 83, início da safra 83/84. Neste instante do tempo a bolsa de Chicago cotava o saco de milho de $60 \mathrm{~kg}$ para entrega em maio, em U\$8,7/Sc $60 \mathrm{~kg}$ ou C $\$ 55.609,24 /$ / Sc $60 \mathrm{~kg}$.

Admite-se que seria este o preço relevante para a decisão do produtor, faltando a inda atualizā-lo para agosto de 83 , mediante taxa de desconto de $12 \%$ a.a., o que conduz a um preço final corrigido de $\operatorname{cr} \$ 85,48 / \mathrm{kg}$ milho. No mesmo período o sulfato de amónio $(20 \% N)$ era cotado em Cr\$76.344/ /ton., ou Cr\$381,7/kg N, de acordo com IEA (1983), enquanto que os outros custos envolvidos na produção situavam-se em Cr\$219789/ha, conforme estimativa dos custos de produção apresentava no Apêndice 1 . 
Determinada assim a função lucro $(\pi)$, foi elabo rado programa de computador destinado a simular 1000 anos hipo téticos de observações, ignorando excessos climáticos de reduzida ocorrência. Utilizou-se procedimentos do pacote estatistico SAS, Statistical Analysis System, executados no computador da EMBRAPA/Sede.

Assim para cada nível de adubação $5,10,15, \ldots$ $100 \mathrm{~kg} / \mathrm{ha}$ foram gerados 1000 resultados potenciais que, adequa damente ordenados, permitiram o estabelecimento das respectivas distribuições cumulativas em intervalos de 5 em $5 \%$.

A partir dai foi possível a aplicação dos modelos de decisão sob incerteza descritos a seguir, totalmente de pendentes das distribuições de probabilidade dos resultados econômicos das alternativas.

\subsubsection{Seleção pela Anälise E-V}

Para cada alternativa foram determinados média ou valor esperado, e desvio padrão dos resultados e foram estes dois parāmetros das distribuições os utilizados para a dis criminação.

0 total de 20 alternativas $(5,10, \ldots 100 \mathrm{~kg} \mathrm{~N} /$ /ha) foi submetido a comparações duas a duas (pairwise) buscan do checar a relação proposta por HANOCH e LEVY (1970),

$$
\left[E\left(x_{j}\right)-E\left(x_{k}\right)\right]^{2}-\left[s^{2}\left(x_{j}\right)-s^{2}\left(x_{k}\right)\right]>0
$$


onde $E\left(X_{j}\right)$ e $E\left(X_{k}\right)$ correspondem aos valores esperados dos lu cros decorrentes da j-ësima e k-ësima alternativa, enquanto que $S\left(x_{j}\right)$ e $S\left(x_{k}\right)$ correspondem aos desvios-padrão.

Na medida em que (41) se verifique, a alternat va jë declarada dominante em relação à $k$, sendo a mais indica da para individuos avessos ao risco, que é o comportamento padrão assumido pela Análise E-V.

4.2.2.4. Seleção pela Domināncia Estocástica

A partir das distribuições cumulativas de probä bi lidade geradas, e que permitem a comparação pelo PGD, foram conseguidas as distribuições cumulativas de segundo grau, cuja comparação permite a seleção pelo SGD, que corresponde a individuos avessos ao risco, $0<r(x)<+\infty$.

Estas distribuições, como mostrado em Capitulo anterior, são obtidas pela acumulação das áreas abaixo das cur vas que representam as cumulativas originais. A relação que permite locar os pontos na cumulativa de segundo grau è dada em ANDERSON (1974a).

$$
S_{i, k}=S_{i, k-1}+P\left(H_{i, k}-H_{i, k-1}\right) \cdot(k-1,5)
$$

onde,

i corresponde à identificação da alternativa $(i=5,10, \ldots, 100)$

$k$ localização do ponto na DCP de $(K=1,2, \ldots, 21)$. 
P intervalo de probabilidade igual a $5 \%$ ou 0,05 $\mathrm{S}_{\mathrm{i}, \mathrm{k}}=$ valor na distribuição cumulativa de segundo grau do k-ësimo intervalo, da i-ésima alternativa

$H_{i, k}=$ valor na distribuição cumulativa do k-ésimo intervalo, da i-ésima alternativa.

E simples verificar que (42) nada mais è que um artifício para fazer uma integração aproximada das àreas abaixo das DCP's, por meio de trapézios sucessivos.

As DCP's de 2! grau são passadas então para grä ficos de forma a permitir a definição das preferências pela Do minância Estocāstica.

Considera-se que a alternativa j é preferida a $k$ desde que $S_{j}(R) \leqslant S_{k}(R)$, para todo e qualquer $R \varepsilon(a, b)$, mantida a desigualdade para ao menos um valor de R.

Caso ocorra a interseção são declaradas igualmente eficientes, uma vez que são não comparáveis.

4.2.2.5. Seleção pela Domināncia Estocāstica com Respeito a uma Função

A seleção das alternativas de acordo com este critério depende da definição dos grupos de individuos, como jà foi referido anteriormente. O paràmetro utilizado è a função de aversão absoluta ao risco, $r(x)$, uma vez que se considera, sejaela a melhor caracteristica do comportamento dos toma dores de decisão. 
Buscou-se definir o conjunto de alternativas pa ra dois tipos básicos de comportamento: aversão e propensão ao risco. Como vimos tanto a Anälise E-V como Segundo Grau de Do minância Estocástica, consideram a aversão ao risco como a úni ca forma de comportamento observada, tal que para todos os individuos $0<r(X)<+\infty$.

Ao se restringir o domínio desta função a limites mais razoáveis e empiricamente verificados, considera-se que seja possivel elevar o poder de discriminação de alternat vas jā que as condições a serem satisfeitas são menos restritivas.

A definição de valores de $r(X)$ para populações rurais não foi objetivo deste trabalho, de forma que nos apoia mos em resultados conseguidos por outros autores.

A informação básica foi a encontrada em CRÓcOMO (1979), que avaliou o comportamento de produtores rurais do mu nicipio de Unaí, considerado um dos maiores produtores de miIho do Estado de Minas Gerais.

A partir de uma amostra de 67 proprietários ficou definido por este autor que os valores de $r(X)$, nesta situação, obedeciam a uma distribuição normal com média $0,088 \times$ $\times 10^{-3}$ e desvio-padrão $0,191 \times 10^{-3}$.

Tais resultados foram extendidos à população considerada neste trabalho, de forma que definiu-se avessos ao risco como o grupo de individuos tais que $0,05 \times 10^{-3} \leqslant r(x) \leqslant$ $\leqslant 0,30 \times 10^{-3}$, e propensos ao risco como os que apresentem fun 
ção utilidade tal que $-0,30 \times 10^{-3} \leqslant r(x) \leqslant-0,05 \times 10^{-3}$.

Desta forma, passou-se a considerar tambēm a propensão ao risco, que era ignorada pelos outros critérios, e reduziu-se bastante o dominio de $r(x)$ para individuos avessos ao risco.

A implementação de metodologiá, como proposta por MEYER (1977), de forma a permitir a comparação das diferen tes alternativas, foi feita através de programa de computador que exige como entrada, os limites de $r(x)$ para os grupos de individuos considerados, e também os 21 valores correspondentes aos intervalos de $5 \%$ de probabilidade, das distribuições cumulativas de probabilidade do lucro das alternativas. 
5. RESULTADOS, DISCUSSÃO E CONCLUSÕES

\subsection{Resultados}

A simulação das 1000 observações gerou as características das distribuif̧ões de probabilidade dos lucros de cada nível de utilização de nitrogênio, empregados na implementação dos modelos de decisão. Alguma delas. como Média, Variância e Assimetria, estão relatadas no Apēndice 2 .

$$
\text { 5.1.1. Anālise E-V }
$$

A partir da média e da variância do lucro de cada alternativa, foi feita a comparação duas a duas de acordo com o critērio proposto na seç̧ão 4.2.2.3..

Observando-se tanto a Figura ll, que "è a disposição das, alternativas no conjunto de eixos cartesianos 
Média e Desvio-Padrão, como a Tabela $5^{1 /}$ que aponta o resultado das comparações, fica claro que para individuos que apresen tam função de utilidade quadrätica, e demonstrem aversão ao risco, as doses de $5,1 \mathrm{C}, 15,20,25$ e $30 \mathrm{~kg} \mathrm{~N} / \mathrm{ha}$, são as mais adequadas.

Tal pode ser entendido uma vez que para qualquer destas seis alternativas, não é possível conseguir outra de maior média, sem que necessariamente se incorra em maior ni vel de risco. Os pontos alinhados na poligonal que vai de 5 a 30 na Figura 11 correspondem à fronteira eficiente, neste ca so de natureza discreta e não contínua.

0 oposto vale para as 14 restantes, ou seja para qualquer delas se encontra pelo menos uma de maior média e menor nível de risco, sendo pois descartadas.

Resulta um poder de discriminação de $6 / 20$, ou $30 \%$

5.1.2. Dominância Estocāstica

A sobreposição dos gräficos relativos as DCP's de Segundo Grau permitiu que se estabelecesse as relações de preferência entre as 20,alternativas, como mostrado na Tabela 6 .

I/ A interpretação das Tabelas 5, 6, 7 e 8 deve ser feita da forma exemplificada a seguir: Na Tabela 5, o resultado das comparações da alterna tiva $N=60 \mathrm{~kg} / \mathrm{ha}$ com as demais é lido localizando-se 60 na colunā la Alternativa, e seguindo na horizontal tem-se que $\mathrm{N}=60 \mathrm{~kg} / \mathrm{ha}$ não ë comparävel a $N=5 \mathrm{~kg} / \mathrm{ha}$, porëm é dominada por $\mathrm{N}=10 \ldots 55 \mathrm{~kg} / \mathrm{ha}$ e do mina $\mathrm{N}=65 \ldots 100 \mathrm{~kg} / \mathrm{ha}$. 
Média

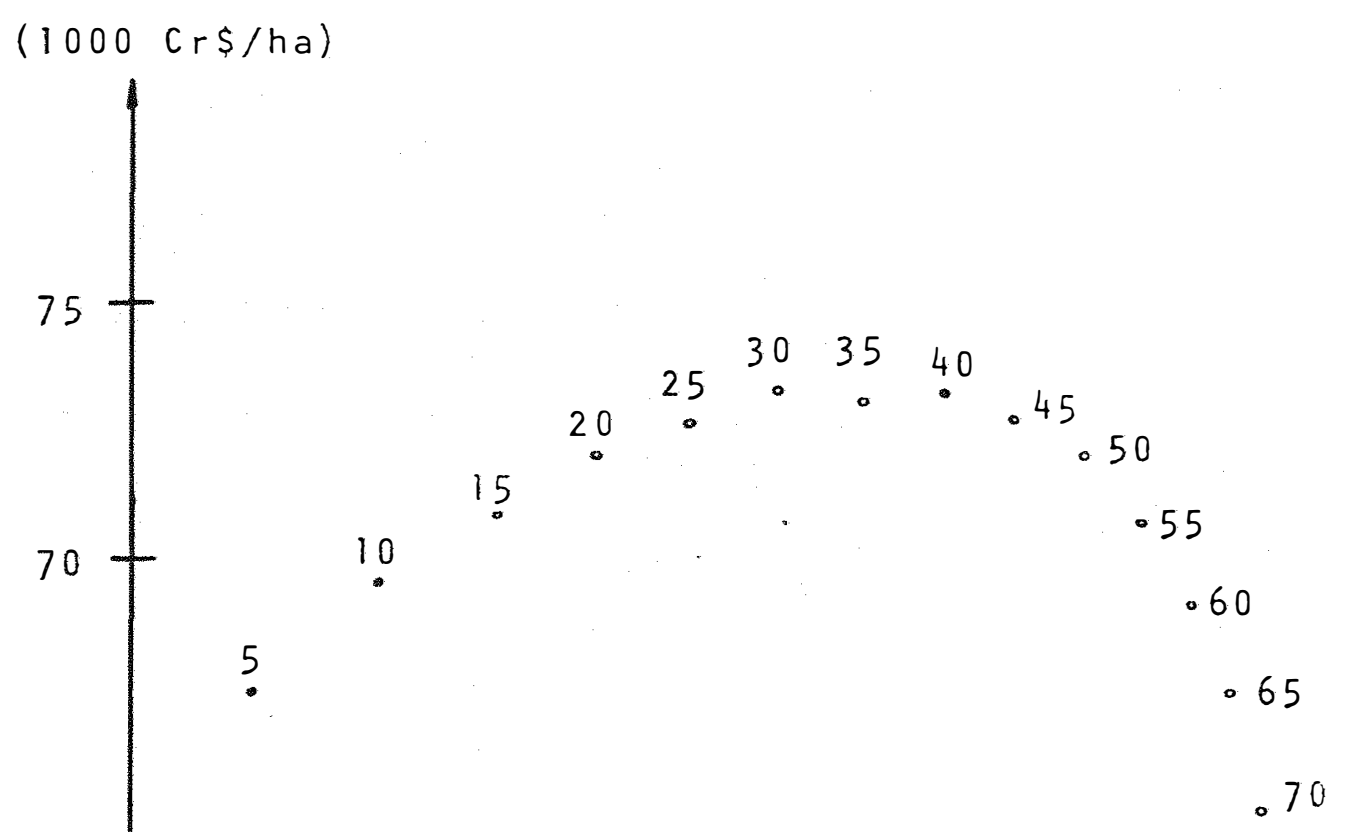

.75

- 80

.85

- 90

-95

.100

45
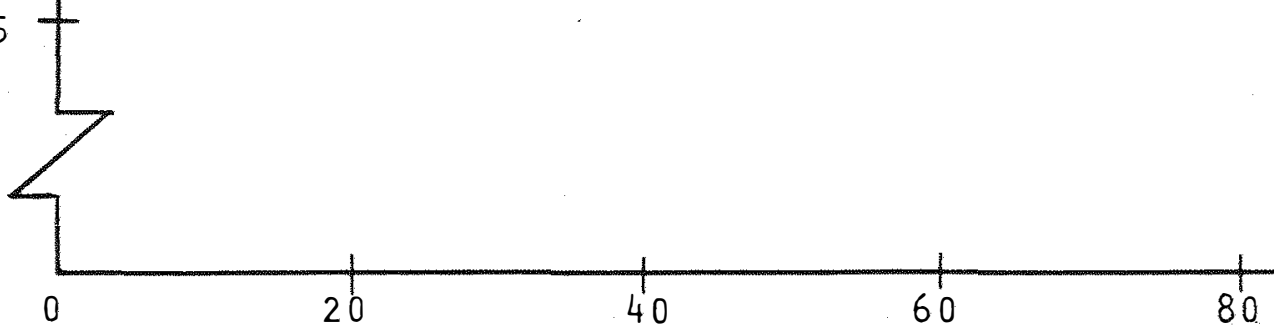

$$
\text { Padrãc }
$$

Figura 11. Relação Média x Desvio-Padrão para os diferentes $(1000 \mathrm{Cr} \$ /)$ niveis de nitrogènio (kg/ha). 


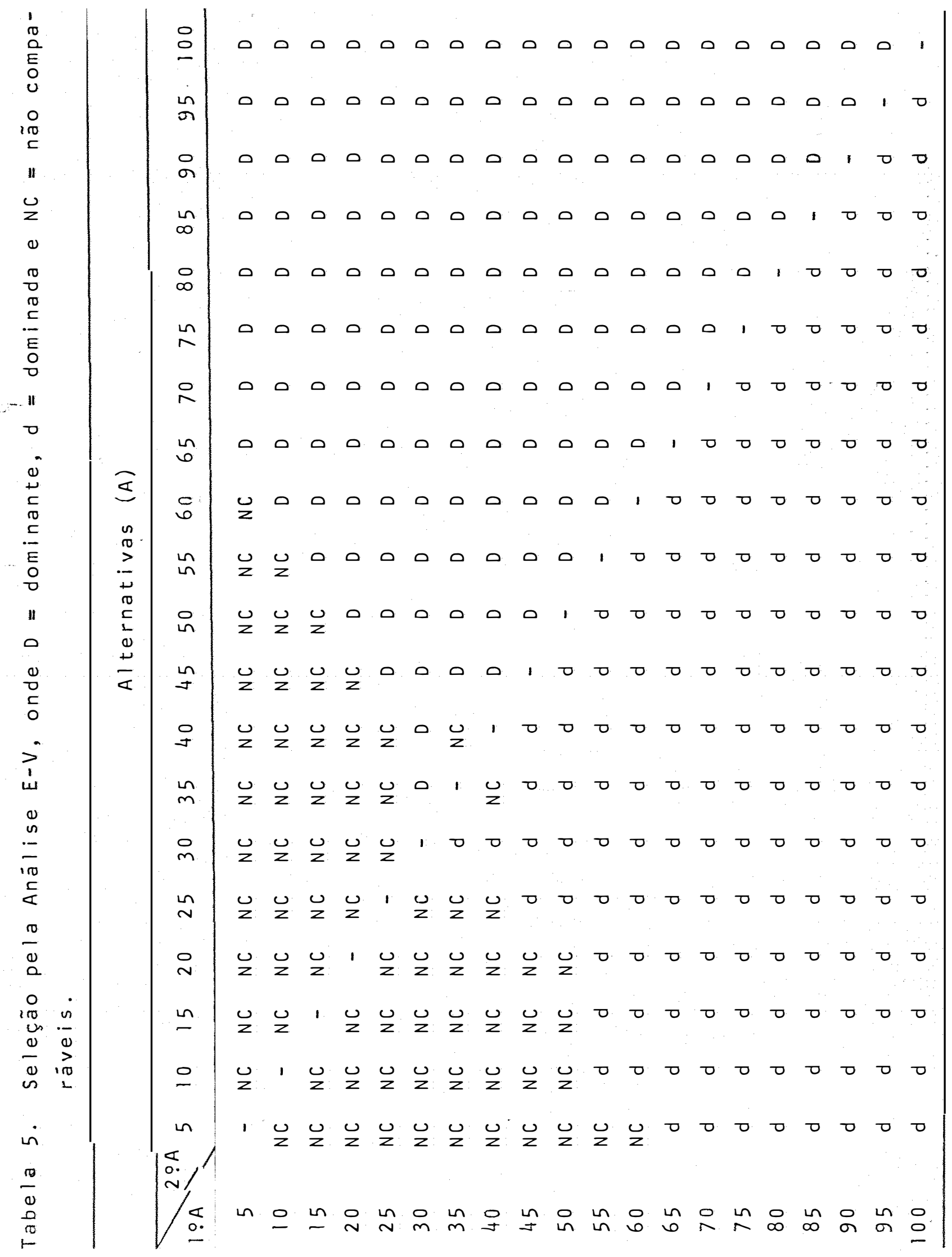




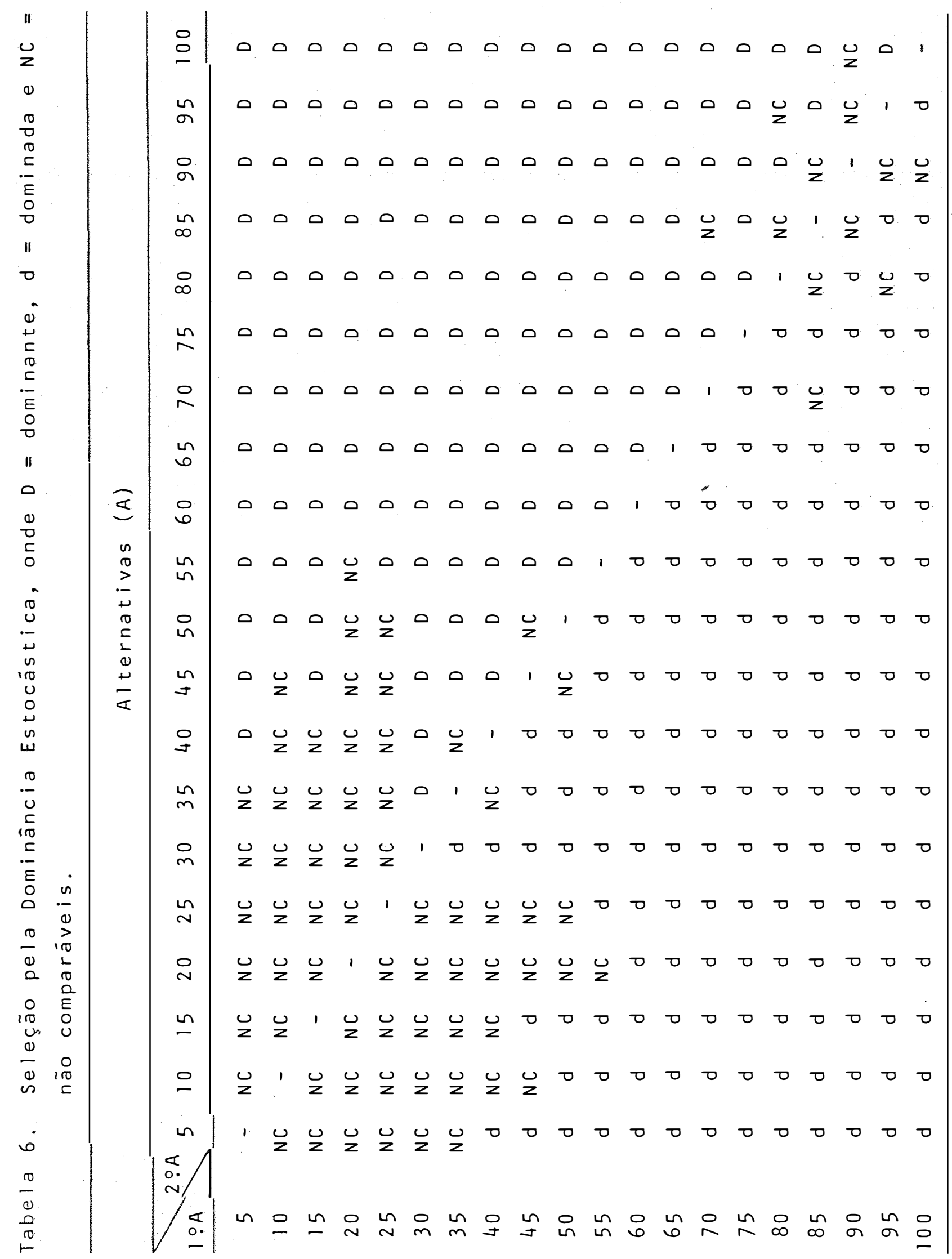


As alternativas selecionadas pelo Segundo Grau de Dominância Estocástica são as que não são dominadas por qualquer outra e como pode ser visto correspondem as doses de $5,10,15,20,25$ e $30 \mathrm{~kg} \mathrm{~N} / \mathrm{ha}$.

o método apresentou poder discriminatörio de al ternativas de $30 \%$

5.1.3. Domināncia Estocástica com Respeito a uma Função

As Tabelras 7 e 8 representam a solução proposta pelo modelo para individuos respectivamente propensos e avessos ao risco.

Para o primeirogrupo, aqueles que aceitam maior variabilidade e se habilitam a maior lucro, a dose de $80 \mathrm{~kg} \mathrm{~N} / \mathrm{ha}$ é a considerada mais adequada, enquanto que para os avessos ao risco e dose mais conservadora $5 \mathrm{~kg} \mathrm{~N} / \mathrm{ha}$ é a recomendada.

Em ambas as condiçōes - propensão e aversão ao risco - o método apresentou poder de discriminação absoluto, já que do rol de alternativas propostas apenas uma foi conside rada eficiente. 
83.

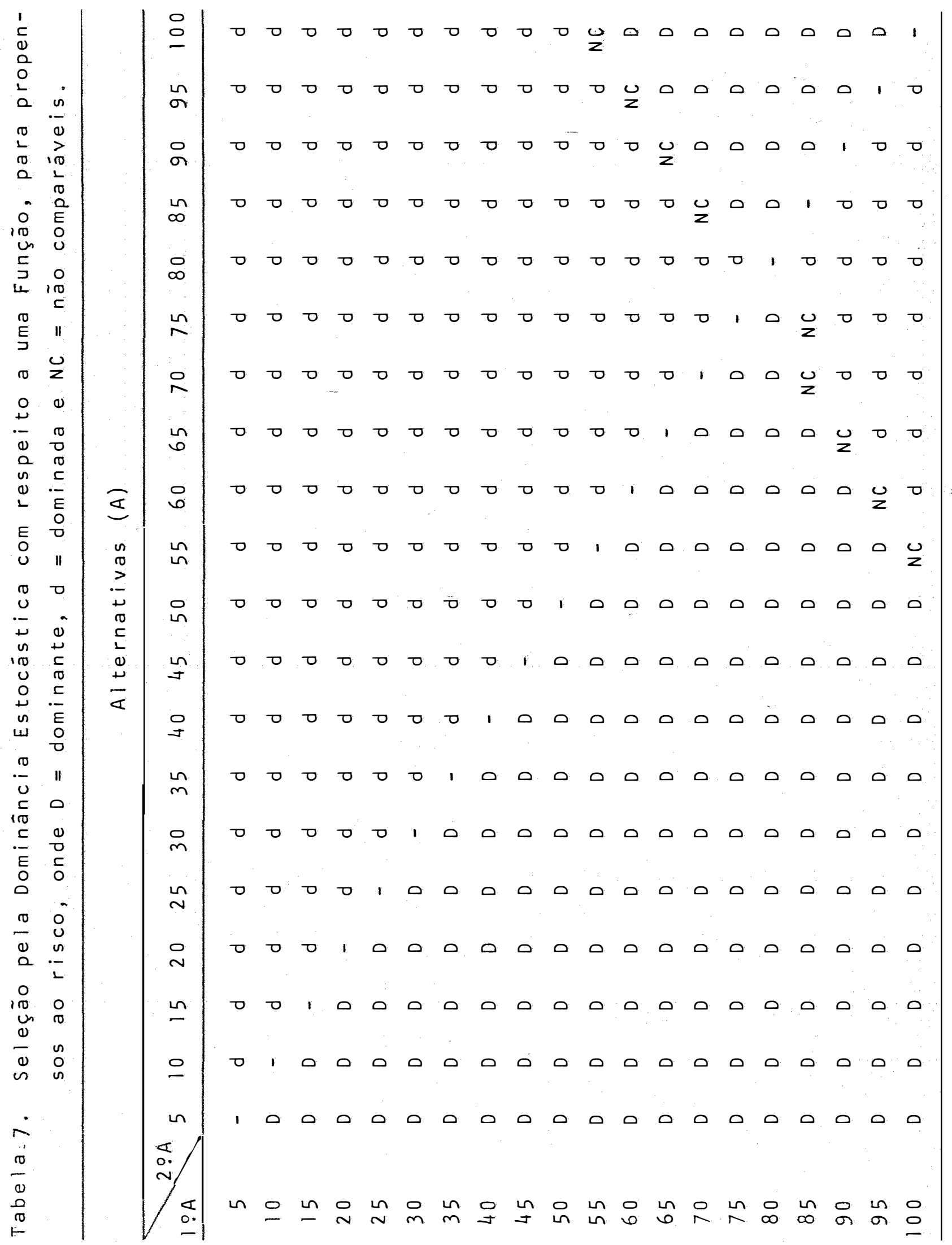




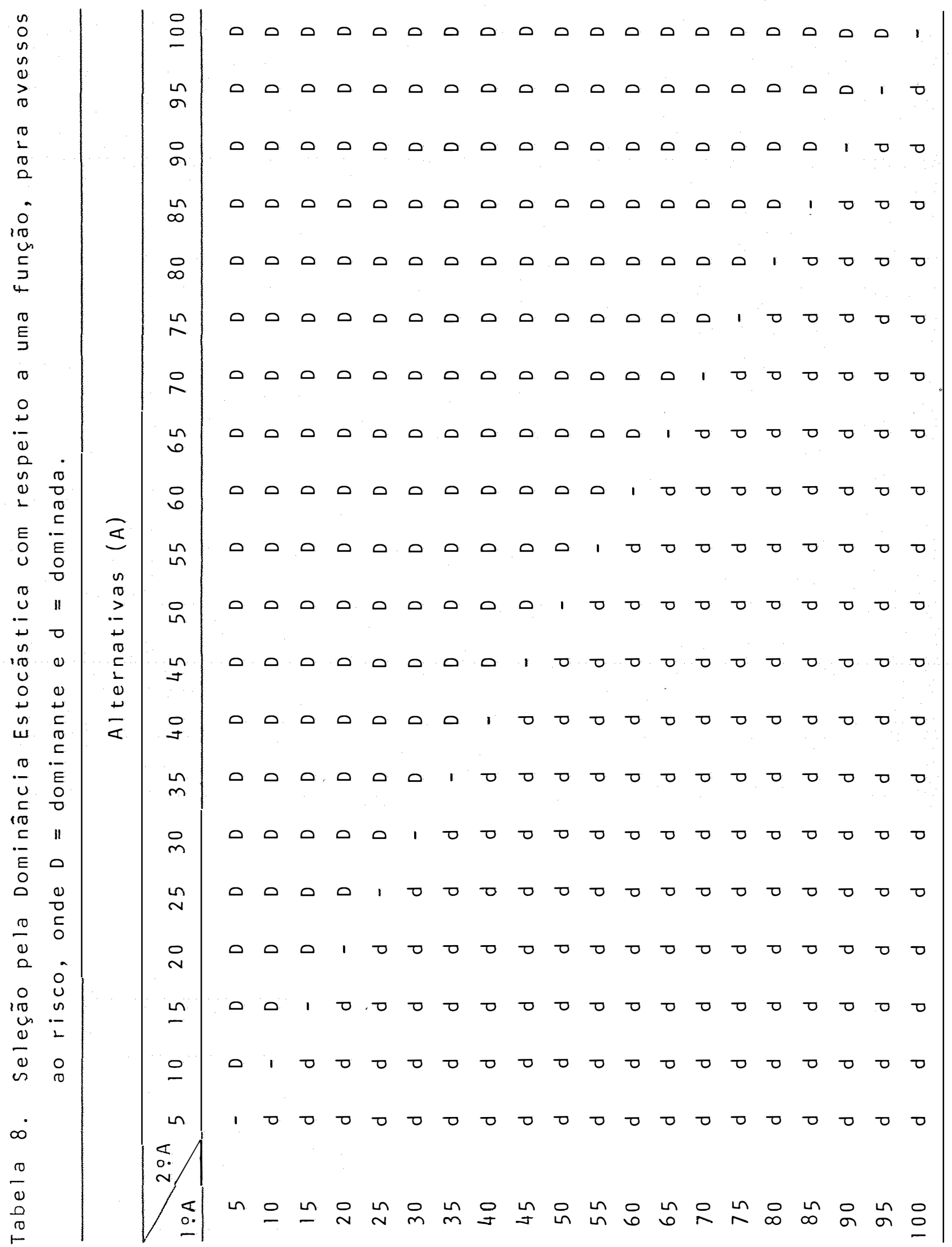




\subsection{Discussão}

A condução dos ensaios experimentais por bom pe ríodo de anos, ao permitir a avaliação da estabilidade dos resultados obtidos, potencializa a análise econômica tornando-a muito mais rica em conteúdo informativo.

No caso presente com apenas três anos de experimentação foi possivel selecionar duas variáveis de caráter a leatörio, que influenciam a produção. Fosse maior este período, a lém de se aumentar os graus de liberdade da regressão, se conseguiria maior certeza do real papel desempenhado por estas variáveis, o que é da maior importância, já que são elas que se considera as responsáveis pela incerteza da produção.

A técnica empregada na simulação dos resultados

foi bastante simples, fundamentada na geração de números randô micos, o que a torna factível em microcomputadores disponiveis nas mais diversas unidades de pesquisa. São très as questões que devem ser levantadas no que toca ao procedimen to utilizado.

Em primeiro lugar as variáveis de clima selecio nadas, precipitação e deficit hidrico foram consideradas absolutamente independentes entre si, face à impossibilidade, em razão dos poucos anos de observação, de se definir o nível de correlação existente. Sem dūvida é um ponto a ser sanado em futuros trabalhos.

Não foi considerada na simulação a participação 
do resíduo da regressão de distribuição normal com média zero e desvio padrão de $735 \mathrm{~kg}$, uma vez que afetaria de forma idêntica as distribuições de probabilidade de todas as alternativas, sendo portanto inócua a sua inclusão.

Talvez a mais crucial das questões se atenha ao fato de que apenas o risco climático tenha sido considerado, colocando-se de lado a incerteza de preço, dada pelo mercado. A justificativa é de que se pressupõe que mesmo consciente des te fato, o produtor, no momento da tomada de decisão, formula sua expectativa do preço que irā vigorar no período de comercialização, baseado em experiências passadas. Não há nada porēm que impeça a utilização de um modelo de expectativas de preço no procedimento ora em questão.

As distribuições de probabilidades resultantes foram todas assimétricas à direita, ou seja apresentaram maior concentração de resultados com valores acima da média (moda e mediana maiores que a média). Deste modo fica prejudicada a hipōtese de distribuições normais, já que estas pressupõem coe ficiente de assimetria nulo, como também todos os momentos impares em relação à origem.

Muito provavelmente se aproximariam da Normal caso o número de variáveis aleatórias fosse maior, uma vez que quando um grande número de variáveis aleatörias independentes atua sobre um determinado fenômeno, seu resultado tem distribuição próxima à Normal.

A anālise das distribuições revela a relação di 
reta entre o nível de utilização do insumo e o nível de risco, dado pelo desvio padrão dos resultados. A razão para tal fato prende-se a pouca ou nenhuma resposta ao nitrogênio em anos desfavoráveis, quando então resultados extremos são alcançados.

As comparações das distribuições pelos critērios de decisão só se mostraram de difícil execução na Dominân cia Estocástica, onde por não se contar cóm rotina de computador, valeu-se da sobreposição de gráficos. Esta tarefa repeti da por 190 vezes, número correspondente às comparações, se revela pouco eficiente, acentuando a possibilidade de equívocos.

Tomando os resultados da anālise E-V obtidos da forma proposta por HANOCH e LEVY, observa-se que em nada diferem dos que seriam obtidos da análise E-V tradicional. A proposição de HANOCH e LEVY se destina a estabelecer a préferencia entre as alternativas presentes na fronteira eficiente, exigindo para isso que

$$
\left[E\left(x_{j}\right)-E\left(x_{k}\right)\right]^{2} \geqslant s^{2}\left(x_{j}\right)-s^{2}\left(x_{k}\right) .
$$

ocorre porém que nas alternativas comparadas, o aumento no risco era sempre muito mais que proporcional que o aumento no retorno esperado, jamais permitindo que esta condição fosse satisfeita, tornando identicas as fronteiras eficien tes.

o conjunto de alternativas selecionadas pela A- 
nälise E-V, corresponde ao composto por ações de baixo nível de risco, não discriminando do modo algum entre estas. Sem dü vida há neste processo um flagrante contra-senso uma vez que coloca na fronteira eficiente, como igualmente adequadas a individuos avessos ao risco alternativas como por exemplo $N=25$ e $N=30$, quando se verifica que a passagem de uma para outra implica num aumento de risco da ordem de 16\%, "compensada" por uma elevação no retorno esperado de apenas $1 \%$.

Fica claro que o modelo E-V admite como avessos ao risco individuos dos mais dispares graus de aversão, conduzindo a indeterminações como a apontada acima. E preciso que sejam mais fortes as pressuposições a respeito da função de utilidade do individuos, sob pena de o método conduzir sempre a resultados de pouca importância.

Vale lembrar que a aparente não normalidade das distribuições atinge frontalmente a Análise E-V, jà que a significância dos coeficientes de assimetria faz com que não possam ser descritas apenas pela média e desvio-padrão. Em sua defesa está presente o argumento de que ao se tratar de distri buições subjetivamente formulađas, não se pode esperar que o individuo se extenda para além destes dois primeiros momentos, ignorando os mais elevados, inclusive assimetria.

A seleção de acordo com a Dominância Estocástica, apesar de seu excessivo rigor na comparação de cada porção das distribuições cumulativas, e da dificuldade de execução, conduziu a um conjunto de alternativas eficientes, idéntico ao 
resultante da Anälise E-V. Este fato só é esperado quando as alternativas comparadas seguem distribuição Normal, quando então duas distribuições só não se interseccionam se e somente se, a de maior média apresentar também menor desvio-padrão, coincidindo com o critério E-V.

Com base nos resultados obtidos pode-se então sugerir que a Anälise E-V deva ser recomendada em relação à Do minância Estocástica, na medida em que conduz a idênticos resultados porēm de execução muito mais simples.

Outra questão a se considerar é que nas compara ções pela Dominância Estocástica muitas vezes só não foi possí vel estabelecer a preferência em razão de pequenas regiões de tangência entre as curvas, ou de intersecção nas caudas inferiores. E esse excessivo rigor que parece reduzir a eficiência do método, contribuindo para um conjunto de alternativas e ficientes muito heterogêneo, e por conseqüência pouco informativo.

As alternativas selecionadas por estes dois cri térios atendem a individuos avessos ao risco, e uma vez verifí cado que o nivel de risco sempre se elevou com a maior utiliza ção do insumo, foram selecionadas aquelas de reduzida utilização do insumo, ou seja as de pouco risco para o capital inves tido.

Resultados mais conclusivos só foram conseguidos quando se avançou nas pressuposições em torno da função de 
utilidade, estabelecendo-se grupos de individuos de acordo com valores de sua função de aversão ao risco.

A Dominância Estocástica com Respeito a uma Fun ção estabeleceu uma só alternativa para cada um dos grupos de individuos - avessos e propensos ao risco. Com isso atendeu- se também a uma parcela ignorada pelos modelos anteriores, pa ra os quais uma dose elevada do insumo - $80 \mathrm{~kg} / \mathrm{ha}$ - è a adequa da.

ocorre que neste método são contabilizadas todas as intersecções entre as curvas, de forma a discriminar en tre alternativas consideradas não comparāveis pela Dominância Estocāstica.

Pode-se argumentar contra a especificação tanto da função exponencial de utilidade, como dos coeficientes de aversão ao risco utilizados. Estes porēm correspondem ao preço a ser pago pela obtenção de resultados mais objetivos, e pä ra grupos de tomadores de decisão próximos ao realmente encontrados.

A função de utilidade exponencial atende à pres suposição de que a predisposição ao risco é função de caracte risticas do individuo, fixas num intervalo de tempo, o que faz com que seu comportamento seja constante no periodo considerado.

As medidas de comportamento usadas, obtidas por outro autor, foram escolhidas pela confiabilidade em sua deter 
minação e por se aplicar a região de produtores de milho, como neste trabalho.

A incorporação destas medidas atende a dois objetivos importantes: o aumento no poder de discriminação de alternativas e o reconhecimento de que outras formas de compor tamento que não a aversão ao risco são também encontradas.

Os resultados da aplicação dos modelos de risco devem estar mais prōximos do tipo de informação demandada pelo produtor, já que são os que maximizam a utilidade esperada e não apenas o lucro. Surgem duas questões,

E possível que as funções de utilidade sejam multidimensionais, hipōtese não considerada neste trabalho. Nes te caso os resultados obtidos não seriam os mais adequados, já que o comportamento presumido na sua obtenção foi distinto, porém ainda assim constituiriam uma evolução quando comparados aos conseguidos apoiando-se na maximização de lucros.

De outro lado, è preciso que se atente para que as distribuições com que se trabalha são objetivas uma vez que obtidas de dados de observação. Assim sendo podem diferir bas tante daquelas subjetivamente formuladas pelos tomadores de de cisão, que resultam de suas expectativas em torno de novas téc nicas.

De qualquer modo, dos modelos de decisão empregados, apoiados na idéia de maximização da utilidade esperada, derivam informações que se supõe facilitem o processo de ado- 
ção e ou mudança de prāticas, jā que atendem a características do comportamento do individuo pouco lembradas nas avaliações usuais.

Fica a sugestão para que em futuros trabalhos se incorpore o risco de preços, e também a possível correlação entre as variáveis de clima, quando da geração de distribuições de probabilidade.

E tambēm preciso que se busque novas estimativas da função de aversão ao risco, uma vez que a qualidade do modelo de Dominância Estocàstica com Respeito a uma Função està na direta dependência destes parâmetros.

\subsection{Conclusões}

A geração de distribuições de probabilidade para os resultados da adubação nitrogenada em milho, conseguida atravēs da simulação de variāveis de clima, aplicados à função de produção, produziu resultados bastante satisfatōrios e foi de implementação bastante simples, permitindo a avaliação do desempenho de modelos de decisão sob risco.

A aplicação destes modelos indicou que para agricultores avessos ao risco apenas doses bastante baixas são adequadas. Modelos que pressupõem exclusivamente esta forma de comportamento, Anālise E-V e Dominância Estocástica, conduzem a idénticos resultados e apresentam reduzido poder de discriminação selecionando como igualmente eficientes 6 das 20 a 
ternativas sob comparação. De acordo com os resultados obtidos a Anälise E-V deve ser preferida pela maior facilidade de execução.

Porēm, as informações derivadas destes modelos são pouco consistentes por considerarem como igualmente eficientes alternativas bastante distintas entre si,são incoerentes se propostas a um grupo homogèneo de agricultores avessos ao risco.

Informações mais objetivas são conseguidas pela aplicação da Dominância Estocāstica com Respeito a uma Função, que apresentou uma só alternativa considerada eficiente tanto para individuos avessos como para propensos ao risco. Para es tes a dose recomendada foi bastante elevada alcançando $80 \mathrm{~kg}$ $\mathrm{N} / \mathrm{ha}$, enquanto que para os avessos foi de $5 \mathrm{~kg} \mathrm{~N} / \mathrm{ha}$.

Evidentemente este maior poder de seleção só è conseguido às custas de maior rigor nas pressuposições em torno da função utilidade do indivíduo, consideradas porém bastan te razoáveis e intuitivas.

Considera-se que a Dominância Estocástica com Respeito a uma Função deva ser o modelo recomendado neste tipo de anālise, uma vez que conta comrotina de computador disponível e conduz a resultados mais objetivos.

A anālise económica de experimentos, envolvendo risco deve ser incorporada aos procedimentos rotineiros de avaliação de resultados experimentais em unidades de pesquisa 
agropecuária, surgindo como uma alternativa ao instrumental ba seado apenas na hipótese de exclusiva maximização de lucros, que se mostra inconsistente com o cenārio em que o produtor ru ral desenvolve sua atividade. Com certeza as informações então geradas estarão mais pröximas às realmente buscadas, tornando mais fácil e rápido o processo de adoção de novas práticas. 
6. LITERATURA CITADA

ALCHIAN, A.A., 1953. The Meaning of Utility Measurement. The American Economic Review. $43(1): 26-50$.

ANDERSON, J.R., 1974a. Risk Efficiency in the Interpretation of Agricultural Production Research. Review of Marketing and Agricultural Economics. $42(3): 131-184$.

ANDERSON, J.R., 1974b. Sparse Data, Estimation Realiability and Risk - Efficient Decisions. The American Journal of Agricul tural Economics. $56(3): 564-572$.

ANDERSON, J.R., J.DILLON e B.HARDAKER, 1977. Agricultural Deci. sion Analysis. Lowa St.Univ.Press.

BAUMOL, W.J., 1958. The Cardinal Utility wich is Ordinal. The Economic Journal. $\quad$ 48.(272):665-672.

BONDAVALLI, B., D.COLYER e E.M.KROTH, 1970. Effects of Wheather, Nitrogen and Population on Corn Yeld Response. Agronomy Journal. $62(5): 669-672$.

CROCONO, C.R., 1979. Risk Efficient Fertilizer Rates: an Appli 
cation to Corn Production in the Cerrado Region of Brazil.

Tese PhD Michigan State University.

de JANVRY, A., 1972. Optimal Levels of Fertilization Under

Risk: The Potencial for Corn and Wheat Fertilization Under Alternative Price Policies in Argentina. The American Journal of Agricultural Economics. $54(1): 1-10$.

DILLON, J.L., 1971. An Expository Review of Bernoullian Decision Theory - Review of Mktg. and Agricultural Economics. $39(1): 1-79$.

DILLON, J.L., 1976. Agricultura, Pesquisa e Probabilidade. Sé rie Pesquisa n: 13. Universidade Federal do Ceará. 25 p.

DILLON, J.L. e P.L.SCANDIZZO, 1976. Atitudes dos Agricultores Nordestinos de Subsistência em Relação ao Risco. Abordagem Amostral. Dep.Ec.Agr., Centro de Ciências Agrärias, UFCe, For taleza. Série Pesquisa $17,26 \mathrm{p}$.

ELLSBERG, D., 1954. Classic and Current Notions of Measurable Utility. The Economic Journal. 54(255):528-556.

FONSECA, V.0., 1976. Anālise Económica da Aplicação de Doses e Fontes de Nitrogênio na Cultura do Trigo, sob Condições de Risco, em Pelotas R.S. Tese de Mestrado IEPE/UFRS. 88 P.

FRIEDMAN, M. e J.SAVAGE, 1948. The Utility Analysis of Choices Involving Risk. Journal of Political Economy. 56(4)279-304. FROHEERG, K. e C.R. TAYLOR, 1975. The Influence of Risk Arising from Weather Variability on the Optimal Nitrogen Fertiliza- 
tion Level of Corn. Illinois Agricultural Economics. 15(2): $: 23-26$.

GARCIA, J.C. e J.C.CRUZ, 1979. Seleção, pela Dominância Estocástica, de Práticas Agricolas Eficientes com Respeito ao Risco - Uma Aplicação para a Cultura do Milho. Revista de Economia Rural. 17(2):131-142.

HADLEY, G., 1967. Introduction to Probability and Statistical Decision Theory. San Francisco, Holden-Day.

HADAR, J. e W.R.RUSSEL, 1969. Rules for Ordering Uncertain Pros pects. American Economic Review. 59:25-34.

HANOCH, G. e H.LEVY, 1970. Efficient Portfolio Selection with Quadratic and Cubic Utility. Rev. of Ec.Studies 43(2):181-9. HENDERSON, J.M. e R.E.QUANDT, 1958. Microeconomic Theory - a Mathematical Approach. Mc.Graw-Hill Book Co. Inc., 291 p. HICKS, J., 1968. Value and Capital. Claredon Press, 0xford. $340 \mathrm{p}$.

IEA, 1983. Informações Econômicas. 13(7). São Paulo.

LIN, W.W. e H.S.CHANG, 1978. Specification of Bernoullian Utility Function in Decision Analysis. Agricultural Economics Research. $\quad 30(1): 30-36$.

LIN, W.; G.W.DEAN e C.V.MOORE, 1974. An Empirical Test of Utility vs. Profit Maximization in Agricultural Production. Ame rican Journal of Agricultural Economics. 56(3):497-508. 
MEYER, J., 1977. Choice Among Distributions. Journal of Economic Theory. 14:326-36.

MOSCARDI, E. e A.de JANVRY, 1977. Attitudes Toward Risk Among

Peasants: An Econometric Approach. The American Journal of Agricultural Economics. $59(4): 710-716$.

OFFICER, R.R. e A.N.HALTER, 1968. Utility Analysis in a Pract

cal Setting. The American Journal of Agricultural Economics. $\underline{50}(2): 257-277$.

OZGA, S.A., 1956. Measurable Utility and Probability: A Simplified Rendering. The Economic Journal. 56(263):419-430.

PEARSE, R.A., 1975. Requirements for Economic Analysis. In: BOFINGER, V.J. e J.L.WHEELER, eds. Deyelopment in Field Design and Analysis. Farnhan Royal, Comme n wealth Agricultural Bureaux, Bulletin 50, p. 169-189.

PORTO, V.H.F., 1980. Anälise Economētrica de Dados Experimentais sobre um Sistema de Produção Trigo - Soja, para a cultu ra do Trigo. Tese de Mestrado ESALQ/USP. 109 p.

PORTO, V.H.F.; E.R.CRUZ e J.A. INFELD, 1982. Metodologia para Incorporação de Risco em Modelos de Decisão Usados na Anälise Comparativa entre Alternativas: 0 Caso da Cultura do Arroz Irrigado. Revista de Economia Rural. 20(2):193-211.

PRATT, J.W., 1964. Risk Aversion in the Small and in the Large. Econometrica. $\quad 32(1-2): 122-136$, January/April.

QUIRK, J.P. e R.SAPOSNIK, 1962. Admissibility and Measurable 
Utility Functions. Rev.of. Ec.Studies. 29(1):140-146.

ROBINSON, L.J. e R:P. KING,1981. An Interval Approach to Measu ring Decision Maker Preferences. American Journal of Agricultural Economics. (71):510-520.

SIMONSEN, M.H., 1966. Anälise Econômica e Escolha Envolvendo Risco. Revista Brasileira de Economia. $20(2-3): 135-168$.

SMITH, W.G. e W.L.PARKS, 1967. A Method for Incorporating Probability into Fertilizer Recomendations. Journal of Farm Economics. $\quad$ 49(5):1511-1515.

STROTZ, R.H., 1953. Cardinal Utility. American Economic Review. $\quad 43(2): 384-397$.

TOBIN, J., 1958. Liquidity Preference as Behavior Towards Risk. Rev.of Ec.Studies. 25(1):65-86.

TSIANG, S.C., 1972. The Rationale of Mean - Standard Deviation Analysis, Skewness Preference, and the Demand for Money. American Journal of Agricultural Economics. 62:354-371.

VON NEUMAN, J. e O.MORGENSTERN, 1953. Theory of Games and Economic Behavior. Princeton University Press. $641 \mathrm{p}$.

WINKLER, R.L., 1972. Introduction to Bayesian Inference and Decision. New York: Holt, Rinehart and Winston. 
$A P \hat{E} N D I C E$ 
101.

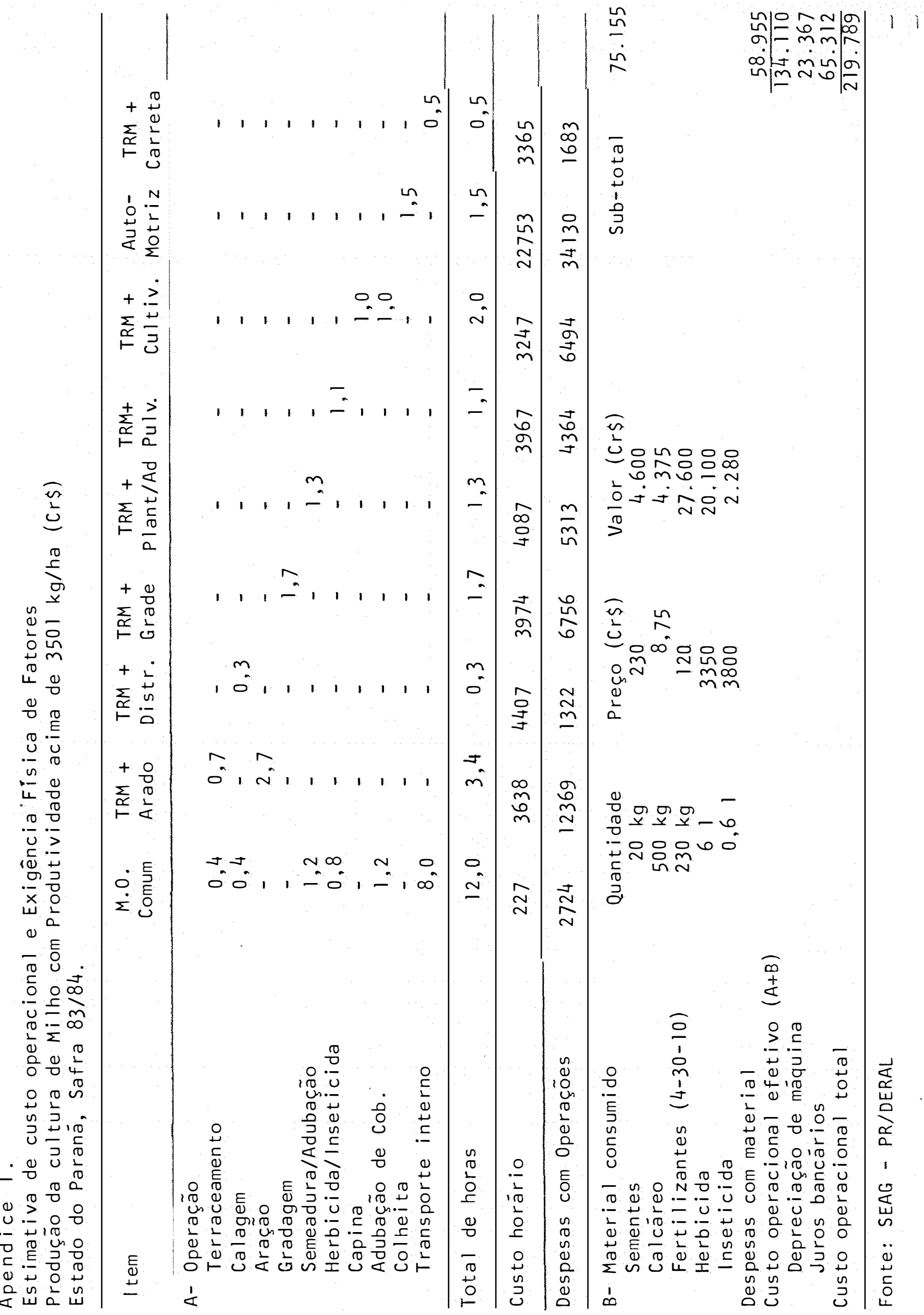


Apêndice 2. Mèdia, Desvio-Padrão e Assimetria das distribuições de probabilidade do lucro associados aos di ferentes niveis de utilização de nitrogênio (N).

\begin{tabular}{|c|c|c|c|}
\hline $\begin{array}{c}M \\
(\mathrm{~kg} / \mathrm{ha})\end{array}$ & $\begin{array}{l}\text { Média } \\
(C r \$)\end{array}$ & $\begin{array}{c}\text { Desvio-Padrão } \\
\text { ( Cr } \$)\end{array}$ & Assimetria \\
\hline 5 & 67729 & 8476 & $-0,846$ \\
\hline 10 & 69580 & 16506 & $-0,842$ \\
\hline 15 & 71084 & 24083 & $-0,835$ \\
\hline 20 & 72278 & 31219 & $-0,826$ \\
\hline 25 & 73019 & 37858 & $-0,809$ \\
\hline 30 & 73655 & 44023 & $-0,812$ \\
\hline 35 & 73349 & 49240 & $-0,852$ \\
\hline 40 & 73575 & 55218 & $-0,792$ \\
\hline 45 & 72995 & 60165 & $-0,782$ \\
\hline 50 & 72125 & 64530 & $-0,778$ \\
\hline 55 & 70900 & 68585 & $-0,766$ \\
\hline 60 & 69396 & 72080 & $-0,759$ \\
\hline 65 & 67653 & 75166 & $-0,744$ \\
\hline 70 & 65296 & 77820 & $-0,732$ \\
\hline 75 & 62687 & 80012 & $-0,719$ \\
\hline 80 & 59796 & 81904 & $-0,700$ \\
\hline 85 & 56517 & 83403 & $-0,682$ \\
\hline 90 & 52867 & 84438 & $-0,664$ \\
\hline 95 & 48751 & 84986 & $-0,639$ \\
\hline 100 & 44483 & 85193 & $-0,621$ \\
\hline
\end{tabular}


APENDICE 3

CRITERIOS DE SELEÇÃO PELO PRIMEIRO E SEGUNDO GRAUS DE DOMINÃNCIA ESTOCÁSTICA (ANDERSON, 1974).

Sejam duas distribuições densidade de probabil dade, $f(X)$ e $g(x)$. A dominância de $f(X)$, pelo Primeiro Grau de Dominância Estocástica, no qual está pressuposta a idéia de utilidade marginal dos resultados positiva, exigeque,

$\bar{U} f-\bar{U} g>0$

ou seja, que a utilidade esperada de $f(X)$ seja maior que a a sociada a $g(X)$, porëm como

$\bar{U} f-\bar{U} g=a_{a}^{\int^{b}} U(x) f(x) d x-a_{a}^{\int^{b}} U(x) g(x) d x$

$\bar{U} f-\bar{U} g=a^{\int^{b}} U(x)\left(d F_{l}(x)\right) d x-a^{\int^{b}} U(x)(d G,(x)) d x$

$\bar{U} f-\bar{U} g=a_{a}^{\int^{b}} U(x)\left[d F_{l}(x)-d G_{l}(x)\right] d x$

A expressão (47) pode ser rearranjadal',

II Se y e z são funções de $x$, então $\left.a^{\int^{b}} y(d z / d x)=\mid y \quad z\right\}_{a}^{b}-a^{\int^{b} z(d y / d x) d x}$ 


$$
\begin{aligned}
\bar{U} f-\bar{U} g= & {\left[U(x)\left[F_{1}(x)-G_{1}(x)\right]\right]_{a}^{b}-} \\
& -a^{\int^{b}}\left[F_{1}(x)-G_{1}(x)\right] U^{\prime}(x) d x
\end{aligned}
$$

e como $F_{1}(a)=G_{1}(a)$ e $F_{1}(b)=G_{1}(b)$, o primeiro termo se anula

$\bar{U} f-\bar{U} g=-a^{b}\left[F_{1}(x)-G_{1}(x)\right] U^{\prime}(x) d x$

que rearranjada,

$\bar{U} f-\bar{U} g={ }_{a} \int^{b} U^{\prime}(x)\left[G_{1}(x)-F_{1}(x)\right] d x$

Uma vez que a dominância de $f(X)$ sobre $g(x)$ e xige que $\bar{U} f-\bar{U} g>0$, e como estä pressuposto que $U^{\prime}(x)>0$, verifica-se que é obedecida desde que $G_{1}(X)>F_{l}(X)$ para todo $x \in(a, b)$, ou de outra forma a distribuição cumulativa de primeiro grau de $g(X)$ deve se manter sempre à esquerda da associada a $f(X)$.

Já a dominância $f(x)$ sobre $g(x)$ pelo Segundo Grau de Dominância Estocástica, conta com a restrição adicional de utilidade marginal dos resultados decrescente. As condições exigidas para seu estabelecimento podem ser entendidas tomando-se (49) que desenvolvida assume a forma,

$-\int^{b} u^{\prime}(x)\left\langle d\left[F_{2}(x)-G_{2}(x)\right] / d x\right\} d x$ 
que integrada por partes como sugerido no rodapé anterior, se torna

$\left[U^{\prime}(x)\left[F_{2}(x)-G_{2}(x)\right]\right]_{a}^{b}-a_{a}^{b}\left[F_{2}(x)-G_{2}(x)\right] U^{\prime \prime}(x) d x$

rearranjada

$\bar{U} f-\bar{U} g=-\left[U^{\prime}(x)\left[F_{2}(x)-G_{2}(x)\right]\right]_{a}^{b}+$

$$
+f^{b} U^{\prime \prime}(X)\left[F_{2}(X)-G_{2}(X)\right] d x
$$

Como a dominância de $f(x)$ sobre $g(x)$ pelo Segundo Grau de Dominância Estocāstica exige que $\bar{U} f-\bar{U} g>0$ e como $U^{\prime}(X)>0$ e $U^{\prime \prime}(X)<0$, verifica-se que esta condição é atendida sempre que $F_{2}(X)<G_{2}(X)$ para todo $x \in(a, b)$, ou seja a distribuição cumulativa de segundo grau de $g(X)$ deve se manter sempre à esquerda daquela associada a $f(X)$. 


\section{APENDICE 4}

A FUNÇÃO UTILIDADE EXPONENCIAL NEGATIVA

$$
\text { Pode apresentar duas formas gerais distintas, }
$$

$U(x)=A+e^{(-c \cdot x)}, \operatorname{com} \quad c<0 \quad e$,

$U(x)=A-e^{(-c \cdot x)}$, com $c>0$

que se apresentam graficamente como mostrado na figura 12 .

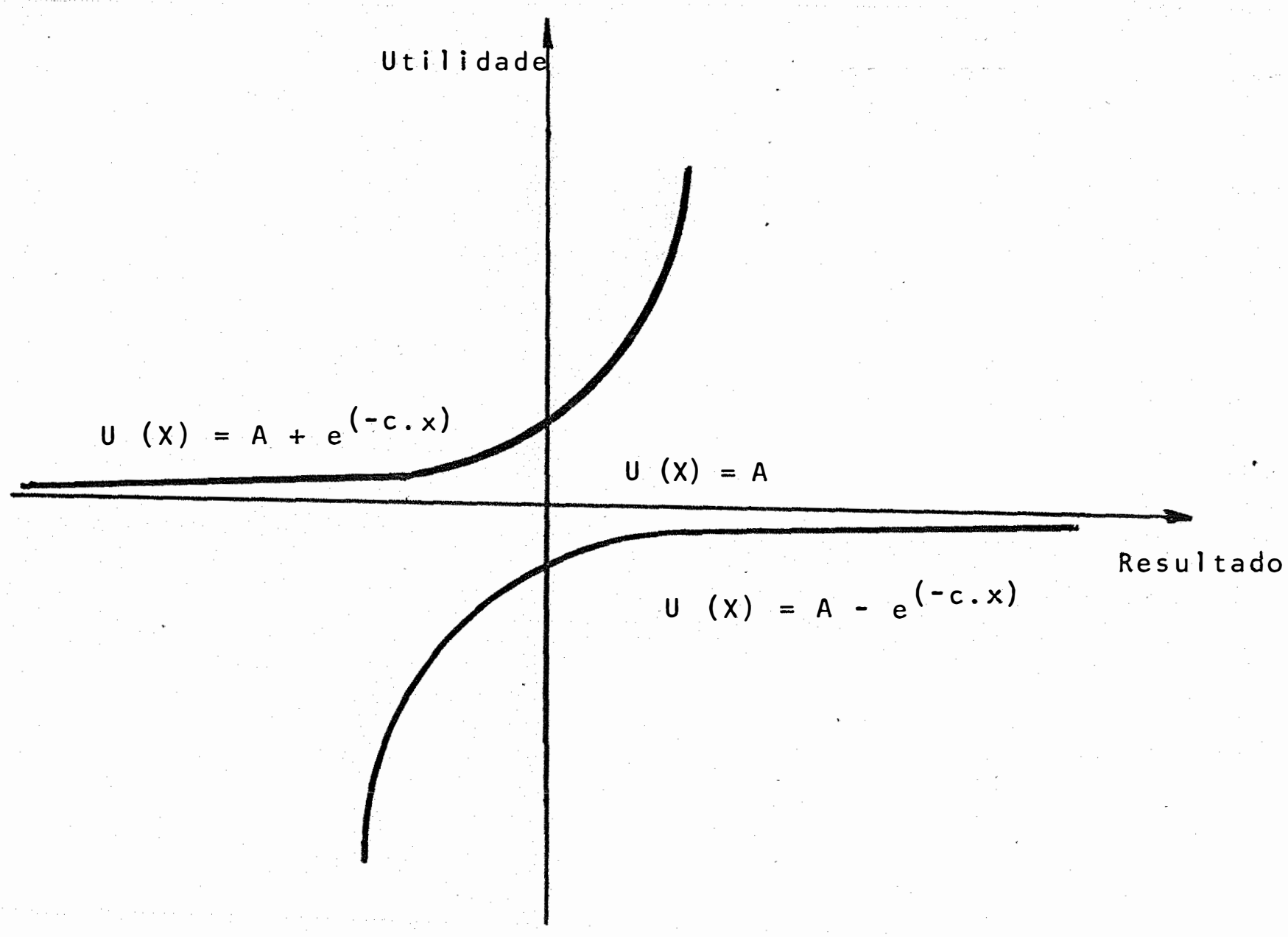

Figura 12. Função Utilidade Exponencial Negativa. 
Verifica-se que à medida que se elevam os valores de $x$, a forma $U(x)=A+e^{(-c \cdot x)}$ se afasta de sua assintota $U(x)=A$ e se torna mais convexa, enquanto que $U(x)=$ $=A-e^{(-c \cdot x)}$ se aproxima de $U(x)=A$ e se torna mais côncava .

Tais funções apresentam uma propriedade bastante particular que é a de que uma possível medida local da concavidade ou convexidade dada pela relação entre suas duas primeiras derivadas.

$$
r(x)=\frac{-u^{\prime \prime}(x)}{u^{\prime}(x)}
$$

não se altera em todo o domínio de $x$, onde $r(x)=c$.

Tal medida é relatada por PRATT (1964) como uma importante medida do comportamento do individuo sob incerteza, é denominada função de aversão absoluta ao risco. Deste modo, (54) caracteriza o comportamento de tomadores de decisão propensos ao risco, com utilidade marginal dos resultados positiva e crescente, enquanto que (55) se associa aos avessos ao risco que apresentam utilidade marginal dos resultados positiva, porēm decrescente.

A forma mais freqüente na literatura, e usada neste trabalho, considera $A=\dot{a}$, de modo que, 
108.

$U(x)=\left\{\begin{array}{l}e^{(-c \cdot x)} \text {, para propensos ao risco }(c>0) \\ x, \text { para indiferente ao risco }(c=0) \\ -e^{(-c \cdot x)}, \text { para avessos ao risco }(c<0) .\end{array}\right.$

Algumas propriedades destas, funções estão presentes na Figura 13.

Propensão

$(c<0)$

$U(x)=e^{(-c \cdot x)}$

$u^{\prime}(x)=-c \cdot e^{(-c \cdot x)}>0$

$u^{\prime \prime}(x)=c^{2} \cdot e^{(-c \cdot x)}>0$

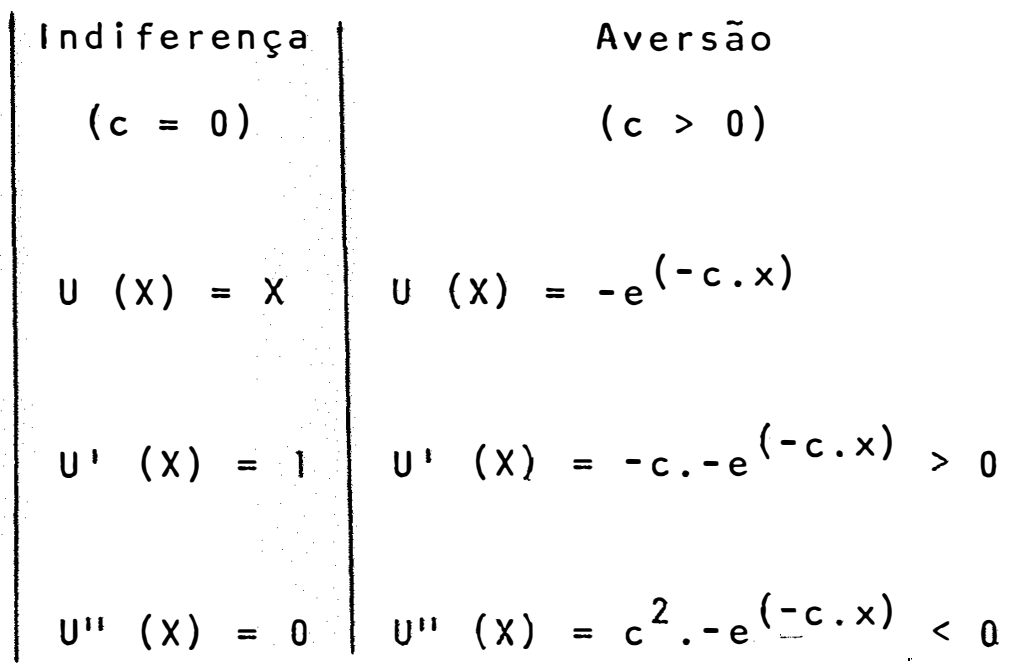

Figura 13. Propriedades das funções utilidade exponenciais negativas. 
A FUNÇÃO QUADRATICA DE UTILIDADE E A ANALLISE EV.

A função de utilidade da forma quadrática, expressa em termos de $\{x\}$, conjunto dos possiveis resultados, a sume a forma,

$U(x)=x+b x^{2}$

Ocorre que sob incerteza de resultados, o que existe é uma função utilidade esperada, obtida aplicando-se a (58) as propriedades da esperança matemática, ou seja

$E[U(X)]=E(X)+b E\left(X^{2}\right)$

Esta nova função pode passar a ser expressa em termos dos momentos das distribuições, bastando para isso que. se verifique que a variância é definida como

$V(x)=E[X-E(X)]^{2}$

$V(x)=E\left\{x^{2}-2 \cdot x \cdot E(x)+[E(X)]^{2}\right\}$

$V(X)=E\left(x^{2}\right)-2 \cdot E(X) \cdot E(X)+[E(X)]^{2}$ 
$V(x)=E\left(x^{2}\right)-[E(x)]^{2}$

que rearranjada

$E\left(x^{2}\right)=[E(x)]^{2}+v(x)$

e substituindo em (59), a torna

$E[U(x)]=E(x)+b[E(x)]^{2}+b V(x)$

que corresponde a sua forma final, onde a utilidade è função da média, $E(X)$, e da variância, $V(X)$, dos possíveis resultados.

HANOCH e LEVY (1970) propõem uma demonstração do critērio Anālise EV, de seleção de alternativas com base na mé dia e variância dos resultados, que pode ser descrito, tomando-se duas possiveis ações, $x_{j}$ e $x_{k}$. Admite-se que $X_{j}$ seja preferida desde que sua utilidade esperada seja maior, ou de outra forma

$E\left[U\left(x_{j}\right)\right]-E\left[U\left(x_{k}\right)\right]>0$

As funções utilidade são aquelas descritas por (18) de forma que por sua substituição em (66) tem-se

$2 L E\left(x_{j}\right)-\left[E\left(x_{j}\right)\right]^{2}-v\left(x_{j}\right)-\left\{2 L E\left(x_{k}\right)-\left[E\left(x_{k}\right)\right]^{2}-v\left(x_{k}\right)\right\}>0$ 
11.1

somando-se os termos semelhantes temos.

$2 L\left[E\left(x_{j}\right)-E\left(x_{k}\right)\right]-\left\{\left[E\left(x_{j}\right)\right]^{2}-\left[E\left(x_{k}\right)\right]^{2}\right\}-\left\{V\left(x_{j}\right)-V\left(x_{k}\right)>0\right.$

que pode ser expressa de modo mais simplificado

$2 L \Delta E-\left(\Delta E^{2}+\Delta V\right)>0$

E imediato que se verifique que (69) é satisfei

ta ou seja $x_{j}$ é preferida a $x_{k}$ se e somente se

$E\left(x_{j}\right)>E\left(x_{k}\right)$

e

$v\left(x_{j}\right)<v\left(x_{k}\right)$ 